\title{
HIGHWAY COST-BENEFIT ANALYSIS SYSTEM
}

\author{
Venkatramani Rajamohan
}

\author{
Thesis submitted to the \\ College of Engineering and Mineral Resources \\ at West Virginia University \\ in partial fulfillment of the requirements for \\ the degree of
}

Master of Science

In

Industrial Engineering

\begin{abstract}
Majid Jaraiedi, Ph.D., Chair
Wafik Iskander, Ph.D.

David R. Martenelli, Ph.D.
\end{abstract}

Morgantown, West Virginia

1999

Keywords: Cost-Benefit Analysis, Red book, Life Cycle Cost Analysis, WVDOH

Copyright 1999 Venkatramani Rajamohan 


\title{
Abstract \\ HIGHWAY COST-BENEFIT ANALYSIS SYSTEM
}

\author{
Venkatramani Rajamohan
}

In this research, a methodology for computing road user cost for various competing alternatives was developed. Also, a software was developed to calculate the road user cost, perform economic analysis and update cost tables. The methodology is based on the manual entitled "A Manual on User Benefit Analysis of Highway and Bus-Transit Improvements" which was published in 1977 by American Association of State Highway and Transportation Officials. The report contains procedures for the calculation of the road user cost, perform economic analysis and further update the cost tables as and when the latest Consumer Price Indices and Producer Price Indices are available.

The software application has been developed in Visual Basic ${ }^{\circledR} 5$, which interact with the cost tables, stored in MS-Excel workbook, according to the user inputs. The software application was later updated to Visual Basic $^{\circledR} 6$ when it was installed at WVDOH. The software application consists of two module, 1) Road User Cost Application and 2) Economic Analysis. Module 1 consists of two sub-modules, Road User Cost Calculation and Update Cost Tables and Indices. The use of this software will result in the computation of the road user cost and economic analysis in a more efficient manner. It enables the decision makers to rationally select the most desirable alternative for building and refurbishing segments of public highways. 


\section{Dedication}

This Thesis is dedicated to Mother and Sri Aurobindo. 


\section{Acknowledgements}

I express my sincere gratitude to Dr. Majid Jaraiedi, for his continued guidance and support during my Masters Program at West Virginia University. He was always available for any suggestions that I sought. I would always remember the trips that I made with him to Charleston.

I also thank Dr. Wafik Iskander, for his ideas and suggestions during the thesis. I would thank him for going through my work meticulously and helping me to achieve perfection.

I am highly indebted to Dr. David R. Martenelli, for his benevolence to fund me in the later part of the thesis. I also appreciate his suggestions in the field of Transportation Engineering.

Finally, I thank God for giving me supporting parents and sister, Subha, whose

inspiration are invaluable. I dedicate the thesis to my Family. I also thank my friends for their support and encouragement. 


\section{Table of Contents}

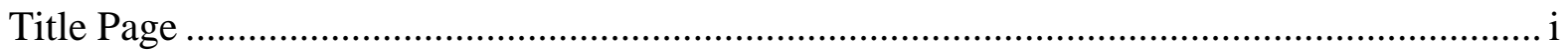

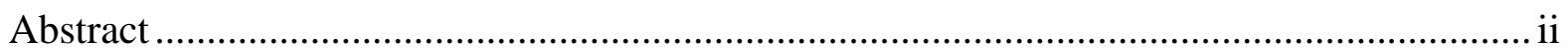

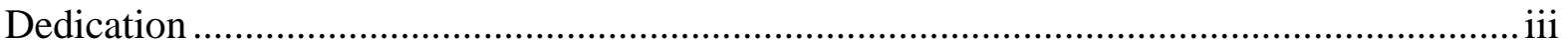

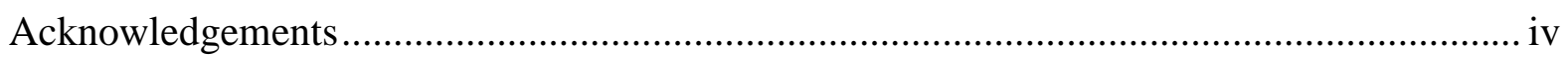

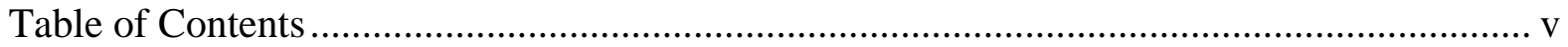

List of Figures ......................................................................................................... vii

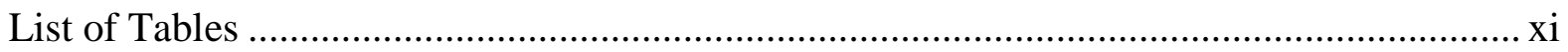

Chapter 1: Introduction and Research Objectives........................................................ 1

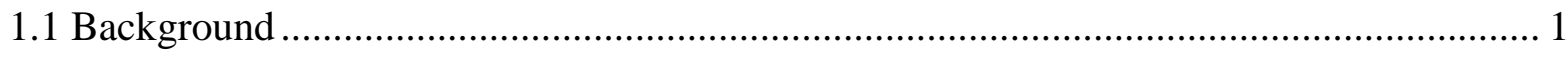

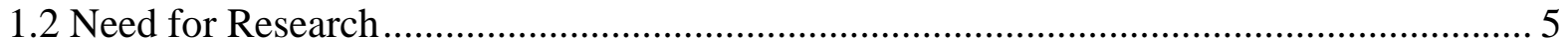

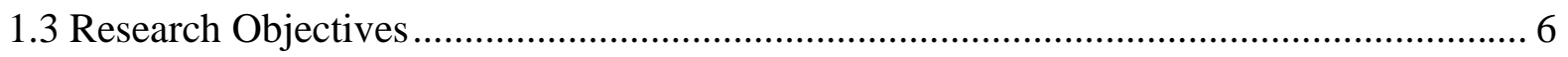

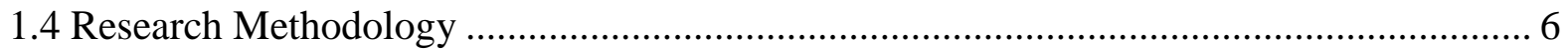

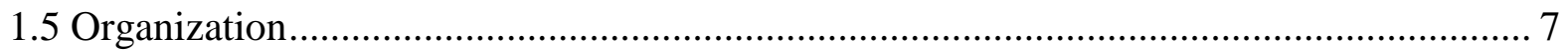

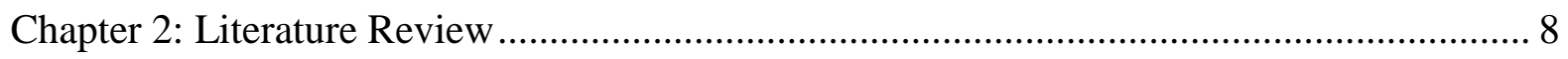

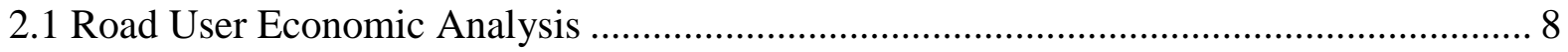

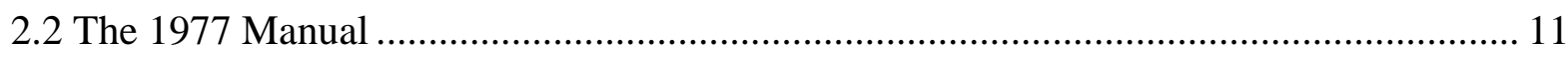

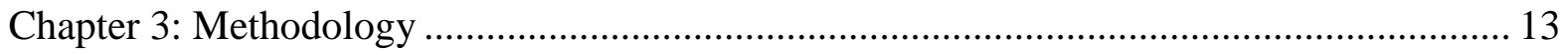

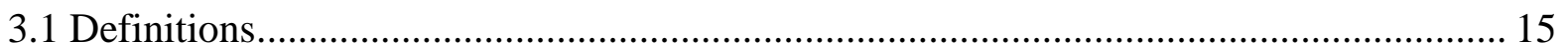

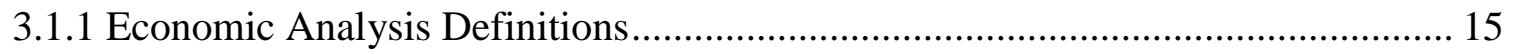

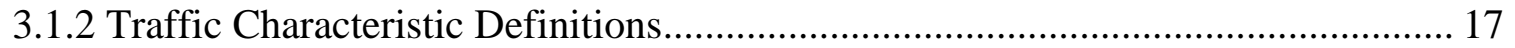

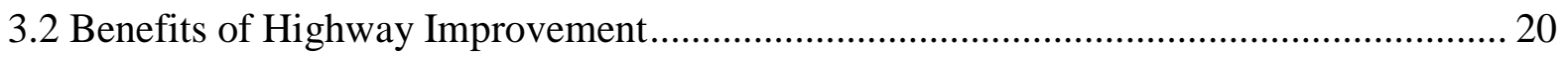

3.3 Measurement of User Benefits (Costs) as Reported in the 1977 Manual....................... 20 


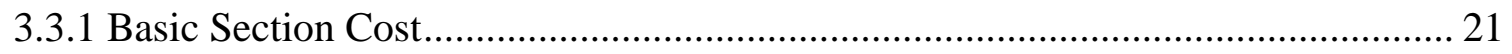

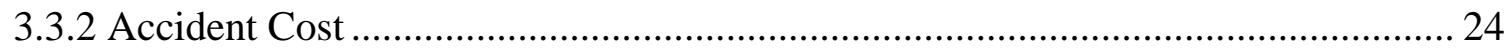

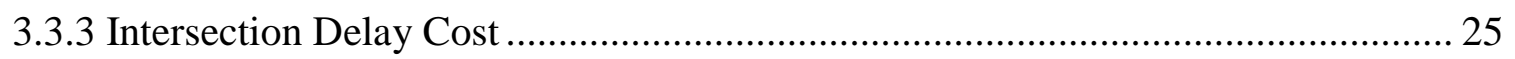

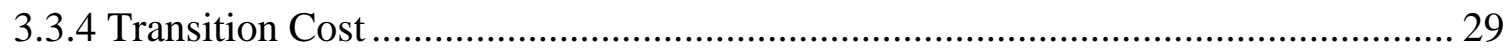

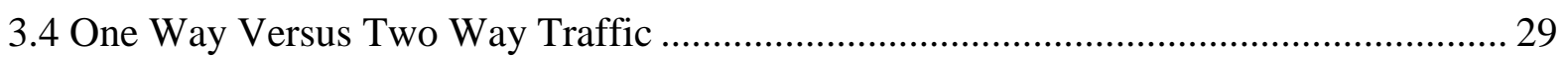

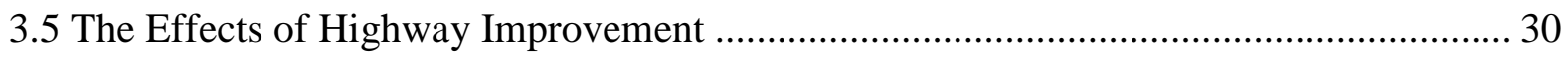

3.6 Economic Analysis Technique as Reported in the Manual ............................................... 31

3.7 Example of a Highway Economic Analysis ………........................................................ 34

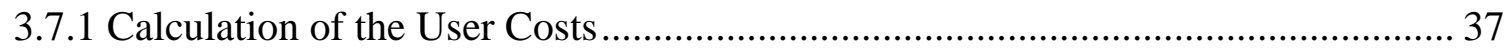

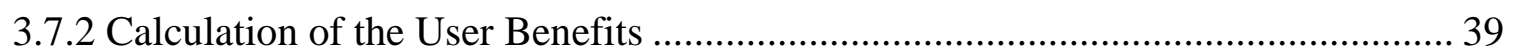

3.7.3 Computation of the Present Value and Measures of Economic Desirability.......... 39

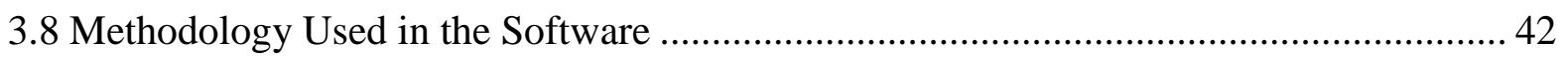

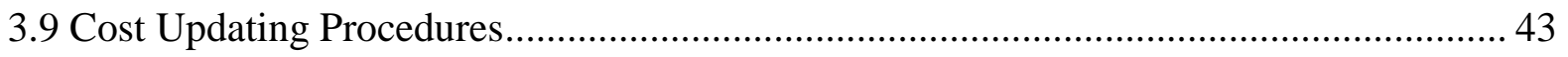

3.9.1 Updating Running Cost Factors .......................................................................... 47

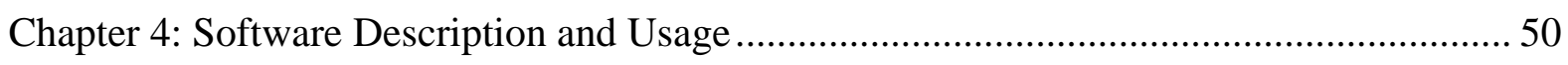

4.1 Software Development Tools ...................................................................................... 51

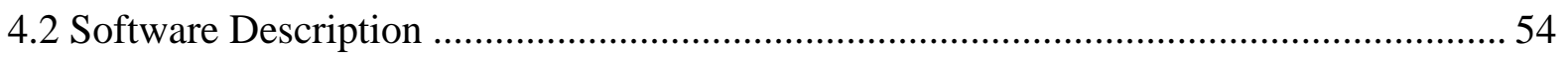

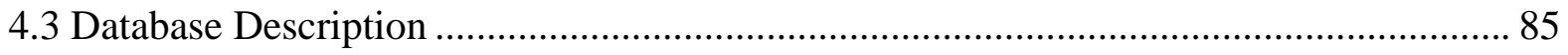

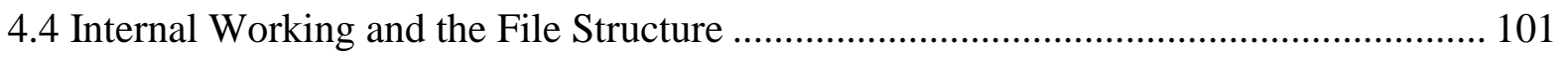

4.5 Valid Ranges for Inputs and Parameters................................................................... 102

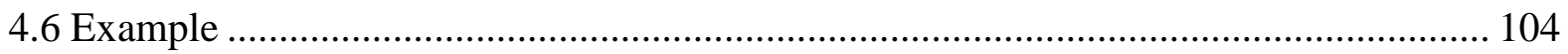

Chapter 5: Conclusions and Recommendations for Future Research.................................. 108

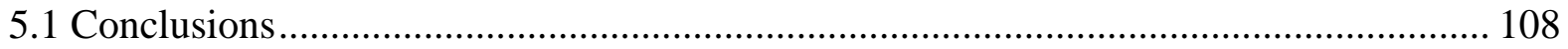


5.2 Recommendations for Future Research

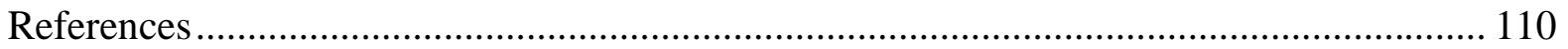

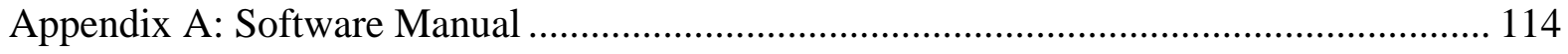




\section{List of Figures}

Figure 3.1: Basic Section costs (B) for passenger cars on Multi-Lane highways. ................ 22

Figure 3.2: Costs due to stopping at intersections (excludes idling) ............................... 27

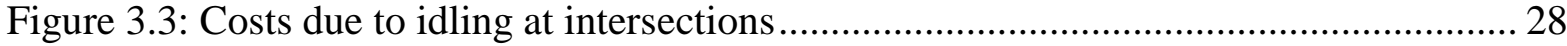

Figure 3.4: Section transition costs...................................................................... 30

Figure 4.1 The Welcome Screen (Welcome.frm) ........................................................... 54

Figure 4.2: The Road User Cost Application Screen (Frmroad.frm)................................. 55

Figure 4.3: The Startup Screen (Startup.frm) ........................................................ 56

Figure 4.4: The Number of Sections Screen (Noofsection.frm) ..................................... 57

Figure 4.5: The Main Screen (Mainscreen.frm) ….................................................. 58

Figure 4.6: The Vehicle Mix Screen (Fmrvehiclemix.frm) …...................................... 59

Figure 4.7: The Basic Section Cost for Passenger Cars Screen (Frmbasicsection.frm) ......... 60

Figure 4.8: The Travel Time Cost for Passenger Cars Screen (Traveltime.frm).................. 61

Figure 4.9: The Grade Cost for Passenger Cars Screen (Gradecost.frm) ............................ 62

Figure 4.10: The Curve Cost for Passenger Cars Screen (Curveform.frm)......................... 63

Figure 4.11: The Speed Change Cost for Passenger Cars Screen (Speedchange.frm) ........... 64

Figure 4.12: The Basic Section Cost for the Total Vehicle Mix Screen

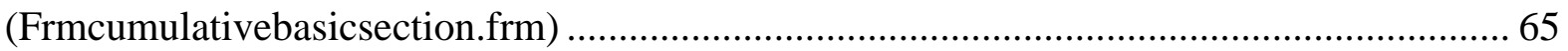

Figure 4.13: The Accident Cost Screen (Accident.frm) ................................................ 66

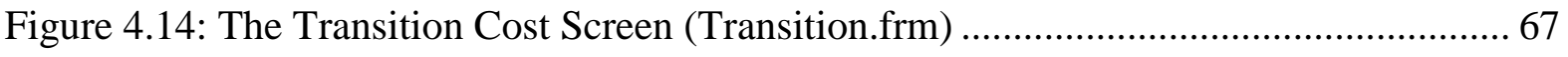

Figure 4.15: The Intersection Delay Cost Due to Stopping Screen (Delaycosts.frm) ........... 68

Figure 4.16 The Intersection Delay Cost Due to Idling Screen (Idlingcosts.frm) ................ 69

Figure 4.17: The Total Cost Screen (Frmtotalcost.frm) ................................................ 70 
Figure 4.18: View/Edit Results Screen (Outputcosts.frm) ........................................... 71

Figure 4.19: The Open/Saveas Dialog Box .................................................................. 73

Figure 4.20: Inputs for the Project Screen (Inputresults.frm) ....................................... 73

Figure 4.21: The Print Results Screen (Frmprint.frm) ............................................... 74

Figure 4.22: The View Results Screen (Viewresults.frm) ............................................. 75

Figure 4.23: Opening an Existing File Screen (Open.frm) ............................................ 76

Figure 4.24: The View/Update Indices Screen (Frmupdateindices.frm) ............................ 78

Figure 4.25: The Economic Analysis Screen (Frmeconomic.frm) .................................... 79

Figure 4.26: The Economic Analysis for Uniform Increase or Decrease Screen

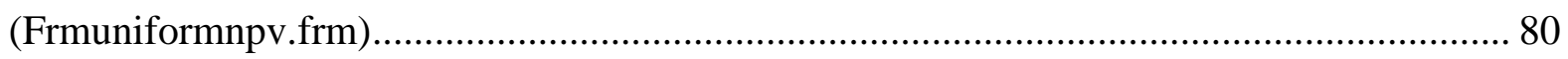

Figure 4.27: The Input Data for Economic Analysis Screen (Frminput.frm)..................... 81

Figure 4.28: The Base or Alternative 0 Screen (Frmbase.frm) ...................................... 82

Figure 4.29: The New Alternative Screen (Frmcurrent.frm) ........................................ 83

Figure 4.30: The Net Present Value Analysis Screen (Frmnpv.frm) ................................. 84

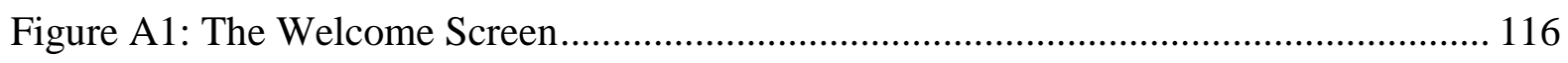

Figure A2: The Road User Cost Application Screen ................................................ 117

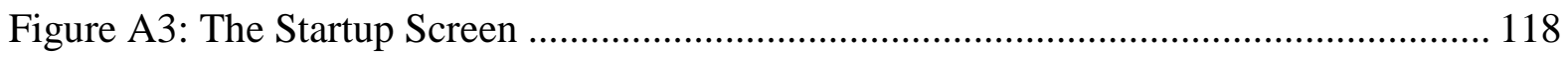

Figure A4: The Number of Sections Screen ............................................................... 119

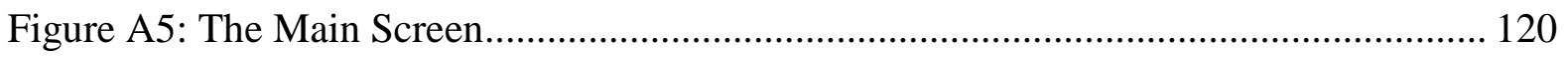

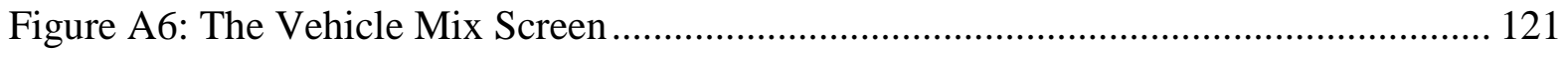

Figure A7: The Basic Section Cost for Passenger Cars Screen ...................................... 122

Figure A8: The Travel Time Cost for Passenger Cars Screen ........................................ 123

Figure A9: The Grade Cost for Passenger Cars Screen .............................................. 124 
Figure A10: The Curve Cost for Passenger Cars Screen ..................................................... 125

Figure A11: The Speed Change Cost for Passenger Cars Screen......................................... 126

Figure A12: The Basic Section Cost for the Total Vehicle Mix Screen............................... 126

Figure A13: The Accident Cost Screen ....................................................................... 128

Figure A14: The Transition Cost Screen …………….................................................. 129

Figure A15: The Intersection Delay Cost Due to Stopping Screen ..................................... 130

Figure A16: The Intersection Delay Cost Due to Idling Screen .......................................... 131

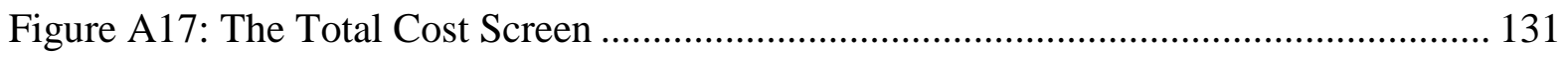

Figure A18: View/Edit Results Screen ...................................................................... 133

Figure A19: The Open/Saveas Dialog Box ………………........................................... 134

Figure A20: Inputs for the Project Screen ................................................................. 134

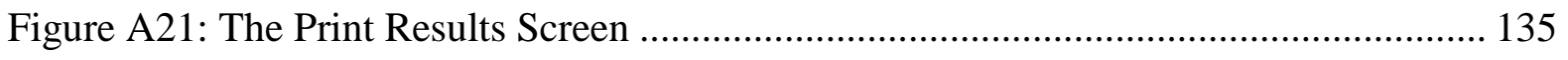

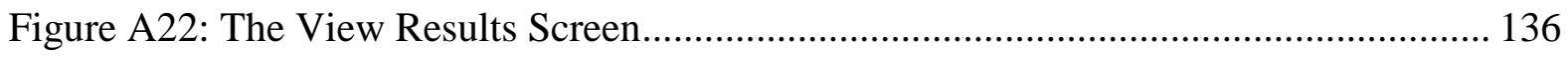

Figure A23: Opening an Existing File Screen ............................................................... 137

Figure A24: The View/Update Indices Screen ............................................................... 140

Figure A25: The Economic Analysis Screen ................................................................... 144

Figure A26: The Economic Analysis for Uniform Increase or Decrease Screen ................. 144

Figure A27: The Input Data for Economic Analysis Screen .............................................. 145

Figure A28: The Base or Alternative 0 Screen ................................................................ 147

Figure A29: The New Alternative Screen.................................................................... 147

Figure A30: The Net Present Value Analysis Screen ........................................................ 148 


\section{List of Tables}

Table 3.1: Type of Costs That Might be Included in the Highway Transportation Cost

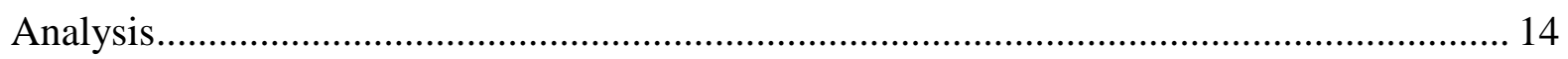

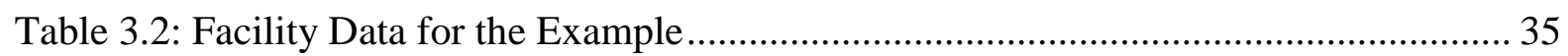

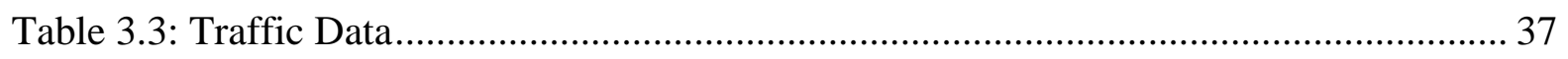

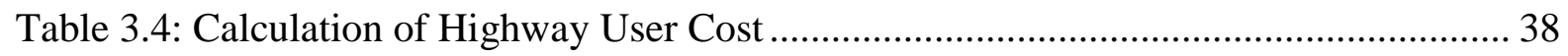

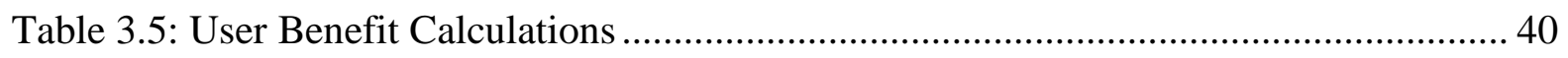

Table 3.6: Calculation of Present Value of Project-Related Costs ........................................... 41

Table 3.7: Consumer and Wholesale Price Indices for January 1975 and May 1994 ............ 45

Table 3.8(a): Multiplier Formula for Updating Running Costs of Passenger Cars ................. 46

Table 3.8(b): Multiplier Formula for Updating Running Costs of Single Unit Trucks.......... 46

Table 3.8(c): Multipliers for Updating Running Costs of 3 S-2 Combination Trucks ........... 47

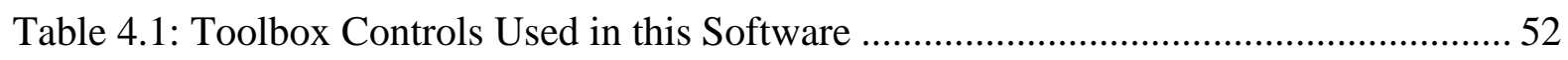

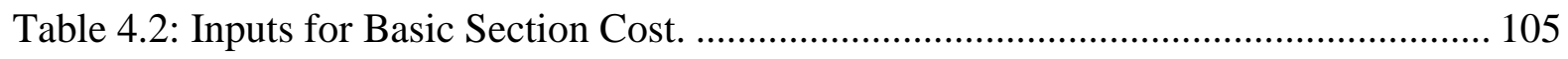

Table 4.3: Inputs for Basic Section Cost for the Vehicle Mix............................................. 105

Table 4.4: The Accident Cost Table …………………..................................................... 106

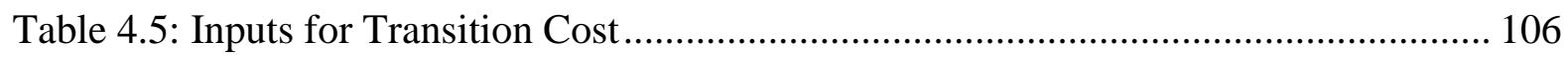

Table 4.6: Inputs for the Intersection Delay Cost ............................................................ 107

Table A1. Consumer Price Indices and their Identity Numbers ......................................... 141

Table A2. Producer Price Indices and their Identity Numbers ........................................... 142

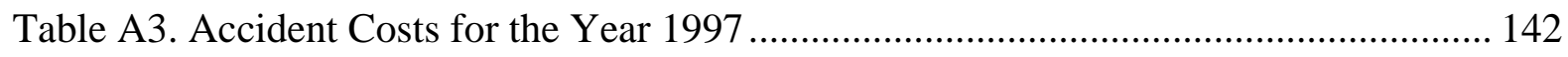

Table A4: Inputs for Basic Section Cost.................................................................. 150

Table A5: Inputs for Basic Section Cost for the Vehicle Mix.............................................. 151 
Table A6: The Accident Cost Table

Table A7: Inputs for Transition Cost ............................................................................ 152

Table A8: Inputs for the Intersection Delay Cost ................................................... 152 


\section{Chapter 1: Introduction and Research Objectives}

\subsection{Background}

The United States of America can be described as a "nation on wheels". The government has given the highest impetus to the growth of highways for they are the lifelines of this country. The period from 1920 to 1970 might well be called the "automobile age" for during this period highway transportation assumed a dominant role in America. This era is also referred to as the Modern Highway Development era for the birth and development of the modern Interstate Highway System.

"With the completion of the Interstate Highway System, highway agencies are increasingly focussing attention on reconstruction and improvement of existing highway systems. The new improvements to existing facilities are being subjected to maximum scrutiny, and a formal economic evaluation of the economic impact is becoming commonplace.”[Wright, 1996]

This report presents a methodology for calculating road user cost based on the 1977 Manual entitled “ A User Benefit Analysis for Highway and Bus Transit Improvements”. The 1977 Manual provides cost factors, nomographs, and guidelines for estimating the economic effects of highway construction. These include most types of highway improvements, such as curve elimination, widening or adding lanes, reducing gradients, new road construction, and intersection controls. The question faced by highway planners is whether the benefits from the reduced user costs for a certain highway exceed the costs required to produce these benefits. Highway improvement alternatives may include:

- Construction of new Freeways, expressways, or roads without access control to supplement or replace existing roads. 
- Widening of existing roads or reconstruction to high geometric standards.

- Straightening or eliminating curves.

- Grade changes, and passing lanes or grades.

- Installing traffic control devices (e.g. signals, signs, barriers).

The 1977 Manual has various sets of nomographs that can be used to calculate the road user cost in a step by step fashion. This Manual is based on the research conducted by the Stanford Research Institute (SRI) under NCHRP Project 2-12, "Highway User Economic Analysis". It describes the theoretical basis for the methodology for economic analysis, the basis of cost factors, and the techniques for constructing nomographs, all developed for use in the Manual. The Manual provides step by step procedures and guidelines, cost factors, nomographs and tables for estimating the economic effects of highway improvements on highway users. The approach to highway improvements expounded in the Manual requires division of highway projects into geometrically similar sections (or composites of several similar sections) that can then be evaluated rapidly through the nomographs and tabular data that are provided for several highway and vehicle types. A brief description of the Manual is presented in Chapter 2.

Since highway projects are designed, constructed and operated with public funding, it is critical that economic analysis be done with prudence. In addition to determining the best project with maximum potential, economic analyses provide not only the present situation but also the future of the project. The Intermodal Surface Transportation Efficiency Act (ISTEA) emphasizes assessment of multimodal alternatives and demand management strategies [Decorla-Souza et. al., 1997]. This emphasis has increased the need for planners to provide good comparative information to decision-makers. Cost-Benefit analysis is a useful 
tool for comparison of the economic worth of alternatives and evaluates the trade-off between economic benefits and costs.

"Section 303," Quality Improvement," of the National Highway Designation Act, amends Section 106 of Title23, United States Code (U.S.C.), by adding a new Subsection (e) entitled “Life Cycle Cost Analysis (LCCA)." Title 23, U.S.C., Subsection 106(e)(1) now directs the Secretary to program that requires States to conduct a life cycle cost analysis of each NHS high cost $(\$ 25,000,000$ or more) usable project segment. This subsection further defines LCCA as "a process for evaluating the total economic worth of a usable project segment by analyzing initial costs and discounted future cost, such as maintenance, reconstruction, rehabilitation, resorting and resurfacing costs, over the life of a project segment” [FHWA Policy Memorandum, 1996].

As used in the LCCA required by 23 U.S.C., 106(e), the following definitions are defined in the FHWA Policy Memorandum in 1996:

“High Cost" refers to usable project segments estimated to cost $\$ 25$ million or more.

“Usable Project Segment" refers to a portion of a highway which a state proposes to construct, reconstruct or improve that when completed could be open to traffic independent of some larger overall project. Such a "usable project segment" could be completed under a single contract or in multiple phases over several years.

To decide between alternatives, sound economic decisions and detailed analysis are required in order to make a choice. Cost effective choice over the life of the asset becomes inevitable. Future high costs or short life of a project can offset low initial cost advantages. The time value of money and well-recognized economic analysis procedures are important 
considerations in the decision making process. Formal analysis using engineering economics can provide an answer.

Engineering economics provide a way to choose between alternatives when the expenditure of capital funds comes into play. Three basic steps are involved in conducting an economic analysis [Stanford Research Institute, 1961]:

1) Identify and define the different alternatives among which a selection is to be made.

2) Identify and define the various elements or factors that may result in differences in the cost of the alternatives and remove from further consideration all events that have happened or may happen regardless of which alternative is selected.

3) Reduce all of the alternatives to a comparable basis by translating all of the applicable factors to a common dollar base and then make a cost comparison among the alternatives over time, considering the time value of money through the use of the compound interest.

Life Cycle Cost Analysis is the most appropriate economic evaluation technique. This analysis considers all the costs incurred in the life of a project. Two important definitions follow:

Life Cycle Costing- Economic assessment of an item, area, system, or competing design alternatives considering all significant costs of ownership over the economic life, expressed in terms of equivalent dollars [Dell'Isola et. al., 1981].

Life Cycle Design- Analysis which considers the construction, operation, and maintenance of a facility during its entire design life [Lindow, 1978]. 
Life Cycle Costs include all costs anticipated over the life of the facility. The economic analysis requires identifying and evaluating the economic consequences of various alternatives over time or the life cycle of the alternative [Peterson, 1985].

Costs incurred in the highway reconstruction include:

- Initial Construction Cost

- Maintenance Costs

- Residual Costs

- Road User Cost

- Right of Way Costs

\subsection{Need for Research}

This report is based on a project sponsored by the West Virginia Division of Highways (WVDOH). The project involved development of turnkey software, based on the 1977 Manual to be used by the WVDOH to compute the road user cost for various projects.

The methodology described in the Manual is quite detailed and time consuming leaving many avenues where the user can commit error. Also, reading the nomographs and tables can be a cumbersome process because of the large amount of information to be processed to calculate the total road user cost. The Division of Highways found it quite necessary and important to develop a simplified software, which can be used to calculate road user cost in a more efficient manner and have the capability to compare various alternative scenarios. 


\subsection{Research Objectives}

The objective of this research was to develop a user friendly computer package based on the 1977 Manual. A complete package was to be developed such that the user can compute the road user cost, do an economic analysis and update the costs to the current year based on the latest costs available, taking into consideration both the time value of money and inflation. The research also involved gathering information from WVDOH officials. The research methodology is described in the next section.

\subsection{Research Methodology}

Based on the requirements and specifications decided based on discussion with WVDOH officials, the application was decided to be developed using Microsoft's Visual Basic $^{\circledR}$ 5.This software is also called the front-end software because it interacts with the user and the database. The software is versatile and has some of the latest features required for client-server architecture. The database has been created in MS-Excel where all the data

required in calculating the user costs are stored. Visual Basic ${ }^{\circledR} 5$ forms a bridge between the user and the database. It helps the user to retrieve necessary information depending on the various choices for input and calculate total user costs for a project. User friendly screens were developed for this purpose where the user can fill in the inputs. These inputs are processed and required tables are referred to automatically to calculate the various components of the road user cost. 


\subsection{Organization}

The report consists of five chapters. Chapter 2 presents a review of the literature regarding the basic work done in this field and the various software used by the departments of transportation in different states. Chapter 3 presents the methodology followed and the list of steps used to compute the road user cost. Chapter 4 consists of the software description, the flowchart for the software, and its mode of operation. Chapter 5 summarizes the conclusions drawn from this research. It also presents the future recommendations that can be carried out on this research. The appendix includes the user manual for the software. A diskette has been included that contains two files:

1) Sourcecode.zip-Contains all the Form files (.frm), Project files (.vbp), and the FRX files (.frx) in a zipped format.

2) Help.txt-An ASCII file containing instructions for user to unzip the files in the Sourcecode.zip and use the software. 


\section{Chapter 2: Literature Review}

Highway user cost benefit analysis has been a hot topic of discussion for a long time. Various federal laws have made it imperative to carry on economic analysis for projects worth over twenty five million dollars. The National Cooperative Highway Research Program is an organization carrying out research in the various fields like administration, transportation planning, design, materials and construction, maintenance, traffic, soils and geology and some special projects. They have sponsored some research in the field of economics that comes under highway administration projects [NCHRP, 1998]. The 1977 Manual is also a product of the research sponsored by NCHRP. These projects are NCHRP Projects 2-12 and 2-12/1 and were carried out at the Stanford Research Institute.

The next section gives a description of various software that have been developed for the economic analysis applications. This chapter also gives a brief description of the 1977 Manual.

\subsection{Road User Economic Analysis}

This section presents various software that are available for performing various aspects of economic analysis for highway construction and improvement.

1) MicroBencost- This software, also called Microcomputer Evaluation of Highway User Benefit, is an effort to computerize the 1977 Manual (also known as the Red Book). The research is Project 7-12 of NCHRP projects and has been conducted at the Texas A\&M

Research Foundation under the supervision of Dr. William F. McFarland. The objective of this project was to develop a comprehensive, user-friendly, portable microcomputer program to conduct comprehensive highway user benefit-cost analysis. The program uses 
support data that can be updated. The focus of the research was directed to analyses at a research level and its immediate area impact. This project constituted review of procedures used in the user cost-benefit analyses to identify data required for determination of vehicle operating costs, accident reduction benefits, travel time values, and other appropriate factors, limited updating of basic data, development of microcomputer software to facilitate the analyses procedure and preparation of user manual and software documentation. The MicroBENCOST software developed as part of this project is capable of performing life cycle cost analysis for a variety of project types and scope, using both default values and user-provided data inputs [NCHRP, 1993]. The software is being enhanced under NCHRP Project 7-12(2) [17].

2) Highway Economic Requirements System (HERS)- The Highway Economic Requirements System was designed to perform highway needs analyses that reflect both the current condition of the highway system and the estimated costs and benefits of potential improvements to the system. Jack Faucett Associates developed HERS with the assistance of Urban Institute, Cambridge Systematics, Inc., and Bellomo-McGee, Inc. (BMI). The system was developed for the Highway Needs and Investment Branch of the Federal Highway Administration (FHWA) which is responsible for maintaining the system. The system enables the user to better examine costs, benefits and national economic implications associated with highway options. HERS uses the description of the current state of the highway system contained in Highway Performance Monitoring System (HPMS) database as a basis of all analyses. A comprehensive description can be found in HERS Overview [FHWA, 1994], Users Guide [FHWA, 1995] and Technical Report [FHWA, 1996]. 
3) Surface Transport Efficiency Analysis Model (STEAM)- This is an enhanced version of a planning tool called Sketch Planning Analysis Spreadsheet Model (SPASM), that was developed by the FHWA in 1995 to assist planners in developing the type of economic efficiency and other evaluative information needed for comparing cross-modal and demand management strategies. The software is based on the principles of economic analysis, and allows the development of monetized impact estimates for a wide range of transportation investments and policies [Decorla-Souza et. al., 1997].

4) StratBENCOST- This software is being developed by Hickling Lewis Brod Inc. as part of the NCHRP Project 2-18/4. The model incorporates an analysis of the network of highways and surrounding roads. The objective of the StratBENCOST model is to present a methodology which allows strategic level planners to integrate highway user costs and benefit -cost analysis into a broad based highway investment evaluation tool. The model is based on NCHRP Project 2.18 which is entitled "Research Strategies for Improving Highway User Cost-Estimating Methodologies" [18] and NCHRP Project 2.18/3 [19], entitled "Development of an Innovative Highway User-Cost Estimation Procedure". This software can be employed at the early stages of strategic planning. Its key features include [19]:

- Demand estimation traffic models.

- Value of time models based on economic data.

- Vehicle operating cost models.

- Environmental effects.

- Construction and disruption costs.

- Risk analysis element to account for uncertainty. 
- Economic evaluation criteria.

This project is still active and has not been published yet by NCHRP [NCHRP Project 2$18 / 4]$.

\subsection{The 1977 Manual}

Economic analysis for highway improvement gained wide acceptance after the publication of the AASHTOP "Red Book" [AASHTO, 1952] in 1952. The Red Book was updated in 1960. Claffey presented an updated highway user cost factors and economic analysis methodology in his report [Claffey, 1971]. "A Manual on User Benefit Analysis of Highway and Bus-Transit Improvement" was published by the American Association of State Highway and Transportation Officials (AASHTO) in 1977. The Manual was written to update, extend and replace the 1960 AASHTO Report entitled "Road User Benefit Analysis for Highway Improvements" [Anderson et. al., 1972]. The Manual is also based on NCHRP Report 133 entitled "Procedures for Estimating Highway User Costs, Air Pollution and Noise Effects" [Curry et. al., 1972], except for the detailed analysis of congestion or queueing, air pollution and noise. It also describes current cost factors and short cut procedures for dealing with various project types described in Winfrey's "Economic Analysis of Highways" [Winfrey, 1968], NCHRP Report 96, "Strategies for the Evaluation of Alternative Transportation Plan" [Thomas et. al., 1970], NCHRP Report 122, "Summary and Evaluation of Economic Consequences of Highway Improvements" [Winfrey, 1971], and NCHRP Report 146, "Alternative Multimodal Passenger Transportation Systems-A Comparative Analysis" [Frye, 1976].

The highway user cost factors in this Manual are shown as a function of either traffic speed or of the ratio of traffic volume to highway capacity (V/C ratio). The highway and 
traffic characteristics that define highway capacity and traffic speed can be translated into these parameters through the use of the Highway Capacity Manual and other design and traffic engineering references. The Manual does not include indirect economic effects such as land values and growth.

The rationale behind such a comprehensive economic analysis is the achievement of maximum service from a given investment. The need for economic analysis of highway improvements was cogently put by the 1960 AASHTO report:

"The tenet that a profit should be returned on an investment applies equally as well to highway projects as to general business ventures. It is unthinkable to enter a business venture with only an estimate as to the initial cost. An estimate as to the continuing cost with an appraisal to the amount of profit to be made is equally essential. For example, it would be ridiculous for a railroad company in conducting business only the cost of the roadbed and its upkeep. Any analysis of railroad costs necessarily includes the cost of operation, maintenance, and depreciation of its rolling stock. In the same sense, the total cost of the highway improvement is the cost to improve and maintain the cost of the highway and to operate all the vehicles thereon. Thus the planning and the design of a highway, particularly the selection of the route and choice between alternatives, can best be done, or have decision aided, by calculating the costs of vehicle operation, accidents, maintenance, time etc, in addition to calculating initial costs. These establish the economic desirability of any highway improvement.” [AASHTO, 1952]

The emphasis of the 1977 manual is to help in conducting engineering economy studies in evaluating relevant alternatives and constructive decision making with the public money. 


\section{Chapter 3: Methodology}

Economic analysis for highway projects was proposed as a decision making tool as early as mid-nineteenth century and gained wide acceptance until after the publications of the AASHTO "Red Book" [AASHTO, 1952] in 1952. The Red Book was updated in 1960 and all literatures on economic analysis were refined. A Stanford Research Institute report prepared for NCHRP served as a basis for the 1977 edition of the AASHTO Red Book. That document, which contains unit highway user cost factors based on the 1975 levels of vehicle performance characteristics and prices, remains the primary reference source for economic analyses in the United States. It serves as the primary basis for the software developed for the West Virginia Division of Highways.

Highway transportation cost is defined as the sum of the highway investment cost, the maintenance and operating costs, and the highway user costs. Highway investment cost includes the cost of right-of-way, engineering design, construction, traffic control devices and landscaping. Maintenance cost is the cost of preserving a highway and keeping it in serviceable condition. Operating costs include the costs of traffic control, lighting, and the like.

Road user cost comprises a major part of the highway transportation costs. They include motor vehicle operating costs, the value of travel time, and traffic accident costs. Usually, only those operating costs that depend on the number of miles traveled, such as the cost of fuel, tires, engine oil, maintenance and a portion of depreciation are included in the highway economic analysis. Registration and parking fees, insurance premiums, and the time dependent portion of depreciation may be excluded when estimating the reduction in user 
costs due to a highway improvement. Table 3.1 summarizes the components of highway transportation costs.

\begin{tabular}{|c|c|}
\hline Type of Cost & Examples \\
\hline Highway Investment Costs & $\begin{array}{l}\text { Engineering Design, Right of Way, Grading } \\
\text { and Drainage, Pavements. }\end{array}$ \\
\hline Highway Maintenance Costs & Mowing, Care of Roadside Parks, Lighting \\
\hline Highway User Costs & \\
\hline $\begin{array}{l}\text { a) Motor Vehicle Operating } \\
\text { Costs }\end{array}$ & Fuel, Lubrication, Tires. \\
\hline b) Travel Time & Total vehicle-hours of travel multiplied by unit \\
\hline c) Accident costs & $\begin{array}{l}\text { Estimated Accident Rate multiplied by Unit } \\
\text { Accident Cost. }\end{array}$ \\
\hline
\end{tabular}

Table 3.1: Type of Costs That Might be Included in the Highway Transportation Cost Analysis

Economic studies for highway purposes are done principally for one or more of the following reasons.

- To determine the feasibility of a project.

- To compare alternative configurations.

- To evaluate various features of highway design, for example, the type of surface to be used. 
- To determine the priority of improvement.

- To allocate responsibility for the costs of highway improvement among various classes of highway users and some indirect benefit to non-users.

- Occasionally, to compare proposals for highway improvement with proposals for other publicly funded projects.

\subsection{Definitions}

The definitions that follow include the principal technical terms used in the report and have been adapted from the 1977 Manual. The listing is broken down into two categories: economic analysis definitions and highway traffic characteristic definitions.

\subsubsection{Economic Analysis Definitions}

- Transportation Improvement Cost- The sum of investment cost, maintenance cost, user costs, and transit user costs associated with a highway. The components of traffic improvement costs are defined in the following sub-sections:

- Highway or Facilities Investment Cost- Total investment required for a highway improvement, including engineering design and supervision, right of way acquisition, construction, traffic control devices (signals and signs) and landscaping.

- Highway Maintenance Cost- The cost of keeping a highway and its appurtenances in serviceable condition. Operating costs for traffic control and lighting should be included with maintenance costs if operating costs differ appreciably between two alternatives. 
- Highway User Costs- The sum of 1) Motor vehicle running cost 2) The value of vehicle user travel time, and 3) Traffic accident costs.

- Motor Vehicle Running Cost- The mileage dependent cost of running automobiles, trucks, and other motor vehicles on the highway, including the expenses of fuel, tires, engine oil, maintenance and that portion of the vehicle depreciation attributable to the highway mileage traveled.

- Value of Travel Time- The result of vehicle travel time multiplied by the average unit value of time.

- Vehicle Travel Time- The total vehicle hours of time traveled by a vehicle.

- Unit Value of Time- The value attributed to one hour of travel time, usually different for passenger cars and trucks.

- Traffic Accident Cost- The costs attributable to motor vehicle traffic accidents usually estimated by multiplying estimated accident rates by average cost per accident.

- User Benefit- The advantages, privileges, and/or cost reductions that accrue to highway motor vehicle users (drivers and owners). Benefits are generally measured in terms of a decrease in user costs.

- Incremental Cost- The net change in dollar costs directly attributable to a given decision or proposal compared with some other alternative (which could be existing condition or do nothing alternative).

- Present Value (PV)- An economic concept that represents the translation of specified amounts of costs or benefits occurring in different time periods into a single amount at a single instant (usually the present). The term Net Present Value (NPV) refers to the net 
cumulative present values of a series of costs and benefits stretching over time. It is derived by applying to each cost or benefit in the series an appropriate discount factor, which converts each cost or benefit to a present value.

- Equivalent Uniform Annual Cost (or Benefit)- A uniform cost (or benefit) that is the equivalent, spread over the entire period of analysis, to all incremental disbursements or costs incurred (or benefits received from) a project.

\subsubsection{Traffic Characteristic Definitions}

The following definitions refer generally tot the highway traffic characteristics.

- Capacity- Highway Capacity Manual defines capacity as the maximum number of vehicles that have a reasonable expectation of passing over a given section of a lane or a roadway in one direction or in both directions for a two-lane or three lane highway during a given time period under prevailing roadway and traffic conditions. In the absence of time modifier, capacity is expressed as an hourly volume.

- Passenger Car- A motor vehicle with a seating capacity of up to nine persons-including taxicabs (for capacity and economy study purposes), station wagons, and two-axle, four tire pickups, panels, and light trucks.

- Truck- A motor vehicle having dual tires on one or more axles, or having more than two axles, designed for cargo rather than passengers. Two types of trucks are considered in this report: 1) 12-kip, six tire, two axle single unit trucks and 2) 54 kip, diesel powered, combination 3-S2 tractor semi-trailer trucks.

- Bus- A vehicle with seating capacity of ten or more passengers. Buses are usually counted as single unit trucks for capacity and economic study purposes. 
- Average Speed (or Average Overall Traffic Speed)- The summation of distances traveled by all vehicles for a specified class of vehicles over a given section of highway during a specified of time, divided by the summation of overall travel times.

- Overall Travel Time- The time of travel including stops and delays on the traveled way.

- Running Speed- The speed over a specified section of highway, equal to the distance divided by the running time (the time the vehicle is in motion). Average Running Speed is the same as the average speed if there are no stops; otherwise it is higher.

- Design Speed- A speed selected for the purposes of design and correlation of those features of a highway, such as curvature, super-elevation, and sight distance, on which the safe operation of a vehicle depends.

- Operating Speed- The highest overall safe speed at which a driver can travel on a given highway under favorable weather conditions and under prevailing traffic conditions.

- Highway types- Four major highway types are considered in this report as described below:

- Freeways and Expressways- Expressways are divided Arterials highways for through traffic with full or partial control of access and generally with grade separations at major intersections; Freeways are expressways with full control of access.

- Multi-Lane Highways- Roads with four or more lanes (that is two or more lanes in each direction), without significant access control features and with low enough adjacent development to permit speed limits of greater than $40 \mathrm{mph}$ and signalization with average spacing of more than one mile. 
- Two-Lane Highways- Roads with two lanes (one in each direction), speed limit of generally forty miles per hour in both directions, and average signal spacing more than one mile. They may have varying degrees of access control.

- Arterials (or Arterial Streets, or Urban or Suburban Arterials)- Major streets and highways outside the central business district having either 1) speed limits of $40 \mathrm{mph}$ or less and 2) average signal spacing of one mile or less.

- Average Annual Daily Traffic- The total yearly volume divided by the number of days in a year, commonly abbreviated as AADT.

- Level of Service- A qualitative measure of the freedom of flow of traffic from constraints, interruptions, or other inconveniences, relative to the best possible conditions for a given type of highway facility. It is the inverse function of the hourly traffic volume or the traffic density at the time of observation.

- Service Volume - The maximum number of vehicles that can pass over a given section of a lane or a road-way in one direction on a Multi-Lane highway or Freeway (or in both directions on a two-lane highway or three lane highway) during one hour while operating conditions are maintained corresponding to the selected or specified level of service.

- Section- A "section" is defined as a road segment that possesses road characteristics considered to be fairly homogeneous; it may be considered as the average of its smaller subsections.

- Road Characteristic- The term "Road Characteristic" is defined as the various attributes of a highway such as the grade percent or curve angle or the type of road surface. 


\subsection{Benefits of Highway Improvement}

The benefits of highway improvement may be direct and readily apparent or may be indirect and difficult to discern. Some benefits may be readily evaluated in monetary gains, and some benefits may be intangible. For convenience, highway benefits have been grouped into two categories.

1) Direct benefits that result from a reduction in highway user costs .

2) Indirect benefits, including benefit to adjacent property and the general public.

The most significant highway benefits are those that result from a reduction in the user costs such as decreased operating costs, higher operating speeds, fewer delays, and decreased accident losses.

\subsection{Measurement of User Benefits (Costs) as Reported in the 1977 Manual}

One of the most difficult aspects of economic analysis for highways is the measurement of highway user benefits (costs). The highway user cost factors in the Manual are shown as a function of either the traffic speed or of the ratio of traffic volume to highway capacity (V/C ratio). The highway user costs for a given section of highway, HU, expressed in dollars per thousand vehicles, is the sum of the Basic Section costs, accident costs, delay costs and transition costs. The basic formula for computing highway user cost is as follows:

$$
\mathbf{H U}=(\mathbf{B}+\mathbf{A}) \times \mathbf{L}+\mathbf{T}+\mathrm{D}
$$

where,

$\mathrm{B}=$ Basic Section cost, consisting of the unit cost (time value and vehicle running costs) per mile, associated with vehicle flow and basic geometric (grades and curves) of the analysis section. The unit is dollars per 1000 vehicle miles. 
$\mathrm{A}=$ Unit accident cost per mile in the analysis section. The unit is dollars per 1000 vehicle miles.

$\mathrm{L}=$ Analysis section length in miles.

$\mathrm{T}=$ Transition cost; additional user unit time and running costs incurred due to changes in the speeds between sections. The unit is dollars per 1000 vehicles.

$\mathrm{D}=$ Additional unit time and running cost due to delays at intersections, at traffic signals, stop signs, or other traffic control devices. The unit is in dollars per 1000 vehicle.

In the following section, a summary of the methodology for calculating each of the cost components is presented.

\subsubsection{Basic Section Cost}

The Manual gives the Basic Section costs in the form of nomographs for three classes of vehicles: Passenger Cars, Single Unit Trucks and 3-S2 Combination Trucks, for four types of highways: Freeways, Two-Lane Highway, Multi-Lane Highways and Arterial. Twelve nomographs are used for the twelve combinations. As an example, one of these nomographs is reproduced in Figure 3.1.

The nomograph in Figure 3.1 is used to compute the Basic Section costs (B) for passenger cars on Multi-Lane highways. This nomograph is entered at the lower left end with average running speed or with the volume-capacity ratio for the representative hour of operation for the analysis section. These relationships for $\mathrm{V} / \mathrm{C}$ ratios and design speed are derived from curves for hourly operating speed for corresponding highway types in the Highway Capacity Manual. Travel time, the inverse of the running speed, can be read at the left ordinate of the lower left graph. A horizontal line at the level of the average running 


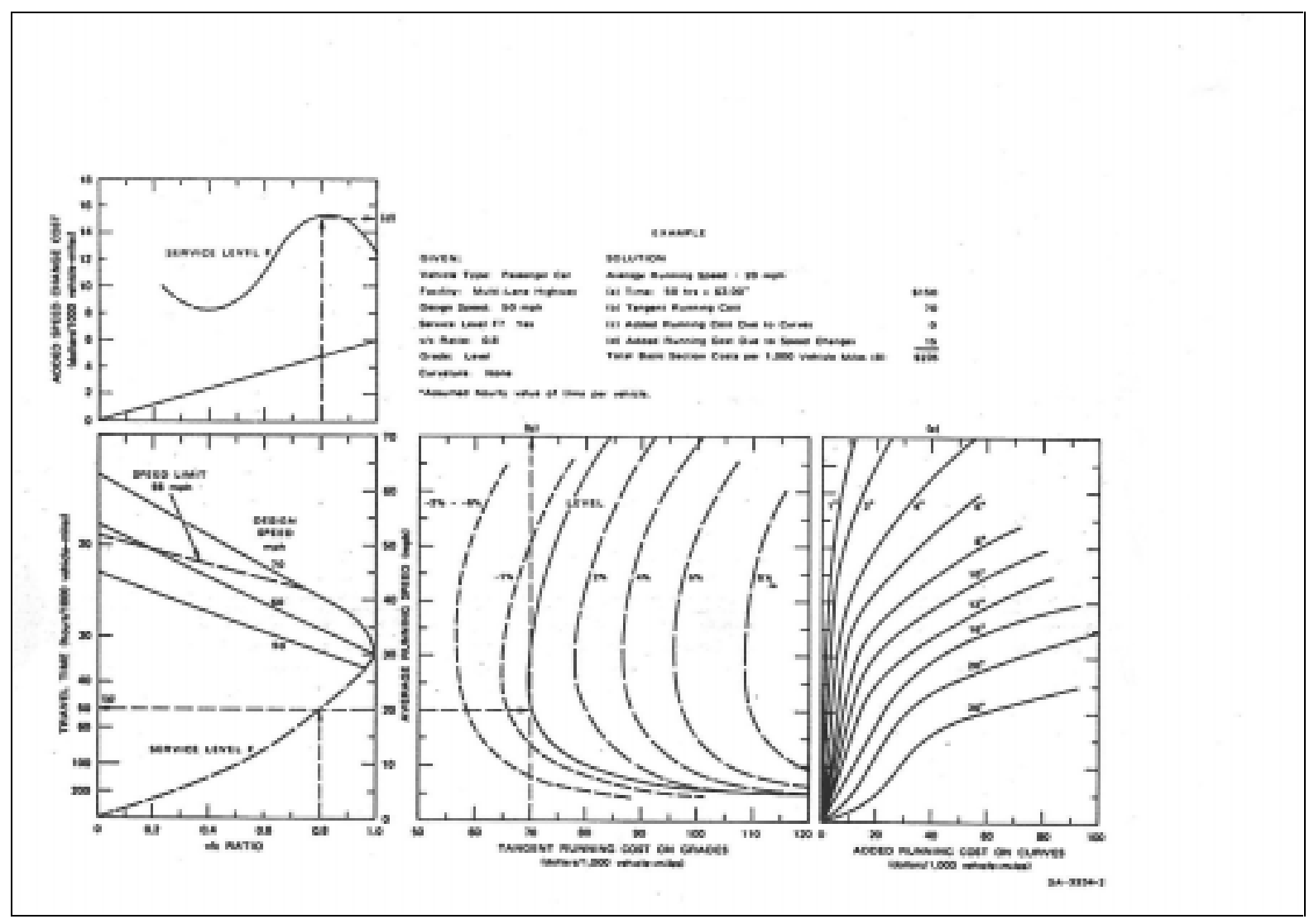

Figure 3.1: Basic Section costs (B) for passenger cars on Multi-Lane highways.

speed is then projected to the right scale to determine the tangent running cost (along a specified grade) and added running costs due to curvature. Finally, additional running costs due to speed change cycles are determined by entering the upper left graph with the volumecapacity ratio and reading the added cost at the ordinate. The added cost due to the speed change cycles is relatively small, except under the level of service $F$ (or queueing) conditions.

The Basic Section costs given in the example are valid only for the paved sections. The cost of operating vehicles on gravel and stone roadway surfaces can be estimated by multiplying the Basic Section costs from the nomograph by an adjustment factor. For passenger cars, the adjustment factor ranges from 1.1 for a speed of 5 miles per hour to about 
1.6 for the speed of $60 \mathrm{mph}$. Larger values are recommended for the single unit trucks and combination trucks. The Basic Section cost has a unit of dollars per 1000 vehicle miles. With a given V/C ratio and design speed, one can use the nomographs in Figures 7 to 18 of the Manual (pp.50-61) to find the following costs:

a) Cost associated with the value of time.

b) Additional costs due to curvature.

c) Additional running cost due to grades.

d) Additional running cost due to speed changes.

The value of travel time is the product of the total vehicle hours of travel (by vehicle type) and the average unit value of time. The magnitude of travel time depends on the average running speed and the number and duration of stops. Studies have indicated that the perceived value of travel time is sensitive to trip purposes and time savings per trip. The travel time cost is in dollars per 1000 vehicle miles. The STEAM software uses a default value of $\$ 6$ per hour for passenger cars and $\$ 24.60$ for commercial trucks as the values for the travel time [Decorla et. al., 1997].

The cost of operating a vehicle on a straight or level tangent is related primarily to the running speed and the gradient of the roadway. A gradient may be positive or negative. Moving a vehicle up a steep positive grade requires more fuel than moving it along a level road at the same speed. Sections with negative gradients can be negotiated with less burden on the engine, but sometimes it may be necessary to apply brakes and that imposes added running cost. These costs are accounted for under grade costs. The unit is dollars per 1000 vehicle miles. 
Curves impose costs in addition to tangent road running costs through the centrifugal force that tends to keep the vehicle following a tangent rather than a radial path. This force is opposed by superelevation of the roadway and the side friction between the tire tread and the road surface. There is a greater expenditure of energy and hence more fuel is required to negotiate curved sections. The unit is dollars per 1000 vehicle miles.

Speed change costs are those incurred when the vehicle changes its speed from a high value to a low value and goes back to the initial speed. The unit is expressed in dollars per 1000 vehicle miles.

\subsubsection{Accident Cost}

Accidents that occur every year on the streets and highways of America represent a great economic loss beside the pain and suffering that they cause. Total economic loss resulting from the motor vehicle accidents was estimated to be $\$ 156.6$ billion in 1992 [Wright, 1996]. This total includes loss incurred in fatal accidents, accidents involving nonfatal personal injury, and those involving only property damage. It follows that from an economic standpoint, highway improvements cause a decrease in accident rates, resulting in monetary saving to the road user and the public in general.

The accident cost can be reported in two ways.

1) The National Safety Council issues periodic report on the costs of vehicular accidents. Once the types of accidents and their frequency are known, accident costs in dollars per year can be calculated by multiplying the frequency (accidents per year) and the cost per accident. Such costs include wage losses, medical expenses, property damages, and insurance administration costs. 
2) Unit accident costs can be estimated on the basis of empirical accident rates that reflect regional effects of the vehicle mix, driver behavior, roadway type, and climate; or can be estimated from the average rates and costs by accident types, as shown in Table 11 and Table 13 of the Manual. The unit is expressed in dollars per 1000 vehicle miles.

To account for savings in accident costs in highway economic studies, accident rates before and after the proposed improvement should be estimated. The analyst should be able to rely on empirical data that will account for regional differences in vehicle mix, driver behavior and climate.

\subsubsection{Intersection Delay Cost}

The most complex aspect of determination of the unit highway user costs is the estimation of the cost of intersection delay (D). Two nomographs are published in the Manual to determine intersection delay costs: one to estimate the unit costs of stopping at a traffic signal and the other to estimate the unit costs of idling. In order to use these nomographs, information on the following traffic and signalization parameters for the intersection being studied are needed.

1) Green to cycle time ratio $(\lambda)$. The ratio of the effective green time of the signal (generally taken to be the actual green time) to the cycle length of the signal, both expressed in the same unit of time (usually seconds).

2) Saturation flow (s). The approach volume in vehicles per hour of green for the intersection when the load factor is 1.0 and the appropriate adjustment factors are applied. In the case of absence of Highway Capacity Manual, recommended values of saturation flow are 1700 and 1800 vehicles per hour times the numbers of approach lanes. 
3) Capacity (c). According to the Highway Capacity Manual, capacity is the service volume of the approach at a load factor of 1.0. It is also equal to the saturation flow times the greento-cycle time ratio.

4) Degree of saturation $(\chi)$. The ratio of the volume of the traffic approaching the intersection (usually in vehicles per hour) to the capacity of the intersection, in the same units.

5) Approach speed. Also termed mid-block speed, is the average running speed at which the vehicle stream approaches the signalized intersection.

The degree of saturation is the ordinate of the left most graph of the nomograph (Figure 3.2). For the given green to cycle time ratio, a line is projected on to the curve on the left most graph to calculate the average stops per vehicle. This is then projected on to the middle graph for the given approach speed, and the point at which it intersects the approach speed is projected on to the ordinate to calculate the added stopping delay in hours per thousand vehicles per signal. The same line is projected on to the right most graph to find the added stopping cost per thousand vehicles per signal. The time cost is the additional delay due to stopping multiplied by the hourly value of time per passenger car multiplied by the adjustment factor for the trucks in the stream. The running cost for the intersection is the additional stopping cost multiplied by the adjustment factor for the trucks in the traffic stream. 


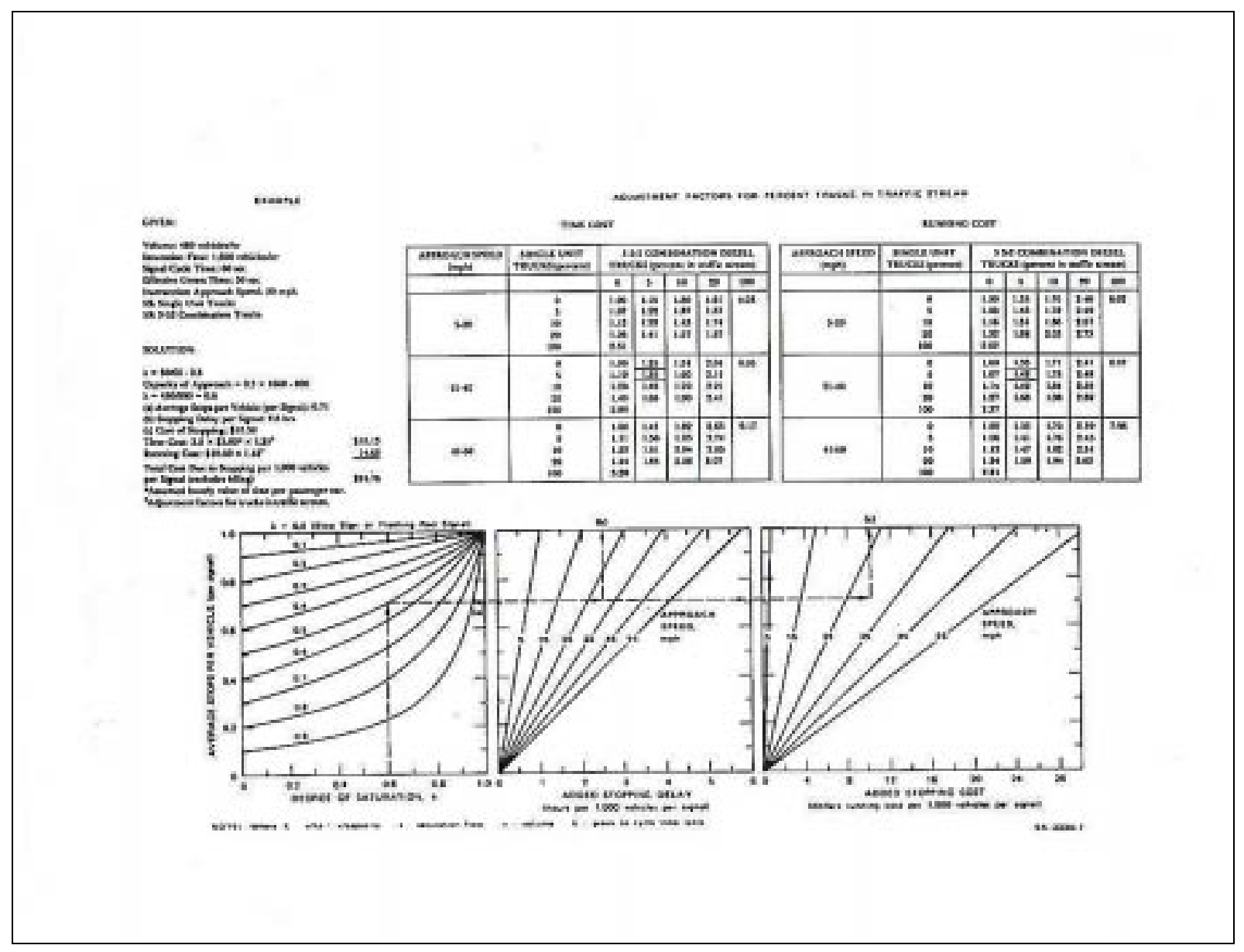

Figure 3.2: Costs due to stopping at intersections (excludes idling)

The idling costs are found with the help of the idling cost nomograph (Figure 3.3). The ordinate of the bottom most graph of the nomograph is entered for the given or calculated degree of saturation. For the given capacity, the intersection point on the graph is located and extended straight upwards to calculate the average delay per vehicle (seconds). A small correction to average delay is also added for the given cycle length and green-to-cycle ratio. This point is on the ordinate of the left upper most graph. It is extended to the right hand side to calculate the idling time in hours per thousand vehicles and the idling costs in dollars per 1000 passenger cars. 


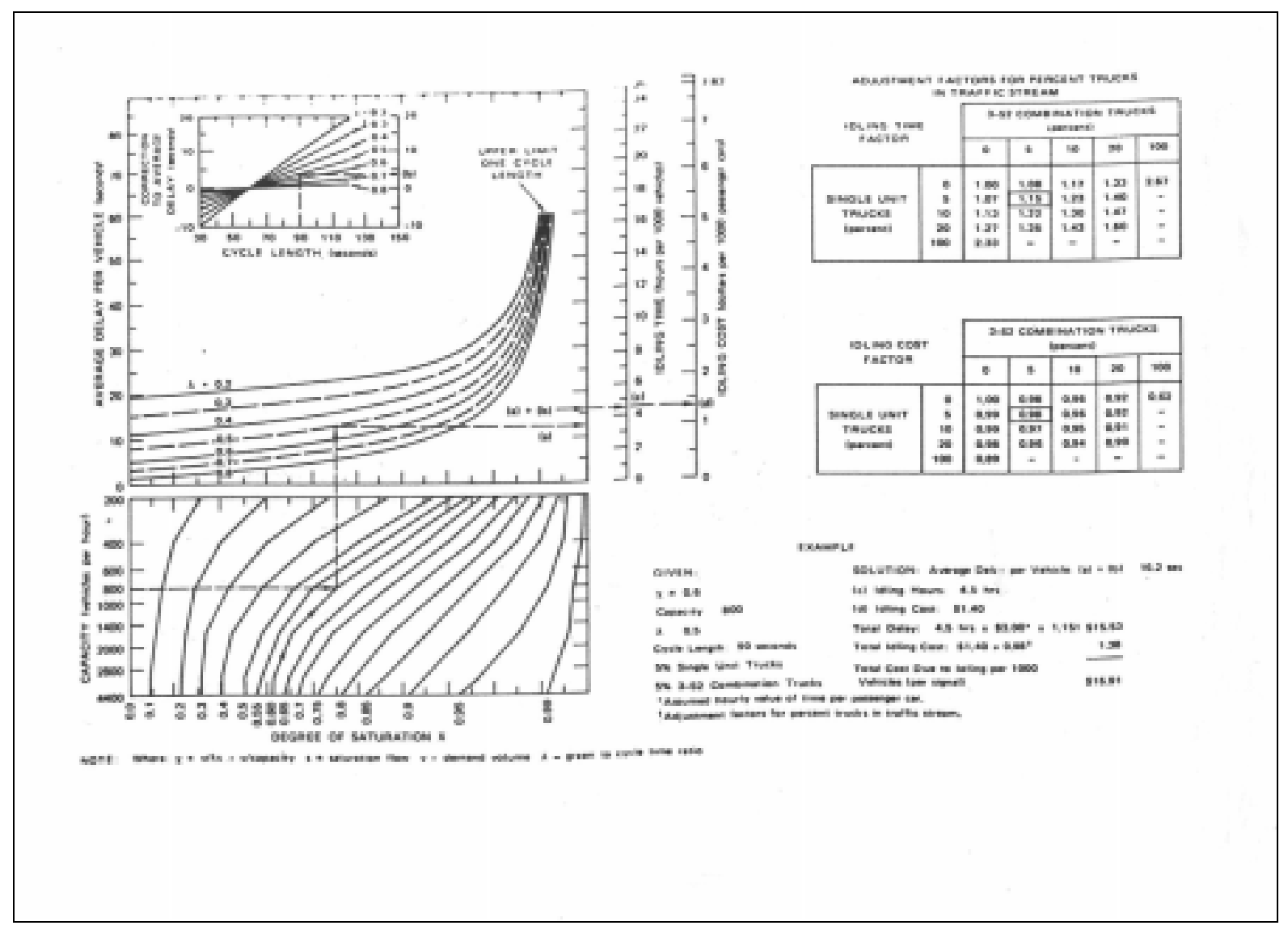

\section{Figure 3.3: Costs due to idling at intersections}

The total delay cost is the idling time multiplied by the hourly value of time per passenger car and the adjustment factor for percent trucks in the stream. The total idling cost is idling cost multiplied by the adjustment factor for the percent trucks in the stream. The total cost due to idling per thousand vehicles per signal is the summation of the above costs. The analysis of intersection delay often requires separate calculations for each direction of approach, especially where opposing and /or crossing approaches have unequal traffic flows or different characteristics (e.g., number and types of intersections, capacity, signalization parameters, and so on). If there are three signalized intersections of approximately the same characteristics included in the overall roadway being analyzed, one intersection might be analyzed and the results multiplied by three. A degree of saturation of 1 implies that all 
vehicles in the traffic stream would stop at the signal at least once and that average delay per vehicle would at least equal the signal cycle time. The unit is expressed in dollars per 1000 vehicles.

\subsubsection{Transition Cost}

Empirical studies have made it possible to estimate the costs of speed changes when vehicles pass between sections with different physical or traffic characteristics. Section transit cost $(\mathrm{T})$ depends on the magnitude of the average speed change. The graphs and tables of the Manual (included in appendices B10 to B12) provide factors to account for excess running costs due to speed change cycles for passenger cars, single unit trucks and 3-S2 combination diesel trucks. These graphs/ tables show the cost of a full speed change cycle and should be divided by 2 for use as one way section transition costs. An example of the graph and table is shown in Figure 3.4. The unit is expressed in dollars per 1000 vehicles.

\subsection{One Way Versus Two Way Traffic}

Costs given by various nomographs relate to one-way traffic on a highway facility. Ordinarily, where improvements affect both sides of the roadway and the traffic is balanced in both directions over the course of a typical day, the benefits (costs) which are calculated from the one-way analysis should be multiplied by two. 


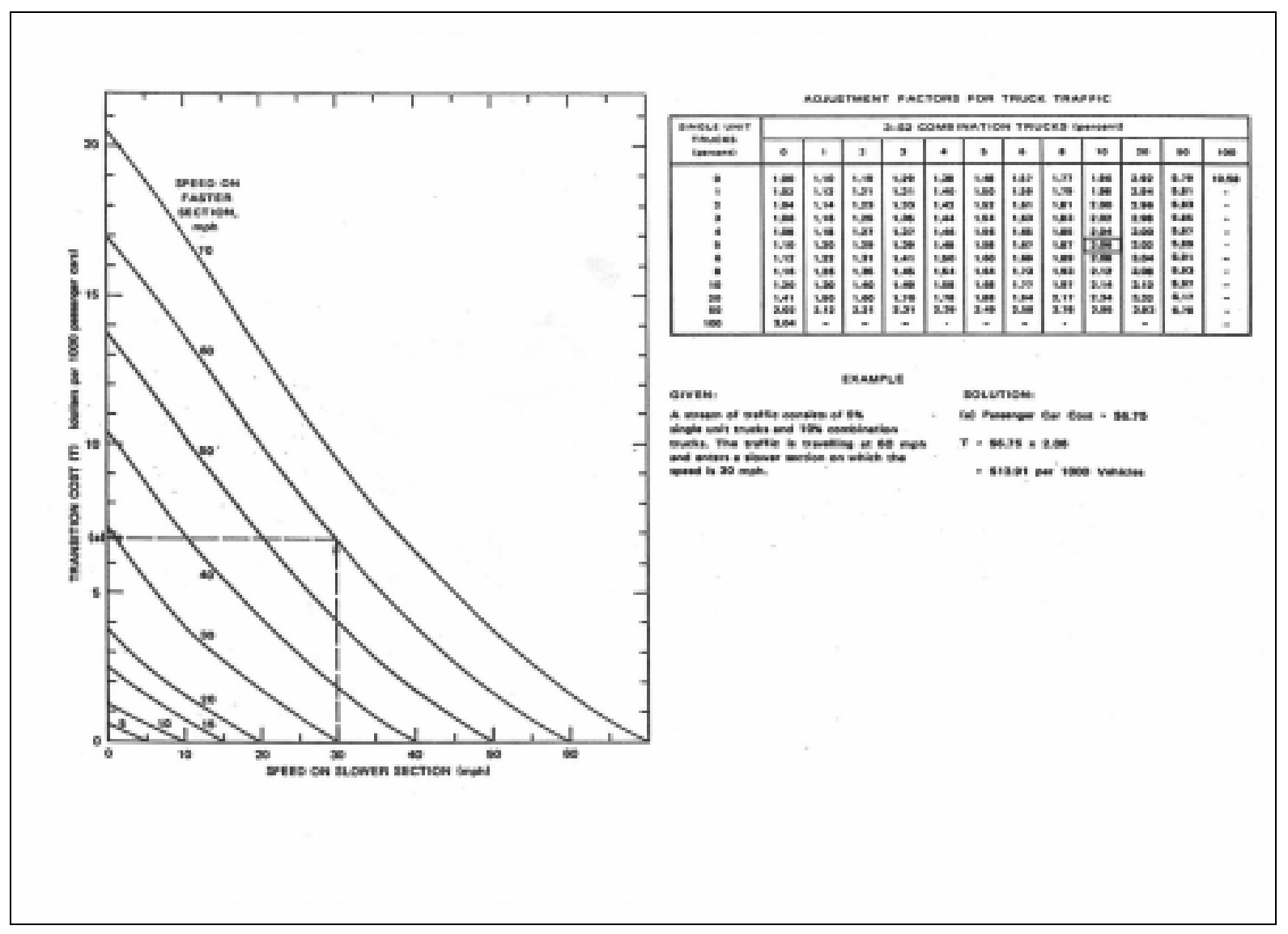

Figure 3.4: Section transition costs.

\subsection{The Effects of Highway Improvement}

Highway economic analyses should account for the changes in traffic volume that are 1) induced by the improvement, and 2) diverted from other routes to the new facility. It is, therefore, recommended that the difference in the user benefits (costs) be multiplied by the average of the traffic volume with and without the improvement.

$$
\text { User Benefits }=\left(\mathrm{U}_{0}-\mathrm{U}_{1}\right)\left[\left(\mathrm{V}_{0}+\mathrm{V}_{1}\right) / 2\right]
$$

where,

$\mathrm{U}_{0}=$ user cost per unit of traffic (vehicles or trips) without the improvements.

$\mathrm{U}_{1}=$ user cost per unit of traffic with the improvement.

$\mathrm{V}_{0}=$ Level of the traffic without the improvement $\left(\mathrm{AADT}_{0}\right)$ 
$\mathrm{V}_{1}=$ Level of traffic with the improvement, including any induced or diverted traffic $\left(\mathrm{AADT}_{1}\right)$

$\mathrm{V} 1$ may be larger than $\mathrm{V}_{0}$, as shown, or smaller when the traffic is diverted to any new parallel facility.

\subsection{Economic Analysis Technique as Reported in the Manual}

Economic analysis intended to provide the economic justification for a particular project or to permit comparison of alternative schemes or locations, in order to determine the priority of improvement, etc. might be carried out by one of several methods. Methods used in engineering economy studies include:

1) Benefit Cost ratio $(\mathrm{B} / \mathrm{C})$

2) Net Present Value (NPV)

3) Comparison of annual costs

4) Determination of the interest rate (internal rate of return) at which the alternatives are equally attractive.

Benefit Cost ratio (B/C) and the NPV methods are more commonly used by highway engineers and administrators.

\subsubsection{Benefit Cost Ratio}

The following formulation of the benefit-cost ratio that utilizes the present values is recommended for all highway and transit applications as an approximate indicator of the project desirability.

$\mathbf{B} / \mathbf{C}=\mathbf{P V}(\Delta \mathbf{U}) /[\mathbf{P V}(\Delta \mathbf{I})+\mathbf{P V}(\Delta \mathbf{M})-\mathbf{P V}(\Delta \mathbf{R})]$

$\mathrm{PV}=$ The present value of the indicated amount or series. 
$\Delta \mathrm{U}=$ User benefits, the reductions in the annual highway user costs due to the investment (costs without the improvement less costs with the improvement).

$\Delta \mathrm{I}=$ Increased investment costs due to the project.

$\Delta \mathrm{M}=$ Increase in the series of the annual maintenance, operating, and administrative costs due to the investment (costs with the improvement less costs without the improvement).

$\Delta \mathrm{R}=$ Increase in the residual value due to the project at the end of the effective life of the project.

Example: If $\Delta \mathrm{U}=\$ 1000, \Delta \mathrm{I}=\$ 900, \Delta \mathrm{M}=\$-100, \Delta \mathrm{R}=0$ then $\mathrm{B} / \mathrm{C}=1000 / 900-100=1.25$

\subsubsection{Net Present Value Method}

The basic criterion for the economic desirability is that the present values of the stream of annual benefits resulting from a project exceed the present value of the costs associated with implementing the project. Since the Net Present Value (NPV) is defined as the difference between the present value of the stream of benefits and the present value of the stream of costs, an equivalent criterion or decision rule can be described as follows: if the (NPV) associated with a particular improvement project or project alternative is greater than zero, the project or the project alternative is economically justified.

NPV can be symbolically expressed as follows:

$$
\mathrm{NPV}=\mathrm{PV}(\Delta \mathrm{U})+\mathrm{PV}(\Delta \mathrm{R})-[\mathrm{PV}(\Delta \mathrm{I})+\mathrm{PV}(\Delta \mathrm{M})]
$$

Stated another way:

$$
\mathrm{NPV}=\left(\mathrm{B}_{0}-\mathrm{C}_{0}\right)+\left(\mathrm{B}_{1}-\mathrm{C}_{1}\right) /(1+\mathrm{i})+\left(\mathrm{B}_{2}-\mathrm{C}_{2}\right) /(1+\mathrm{i})^{2}+\ldots . .+\left(\mathrm{B}_{\mathrm{n}}-\mathrm{C}_{\mathrm{n}}+\mathrm{R}\right) /(1+\mathrm{i})^{\mathrm{n}}
$$


Where $\mathrm{B}_{0}$ and $\mathrm{C}_{0}$ are the benefit and the cost for the initial year, $\mathrm{B}_{1}$ and $\mathrm{C}_{1}$ for the first year, $B_{2}$ and $C_{2}$ for the second year, and so forth; $R$ is the residual value, $i$ is the discount rate, and $\mathrm{n}$ is the analysis period.

The Net Present Value is computed as:

$\mathrm{NPV}=$ Present value of the benefits - Present value of the costs.

An approximate way of calculating the present value has been provided in the Manual. The present worth factor is given by:

$$
P W_{g}=e^{(r-i) * n}-1 /(r-i)
$$

where,

$\mathrm{i}=$ interest rate

$r=$ rate of growth of annual value

$\mathrm{n}=$ analysis period (years)

The annual average growth rate $r$ can be approximated on the basis of estimates of two years' values:

$$
\mathbf{r}=\ln (\alpha) / \mathbf{Y}
$$

where, $\alpha=$ ratio of annual benefits in a future year to the annual benefits in the first year and $\mathrm{Y}$ is the period of estimate, which starts at the beginning of the first year and terminates at the end of the future year. The period of estimate does not need to be equal to the length of analysis period as long as the assumption of constant annual geometric growth or decline holds over the entire analysis period.

The procedure described above is used to calculate the present value of a stream of benefits or costs only when the annual values are estimated to increase or decrease at an approximately equal percent rate that is a constant positive or negative geometric growth. If 
the annual percent rate fluctuates, the user has to revert to calculation of the present values based on Equation 3.5. Both options for calculating the present value have been provided in the software.

\subsubsection{Decision Rules in Economic Analysis}

Rules of application of the $\mathrm{B} / \mathrm{C}$ ratio and the Net Present Value techniques depend on whether there are budgetary constraints and whether the projects under consideration are independent or mutually exclusive. When there are no budgetary constraints and independent projects are being compared, the selection of one project would not preclude the selection of other projects. In this instance all projects with positive Net Present Values or benefit cost ratios greater than 1 would be economically feasible.

When the investment budget is constrained, the analyst should select the combination of projects that produces a maximum Net Present Value but does not exceed the available budget. Alternatively and approximately, projects may be selected in order of decreasing B/C ratios, adding projects until the budget is exhausted.

In case of mutually exclusive projects, the alternative with the highest Net Present Value is chosen. If benefit cost ratios is used to select the preferred project, the selection must be made in increments. Beginning with the lowest cost alternative having a $\mathrm{B} / \mathrm{C}$ ratio greater than 1 , each increment of additional cost is justified only if the incremental $\mathrm{B} / \mathrm{C}$ ratio is greater than 1 [Oglesby et. al., 1982].

\subsection{Example of a Highway Economic Analysis}

The following example adapted from the user benefit analysis section of the Manual illustrates the application of some of the data and procedures presented. 
A highway agency is considering the elimination of a S-shaped curve on a MultiLane highway. Total construction cost for the improvement is estimated to be $\$ 2$ million and will be incurred at the inception of the project. Annual maintenance costs are anticipated to be $\$ 2,000$ less after the improvement because the elimination of the curve reduces pavement and guard rail damage. The growth factor for annual maintenance cost is assumed to be zero.

The $\mathrm{S}$ curve is made up of two continuous 8 degree curves in reverse alignment to each other. Since the curves are of the same degree of curvature, they can be analyzed together, and since the traffic can be assumed to be uniform over the entire affected roadway, the analyst may view the improvement in terms of a single analysis section, designated as $\mathrm{AB}$.

The characteristics of the existing route (alternative 0) and the proposed route (alternative 1) are summarized in Table 3.2.

\begin{tabular}{|c|c|c|c|c|c|c|}
\hline Alternative & Section & $\begin{array}{c}\text { Length } \\
\text { (Miles) }\end{array}$ & \multicolumn{2}{|c|}{ Basic Section Data } & $\begin{array}{c}\text { Design Speed } \\
\text { (mph) }\end{array}$ \\
\hline & & & Lanes (one way) & Grade & Curvature & \\
\hline 0 & $\mathrm{AB}$ & 0.2 & 2 & $0 \%$ & 8 degree & 50 \\
\hline 1 & $\mathrm{AB}$ & 0.16 & 2 & $0 \%$ & 0 degree & 60 \\
\hline
\end{tabular}

Table 3.2: Facility Data for the Example

The analyst has obtained the traffic estimates with and without the proposed improvement for the first and the last year of the twenty-year analysis period. It is assumed that the level of service, F, does not occur during the analysis period, and that the hourly 
variation of the traffic is small enough such that the explicit consideration of peaking characteristics is unnecessary. Hence, the analysis is performed on an AADT basis. This entails utilizing the traffic volume data for a typical hour of the day in each of the study years. Such traffic data are summarized in Table 3.3, where a typical one way hourly volume is defined as AADT divided by 18 (the number of hours assumed for a day). Note also that capacity in year 20 is somewhat below that of year 1 . This is to reflect normal deterioration of the roadways over the years.

The traffic is assumed to be made of only passenger cars. The average running speed is a function of the V/C ratio and other road characteristics and is computed from the nomograph (Figure 3.1) and summarized in Table 3.3. Since speeds on the analysis section will change as a result of the improvement, transition costs between sections will change; thus speed on the previous section and the subsequent sections must be specified. 


\begin{tabular}{|c|c|c|c|c|c|c|c|c|c|}
\hline Alternative & Section & $\begin{array}{c}\text { Study } \\
\text { Year }\end{array}$ & Period & $\begin{array}{c}\text { One Way } \\
\text { Volume }\end{array}$ & $\begin{array}{c}\text { One Way } \\
\text { Capacity }\end{array}$ & $\begin{array}{c}\text { V/C } \\
\text { Ratio }\end{array}$ & $\begin{array}{c}\text { Avg. } \\
\text { Running } \\
\text { Speed }\end{array}$ & \multicolumn{2}{|c|}{ Speed on } \\
\hline & & & & & & & & $\begin{array}{c}\text { Previous } \\
\text { Next } \\
\text { Section }\end{array}$ \\
\hline 0 & AB & 1 & Typical & 1900 & 3800 & 0.5 & 36 & 41 & 50 \\
\hline 1 & AB & 1 & Typical & 2000 & 3800 & 0.53 & 41 & 41 & 50 \\
\hline 0 & AB & 20 & Typical & 2900 & 3500 & 0.83 & 30 & 30 & 45 \\
\hline 1 & AB & 20 & Typical & 3000 & 3500 & 0.84 & 30 & 30 & 45 \\
\hline
\end{tabular}

Table 3.3: Traffic Data

\subsubsection{Calculation of the User Costs}

The above facility and traffic data enable calculation of the user costs on the existing route and the proposed route as shown in Table 3.4. Unit highway user costs (HU) are calculated from the equations given in the report by using the section costs, section length and the transition costs. Basic Section Costs (B) and Transition Costs (T) are derived from the nomograph. A unit value of time of $\$ 6$ is assumed. Determination of B and $\mathrm{T}$ for the existing route (alternative 0) is as follows. Entering the lower left hand (speed flow chart) of Figure 3.1 with a V/C ratio of .50 and a design speed of $50 \mathrm{mph}$ yields an average running speed of $36 \mathrm{mph}$ and a corresponding travel time of 27.8 hours per thousand vehicle miles. 
Tangent running cost at $36 \mathrm{mph}$ on a level grade is approximately $\$ 71$ per thousand vehicle miles (KVM). Additional running cost due to an 8-degree curve is approximately $\$ 20$ per KVM. Added running costs due to the speed changes are approximately equal to $\$ 3$ per $\mathrm{KVM}$. Total running cost per $\mathrm{KVM}$ on the existing route is thus about $\$ 94.00(\$ 71+\$ 20+\$ 3)$. Adding this to a total time value of about $\$ 166.80$ (27.8 x $\$ 6$ per hour) per KVM yields a total unit Basic Section cost for the existing route in year 1 of $\$ 260.80(\$ 94.00+\$ 166.80)$ per KVM.

\begin{tabular}{|c|c|c|c|c|c|c|}
\hline Alternative & Section & $\begin{array}{l}\text { Study } \\
\text { Year }\end{array}$ & Period & B * L & $+T$ & $\begin{array}{l}\text { = One } \\
\text { Way HU } \\
\text { per KV }\end{array}$ \\
\hline 0 & $\mathrm{AB}$ & 1 & $\begin{array}{c}\text { Typical } \\
\text { hour }\end{array}$ & $260.80 * 0.20$ & 3.5 & $\$ 55.66$ \\
\hline 1 & $\mathrm{AB}$ & 1 & $\begin{array}{c}\text { Typical } \\
\text { hour }\end{array}$ & $216.6 * 0.16$ & 1.7 & $\$ 36.35$ \\
\hline 0 & $\overline{\mathrm{AB}}$ & 20 & $\begin{array}{c}\text { Typical } \\
\text { hour }\end{array}$ & $285.9 * 0.20$ & 3.0 & $\$ 60.18$ \\
\hline 1 & $\mathrm{AB}$ & 20 & $\begin{array}{c}\text { Typical } \\
\text { hour }\end{array}$ & $262 * 0.16$ & 2.0 & $\$ 43.92$ \\
\hline
\end{tabular}

\section{Table 3.4: Calculation of Highway User Cost}

Entering Figure 3.4 with a speed of $41 \mathrm{mph}$ on the faster existing section and the 36 mph on the section being analyzed yields an added one way transition cost of $\$ 1$ per 
thousand vehicles. Similarly, for the transition from the section, with an assumed speed of 50 mph the transition cost is approximately $\$ 2.50$ per $\mathrm{KV}$. Total one way section transition cost is thus $\$ 3.50$ per $\mathrm{KV}$.

Similar applications of the figures to the proposed route in year 1 and both the existing and proposed route in year 20 yield corresponding values for both $\mathrm{B}$ and $\mathrm{T}$. The absence of curves under alternative 1 reduces the Basic Section cost B, relative to alternative 0 , while reduction in the magnitude of speed changes between sections reduces the $\mathrm{T}$ value for alternative 1 relative to alternative 0. Multiplying the Basic Section costs by the section length $\mathrm{L}$ and adding section transition costs yield in the one way highway user costs per $\mathrm{KV}$.

\subsubsection{Calculation of the User Benefits}

Benefits in the first and $20^{\text {th }}$ years, as an example, can be calculated from the above user cost (HU) estimates by applying the following equation:

One way annual user benefits $=($ Days per year $) \mathrm{x}($ Hours per day $) \mathrm{x}($ User benefits $)$

The calculations for the example are shown in Table 3.5.

\subsubsection{Computation of the Present Value and Measures of Economic Desirability.}

Using the assumption that benefits grow by an equal annual percentage rate, the benefits for the two representative years may be converted to an estimate of the present value of all benefits by the application of the equations for calculating the present worth.

Using the ratio $\alpha$ of benefits in the $20^{\text {th }}$ year to the $1^{\text {st }}$ year $(315,143 / 247,390=1.2738)$, the rate of growth of annual value is calculated using Equation 3.7, which is $r=\ln (\alpha) / 20=$ 0.0121. For an assumed 25 year analysis period, $\mathrm{n}=25$ and a 4 percent discount rate, $\mathrm{i}=0.04$ a present worth factor $\left(\mathrm{PW}_{\mathrm{g}}\right)$ of approximately 17.999 is obtained by the Equation 3.6. 
$\mathrm{PW}_{\mathrm{g}}=\mathrm{e}^{(\mathrm{r}-\mathrm{i})^{*} \mathrm{n}}-1 /(\mathrm{r}-\mathrm{i})=17.999$.

\begin{tabular}{|c|c|c|c|c|c|c|}
\hline Section & $\begin{array}{l}\text { Study } \\
\text { Year }\end{array}$ & Period & $\begin{array}{l}\text { Days } \\
\text { per } \\
\text { Year }\end{array}$ & $\begin{array}{l}\text { Hours } \\
\text { per day } \\
\text { in } \\
\text { period }\end{array}$ & $\left(H_{U_{0}}-H_{U_{1}}\right) *\left(\mathbf{V}_{0}+\mathbf{V}_{1}\right) / 2$ & $\begin{array}{c}\text { One Way } \\
\text { Annual } \\
\text { Benefits }\end{array}$ \\
\hline $\mathrm{AB}$ & 1 & $\begin{array}{c}\text { Typical } \\
\text { hour }\end{array}$ & 365 & 18 & $(55.66-36.35) *(1.9+2.0) / 2$ & $\$ 247,390$ \\
\hline$A B$ & 20 & $\begin{array}{c}\text { Typical } \\
\text { hour }\end{array}$ & 365 & 18 & $(60.18-43.92) *(2.9+3.0) / 2$ & $\$ 315,143$ \\
\hline
\end{tabular}

Table 3.5: User Benefit Calculations

The present value of the benefits would then be $(17.999 * 247,390)=\$ 4,452,780.10$ approximately. Since the improvement affects traffic symmetrically in both directions, this one way benefit estimate is multiplied by 2 to yield the total present value of the project's benefits as approximately $\$ 8.9055$ million.

A complete project analysis also requires conversion of the project costs and related items into the present values. Project costs include the capital cost of construction and the maintenance expenses that are incurred on the section after the improvement. A present value adjustment of the residual or scrap value of the project after the 25 year analysis period is also necessary. The total construction cost incurred at the inception of the project is $\$ 2$ million, which is also the present value. Annual maintenance costs are anticipated to be $\$ 2,000$ less after the improvement. The project is estimated to have a residual value of $\$ 500,000$ in its $25^{\text {th }}$ year. Again using a discount rate of 4 percent, the streams of annual maintenance cost savings are converted to the present value by using the appropriate present 
worth series factor. The conversion of all projects related costs are summarized in the Table 3.6. The values 15.62 and 0.375 are the series present worth factor and the lumpsome present worth factors, which gives the present worth of these values.

\begin{tabular}{|c|c|c|}
\hline Item & Value * Rate & Present Value \\
\hline Construction Cost & $\$ 2,000,000 * 1.00$ & $\$ 2,000,000$ \\
\hline Changes in Annual Maintenance Expenditure & $-\$ 2,000 * 15.62$ & $-\$ 31,244$ \\
\hline Residual Value in 25 Years & $-\$ 500,000 * 0.375$ & $-\$ 187,558$ \\
\hline Present Value of all Costs & & $\$ 1,781,198$ \\
\hline
\end{tabular}

\section{Table 3.6: Calculation of Present Value of Project-Related Costs}

The Net Present Value is the difference between the present values of the benefits and the present values of the cost:

Net Present Value $=$ Present Values of the Benefits - Present Value of the Costs

$$
\begin{aligned}
& =\$ 8,905,560-\$ 1,718,198 \\
& =\$ 7,187,362
\end{aligned}
$$

The Net Present Value of $\$ 7,187,362$ indicates that the project is economically desirable. The benefit cost ratio also suggests that the project is feasible because $(\$ 8,905,560)$ $/(\$ 2,000,000-\$ 31,244-\$ 187,558)$ or 4.99 is greater than 1.

However if there are budgetary constraints, the decision-maker should investigate other projects or project alternatives for their relative economic attractiveness before making a decision to implement the current project. 


\subsection{Methodology Used in the Software}

The formula used in the project is based on Equation 3.1, which is slightly changed to correct for units and the number of sections. For a project consisting of $\mathrm{c}$ sections, the highway road user cost, expressed in yearly cost per 1000 daily vehicles, computed for all sections, is as follows.

$\mathbf{H U}=\Sigma_{\mathbf{i}}\left(\left(\left(\mathbf{B}_{\mathrm{i}} * \mathbf{L}_{\mathbf{i}}+\mathbf{T}_{\mathbf{i}}+\mathbf{D}_{\mathbf{i}}\right) * 365 * \mathbf{A A D T}_{\mathbf{i}} / 1000\right)+\mathbf{A}_{\mathbf{i}}\right) / \mathbf{A A D T}_{\text {avj }}$

where,

$B_{i}=$ Basic Section costs, for section $i$, consisting of the unit cost (time value and vehicle running costs) per mile, associated with vehicle flow and basic geometric (grades and curves) of the analysis section, $\mathrm{i}=1,2,3, \ldots . \mathrm{c}$, where $\mathrm{c}$ is the total number of sections.

$A_{i}=$ Accident costs per year in section $i$.

$\mathrm{L}_{\mathrm{i}}=$ Analysis section length in miles, for section $\mathrm{i}$.

$\mathrm{T}_{\mathrm{i}}=$ Transition costs, additional user unit time and running costs incurred due to changes in the speeds between sections, for section i.

$\mathrm{D}_{\mathrm{i}}=$ Additional unit time and running costs due to delays at intersections, at traffic signals, stop signs, or other traffic control devices for section i.

$\mathrm{AADT}_{\mathrm{i}}=$ The Average annual daily traffic for section $\mathrm{i}$.

$\mathrm{AADT}_{\text {avj }}=$ The weighted average of annual daily traffic $=\Sigma\left(\mathbf{A A D T}_{\mathbf{i}} * \mathbf{L}_{\mathbf{i}}\right) / \Sigma \mathbf{L}_{\mathbf{i}}$

In order to represent or model all daily traffic within peak and off peak periods, it is suggested that traffic in minimum traffic hours be added to off peak traffic and that minimum traffic hour be represented as having zero traffic. The total peak and off peak will then add up to less than the total hours in a day. A model day of 18 hours is suggested, with traffic in the 
six hours from 12 midnight to 6 am added to off peak traffic. To compute the annualized benefits for a project, a factor of 365 is applied to the unit daily cost.

The Basic Section cost is calculated in the same way as described in the 1977 Manual (Section 3.2.1). The two methods in which accident cost is calculated are described in Section 3.2.2. The first method is adopted in the software. The methods to calculate the intersection delay costs and transition costs, respectively, are the same as those described in Section 3.2.3 and Section 3.2.4 and have been adopted in the software without any changes.

The road user benefit is calculated by substituting in Equation 3.2 the value of $\mathrm{HU}$ for old alternative and the new alternative calculated by Equation 3.7 and the $\mathrm{AADT}_{\text {avj }}$ for the old alternative and the new alternative calculated by Equation 3.9.

Thus, the formula is as follows:

$$
\text { User benefits }=\left(\mathrm{HU}_{\mathbf{0}}-\mathrm{HU}_{\mathbf{1}}\right)\left[\left(\mathrm{AADT}_{\mathrm{avj}(0)}+\mathrm{AADT}_{\mathrm{avj}(1)}\right) / 2\right]
$$

The unit is in dollars per year. Among the various types of economic analysis that can be performed to verify whether a project is desirable or not, the Net Present Value technique as described in Section 3.5.2 has been used in the software. An example is provided in Chapter 4 to illustrate the results produced by the software using the above methodology.

\subsection{Cost Updating Procedures}

It is noted that the nomographs shown in Figures 3.1 through 3.4 are based on January 1975 price levels. It is recommended that the cost factors be reviewed and updated once a year when the latest CPI's become available. The 1977 Manual recommends a cost updating procedure that employs multipliers based on commonly available consumer and wholesale price indices published by the U.S. Bureau of Labor Statistics. It is noted that the 
indices published in the 1977 Manual have been indexed to the period 1982-84 as a base unit of 100 .

Table 3.7 gives a list of consumer price indices and wholesale price indices (now termed as wholesale price indices) updated to May 1997. The table also shows the January 1975 values as well as those values that have been adjusted for rebasing. These indices make it possible to update the user costs from the nomographs for inflation.

A series of updating formulas was published in the 1977 Manual that accounts for the various components of the user costs and recognizes that these components may escalate at different rates. These formulas have been rearranged and shown in Tables 3.8(a) through 3.8(c). The formula provides a weighted average multiplier that accounts for the varying rates of inflation. In the first formula in Table 3.8(a), for example, fuel costs accounted for 28 percent of total passenger car running costs on level tangents, motor oil accounts for 1 percent, tires account for 5 percent, and so on. In these formulas, for a given index variable, $\mathrm{R}_{\mathrm{i}}$ represent the ratio of the value of the present consumer price index to the adjusted value of the January 1975 index and the subscript i denotes the component ( $f$ for fuel or fs for fuel, single unit truck and so on). 


\begin{tabular}{|l|c|c|c|}
\hline \multicolumn{1}{|c|}{ Index } & Jan-1975 & $\begin{array}{c}\text { January 1975 Value } \\
\text { Adjusted For } \\
\text { Rebasing }\end{array}$ & $\begin{array}{c}\mathbf{1 9 9 7} \\
\text { Index }\end{array}$ \\
\hline CPI, Total & 156.1 & 52.1 & 160.5 \\
\hline CPI, Private Transport & 142.2 & 48.0 & 141.0 \\
\hline $\mathrm{C}_{\mathrm{f}}$, Fuel & 160.2 & 45.1 & 106.2 \\
\hline $\mathrm{C}_{\mathrm{o}}$, Motor Oil & 152.8 & 65.3 & 131.4 \\
\hline $\mathrm{C}_{\mathrm{t}}$, Tires & 124.9 & 69.2 & 100.2 \\
\hline $\mathrm{C}_{\mathrm{m}}$, Maintenance & 170.1 & 53.7 & 162.7 \\
\hline $\mathrm{C}_{\mathrm{d}}$, Depreciation & 123.4 & 63 & 144.3 \\
\hline WPI, Industrial Commodities & 167.5 & 53.6 & 127.7 \\
\hline $\mathrm{P}_{\mathrm{fs}}$, Fuel, Single Unit Truck & 198.9 & 30.6 & 81.5 \\
\hline $\mathrm{P}_{\mathrm{fc}}$, Fuel, Combination Truck & 237.6 & 29.8 & 80.7 \\
\hline $\mathrm{P}_{\mathrm{o}}$, Motor Oil & 151.5 & 51.2 & 98 \\
\hline $\mathrm{P}_{\mathrm{t}}$, Tires & 152.0 & 58.0 & 156.5 \\
\hline $\mathrm{P}_{\mathrm{ds}}, \quad$ Depreciation, Single Unit \\
\hline Truck & 148.9 & 55.8 & \\
\hline $\mathrm{P}_{\mathrm{dc}}, \quad$ Depreciation, Combination \\
Truck & 148.9 & 49.3 & \\
\hline
\end{tabular}

Table 3.7: Consumer and Wholesale Price Indices for January 1975 and May 1994 


\begin{tabular}{|l|l|}
\hline \multicolumn{1}{|c|}{ Conditions For Use } & \multicolumn{1}{c|}{ Updating Formula } \\
\hline General and Level Tangents & $M=0.28 \mathrm{R}_{\mathrm{f}}+0.01 \mathrm{R}_{\mathrm{o}}+0.05 \mathrm{R}_{\mathrm{t}}+0.27 \mathrm{R}_{\mathrm{m}}+0.39 \mathrm{R}_{\mathrm{d}}$ \\
\hline Positive Grades & $\mathrm{M}=0.40 \mathrm{R}_{\mathrm{f}}+0.02 \mathrm{R}_{\mathrm{o}}+0.05 \mathrm{R}_{\mathrm{t}}+0.16 \mathrm{R}_{\mathrm{m}}+0.37 \mathrm{R}_{\mathrm{d}}$ \\
\hline Negative Grades & $\mathrm{M}=0.17 \mathrm{R}_{\mathrm{f}}+0.03 \mathrm{R}_{\mathrm{o}}+0.06 \mathrm{R}_{\mathrm{t}}+0.20 \mathrm{R}_{\mathrm{m}}+0.54 \mathrm{R}_{\mathrm{d}}$ \\
\hline Excess Curve Cost & $\mathrm{M}=0.22 \mathrm{R}_{\mathrm{f}}+0.01 \mathrm{R}_{\mathrm{o}}+0.77 \mathrm{R}_{\mathrm{t}}$ \\
\hline Speed Change and Stopping Cost & $\mathrm{M}=0.35 \mathrm{R}_{\mathrm{f}}+0.01 \mathrm{R}_{\mathrm{o}}+0.41 \mathrm{R}_{\mathrm{t}}+0.02 \mathrm{R}_{\mathrm{m}}+0.21 \mathrm{R}_{\mathrm{d}}$ \\
\hline Idling Cost & $\mathrm{M}=0.83 \mathrm{R}_{\mathrm{f}}+0.01 \mathrm{R}_{\mathrm{o}}+0.05 \mathrm{R}_{\mathrm{m}}+0.11 \mathrm{R}_{\mathrm{d}}$ \\
\hline
\end{tabular}

Table 3.8(a): Multiplier Formula for Updating Running Costs of Passenger Cars

\begin{tabular}{|l|l|}
\hline \multicolumn{1}{|c|}{ Conditions For Use } & \multicolumn{1}{c|}{ Updating Formula } \\
\hline General and Level Tangents & $\mathrm{M}=0.40 \mathrm{R}_{\mathrm{fs}}+0.01 \mathrm{R}_{\mathrm{o}}+0.04 \mathrm{R}_{\mathrm{t}}+0.30 \mathrm{R}_{\mathrm{m}}+0.25 \mathrm{R}_{\mathrm{ds}}$ \\
\hline Positive Grades & $\mathrm{M}=0.54 \mathrm{R}_{\mathrm{fs}}+0.01 \mathrm{R}_{\mathrm{o}}+0.01 \mathrm{R}_{\mathrm{t}}+0.24 \mathrm{R}_{\mathrm{m}}+0.20 \mathrm{R}_{\mathrm{ds}}$ \\
\hline Negative Grades & $\mathrm{M}=0.21 \mathrm{R}_{\mathrm{fs}}+0.03 \mathrm{R}_{\mathrm{o}}+0.04 \mathrm{R}_{\mathrm{t}}+0.33 \mathrm{R}_{\mathrm{m}}+0.39 \mathrm{R}_{\mathrm{ds}}$ \\
\hline Excess Curve Cost & $\mathrm{M}=0.24 \mathrm{R}_{\mathrm{fs}}+0.01 \mathrm{R}_{\mathrm{o}}+0.74 \mathrm{R}_{\mathrm{t}}+0.01 \mathrm{R}_{\mathrm{m}}$ \\
\hline Speed Change and Stopping Cost & $\mathrm{M}=0.36 \mathrm{R}_{\mathrm{fs}}+0.48 \mathrm{R}_{\mathrm{t}}+0.04 \mathrm{R}_{\mathrm{m}}+0.12 \mathrm{R}_{\mathrm{ds}}$ \\
\hline Idling Cost & $\mathrm{M}=0.80 \mathrm{R}_{\mathrm{fs}}+0.01 \mathrm{R}_{\mathrm{o}} \quad+0.04 \mathrm{R}_{\mathrm{m}}+0.15 \mathrm{R}_{\mathrm{ds}}$ \\
\hline
\end{tabular}

Table 3.8(b): Multiplier Formula for Updating Running Costs of Single Unit Trucks 


\begin{tabular}{|l|l|}
\hline \multicolumn{1}{|c|}{ Conditions For Use } & \multicolumn{1}{c|}{ Updating Formula } \\
\hline General and Level Tangents & $M=0.31 \mathrm{R}_{\mathrm{fc}}+0.01 \mathrm{R}_{\mathrm{o}}+0.11 \mathrm{R}_{\mathrm{t}}+0.37 \mathrm{R}_{\mathrm{m}}+0.20 \mathrm{R}_{\mathrm{dc}}$ \\
\hline Positive Grades & $\mathrm{M}=0.61 \mathrm{R}_{\mathrm{fc}}+0.01 \mathrm{R}_{\mathrm{o}}+0.04 \mathrm{R}_{\mathrm{t}}+0.27 \mathrm{R}_{\mathrm{m}}+0.09 \mathrm{R}_{\mathrm{dc}}$ \\
\hline Negative Grades & $\mathrm{M}=0.03 \mathrm{R}_{\mathrm{o}}+0.14 \mathrm{R}_{\mathrm{t}}+0.50 \mathrm{R}_{\mathrm{m}}+0.39 \mathrm{R}_{\mathrm{dc}}$ \\
\hline Excess Curve Cost & $\mathrm{M}=0.07 \mathrm{R}_{\mathrm{fc}}+0.01 \mathrm{R}_{\mathrm{o}}+0.90 \mathrm{R}_{\mathrm{t}}+0.02 \mathrm{R}_{\mathrm{m}}$ \\
\hline Speed Change and Stopping Cost & $\mathrm{M}=0.20 \mathrm{R}_{\mathrm{fc}}+0.73 \mathrm{R}_{\mathrm{t}}+0.02 \mathrm{R}_{\mathrm{m}}+0.05 \mathrm{R}_{\mathrm{dc}}$ \\
\hline Idling Cost & $\mathrm{M}=0.64 \mathrm{R}_{\mathrm{fc}}+0.01 \mathrm{R}_{\mathrm{o}}+0.14 \mathrm{R}_{\mathrm{m}}+0.21 \mathrm{R}_{\mathrm{dc}}$ \\
\hline
\end{tabular}

Table 3.8(c): Multipliers for Updating Running Costs of 3 S-2 Combination Trucks

The following example demonstrates the updating procedure. The base year to which a value of 52.1 is assigned is 1975; so if the current year at present has a price index value of 160.5 , the new unit value of time, for a passenger corresponding to a value of $\$ 2$ in 1975 would be:

$(160.5 / 52.1) * \$ 2=\$ 6.16$.

\subsubsection{Updating Running Cost Factors}

The updating procedures are described for two cases in the 1977 Manual. Case 1 is for proportional cost changes when the components of running costs increase in about the same proportion and Case 2 is for non-proportional cost changes when the components change in significantly different proportions.

Case 1-For proportional cost changes: The updating procedure is the same as described above in the example. However, for passenger cars, it is suggested that the private transportation component of the consumer price index be used as the relevant index. For 
updating truck-running costs, U.S. industrial commodities wholesale price index (WPI) should be used form Table 3.7.

Case 2-For non-proportional cost changes: It is suggested that an updating multiplier be based on the composite multiplier formulas reflecting individual price changes. This is more accurate compared to Case 1.

Tables 3.8 (a), (b) and (c), as reproduced from the Manual, show the formulas for various conditions of operations for passenger cars, single unit trucks and combination trucks. For example, suppose it is desired to update level tangent running costs for the passenger cars to the year 1997 with 1982-84 as base, in which the relevant index values are as follows:

$\mathrm{C}_{\mathrm{f}}=$ Index for private transportation, regular and premium gasoline $=106.2$

$\mathrm{C}_{\mathrm{o}}=$ Index for private transportation, motor oil $=131.4$

$\mathrm{C}_{\mathrm{t}}=$ Index for private transportation, tires, new, tubeless $=100.2$

$\mathrm{C}_{\mathrm{m}}=$ Index for private transportation, auto repairs and maintenance $=162.7$

$C_{d}=$ Index for private transportation, automobiles, new $=144.3$

The relevant index values for 1975 with $1982-84$ as base are as follows:

$$
\mathrm{C}_{\mathrm{f}}=45.1
$$

$\mathrm{C}_{\mathrm{o}}=65.3$

$\mathrm{C}_{\mathrm{t}}=69.2$

$\mathrm{C}_{\mathrm{m}}=53.7$

$\mathrm{C}_{\mathrm{d}}=63$

The updating multiplier, $\mathrm{M}$, is computed as: 
$\mathrm{M}=0.28 *(106.2 / 45.1)+0.01 *(131.4 / 65.3)+0.05 *(100.2 / 69.2)+0.27 *(162.7 / 53.7)+$ $0.39 *(144.3 / 63)=2.434$.

Similar computations can be performed to obtain other coefficients. This multiplier would then be applied to any level tangent cost factor developed from data in the Manual to obtain corresponding running cost factors updated to the current year. The latest consumer price index is used as input to calculate the running costs. This index can be found in the publications of the U.S. Department of Labor.

Accident costs can be updated using the latest information published by the National Safety Council. Every year, the latest rates for the various types of accidents categorized based on severity, i.e. fatal accidents, injury accidents, and property causing accidents, are published by the Council. The frequency of the various categories of accident can be multiplied by the latest accident costs from the National Safety Council to compute the annual accident costs.

Delay costs are again time dependent. So the updating methodology is the same as updating the unit value of time as shown in Tables 3.8 (a), (b) and (c).

The transition costs are the costs due to the speed change. Factors, which affect transition costs, are the cost of fuel, motor oil, cost of tires and maintenance costs. The updating procedure is similar to the updating procedure for non-proportional cost changes of the running costs described in Tables 3.8 (a), (b) and (c). 


\section{Chapter 4: Software Description and Usage}

The software described in this report was developed to facilitate the use of the 1977 Manual. It performs all cost calculations stipulated in the Manual to compute road user cost for a highway construction or improvement project. In addition, the software can be used to perform Net Present Value analysis for a single project and comparison of various alternatives. The software consists of the following two main modules:

1) User Cost-Benefit Application, and

2) Economic Analysis.

The first module is again divided into two sub-modules based on the type of the operation carried out.

The first sub-module is designed to calculate the road user cost for the construction or refurbishment of "uniform" highway sections. It is thus necessary to divide the project under consideration into sections of reasonably similar geometric characteristics and traffic conditions before using this module. This module is also used to update the road user cost tables and forms the second sub-module.

The Economic Analysis module is designed to help determine whether a given project or certain project alternatives can be deemed economically justifiable and to compare different alternatives.

The first module is based on the methodology described in Chapter 3. This module supply information needed for the second module to perform economic analysis and provide economic justification of the project. 


\subsection{Software Development Tools}

The software is built on an application development tool called Microsoft Visual Basic $^{\circledR}$ 5. This means that, like other development tools such as Borland Delphi, Microsoft Visual $\mathrm{C}++$, and others, one can use Visual Basic $^{\circledR} 5$ to construct software products that solve specific problems. This tool is often called the front end because this is the software that interacts with the user. As Microsoft's premium programming language, Visual Basic ${ }^{\circledR} 5$ is the easiest object-oriented programming approach for application development. Microsoft Visual Basic ${ }^{\circledR} 5$ is a sophisticated front end, which has some powerful features. The other end is the backend, which the user does not interact with, but this is the part of the software that interacts with the front end. Thus the front end has the unique ability of interacting with both the user and the backend software. The back end for the software developed here is Microsoft Excel, which is the data base handler. The database handler is the software where the database resides. Both Visual Basic ${ }^{\circledR} 5$ and Microsoft Excel are products of Microsoft making it both compatible and easily connected to each other. The Jet Database Engine is used to establish such connection.

Visual Basic ${ }^{\circledR} 5$ has several outstanding features that have made it an efficient tool for application development. It essentially consists of Forms or Screens, which are any normal screen. In Visual Basic ${ }^{\circledR}$ 5, the programmer builds the forms. These forms are similar to the screens displayed by Windows 95 or Windows NT, such as logon dialog box shown at the start up. The only difference is that the programmer decides get to choose how these dialog boxes appear, when they appear, and what they do. Control Buttons or Toolbox Controls are a set of controls that are used on the custom designed forms. Table 4.1 provides a set of toolbox controls that have been used on the forms to arrive at the desired results in this 
software. Control Buttons are located in the toolbox and are dragged with the help of the mouse and placed on the screen or form. The positioning of these control buttons are often specified by the software designer.

\begin{tabular}{|l|l|}
\hline \multicolumn{1}{|c|}{ Control } & \multicolumn{1}{|c|}{ Use/Description } \\
\hline Text Box & Displays and allows data entry. \\
\hline Label & Displays plain text on forms, such as captions for other \\
\hline Combination Drop-down & Shows a current value selected from the list of possible \\
\hline Command Button & values \\
\hline Option Button & Initiates an action. \\
\hline Frame & Implemented in groups, lets the user make a choice for a \\
& small number of options. \\
\hline
\end{tabular}

\section{Table 4.1: Toolbox Controls Used in this Software}

A number of other controls are also used. The controls are described individually in the forms, where they are used. The Code Window, which is screened from the user, is the driving force behind the software. Another property of Visual Basic ${ }^{\circledR} 5$ that was used in this project is the Data Bound Controls. Bound Data Controls are the same as any other Visual Basic $^{\circledR} 5$ control objects, except that they may have been given additional properties, events, and methods that allow the user to "bind" them directly to one or more data tables. The binding makes it easy to create data-aware input and display objects that the user can user to 
perform data input and display with little program code. The Data Control makes it easy to write Visual Basic ${ }^{\circledR} 5$ programs that handle all of the following processes [Douglas, 1997]:

- Loading data from a database into a Visual Basic ${ }^{\circledR} 5$ Data object.

- Selecting the data records requested by the user.

- Loading form controls with the value of the requested records.

- Trapping simple user input errors.

- Enforcing database integrity rules.

- Updating the data object with modified data from the form control.

Visual Basic ${ }^{\circledR} 5$ Data Control is a control used to gain access to database tables. The Data Control allows the user to establish a link to a single Dynaset Data object or Table or Snapshot in a database. Basically, the Data Control is a link between the database and the bound controls that the user uses to display the information. By default, the Data Control creates a Dynaset-type recordset from one or more of the tables in the database. To perform the linking to the MS-Excel sheets, the user has to select the Table-type recordset. The recordset created by Data Control is determined by the settings of the DatabaseName and the RecordSource properties. The recordset is created as the form containing the Data Control loads and is activated. The recordset is active until the form is unloaded, at which the recordset is released. This is the principle of database connectivity. It is possible to have more than one Data Control on a single form.

The three main properties of Data Control that have been used are the DatabaseName property, RecordSource Property and the Connect property. The DatabaseName property contains the name of the database the user wants to access. The Connect property helps the Jet Engine to know the type of database that is being connected at run time. MS-Excel has 
been used because the Visual Basic ${ }^{\circledR} 5$ Data Control can gain easy access to the database tables present in the Excel Sheets.

\subsection{Software Description}

Various forms consist the basic building block of the software. These forms and the inherent code helps in connecting the user to the database and retrieve the user costs. The forms have a .frm extension. The forms are also called screens. The toolbox controls as described in Table 4.1 are used as required to construct these links. The forms are described as they appear in the program.

\section{- The Welcome Screen (Welcome.frm)}

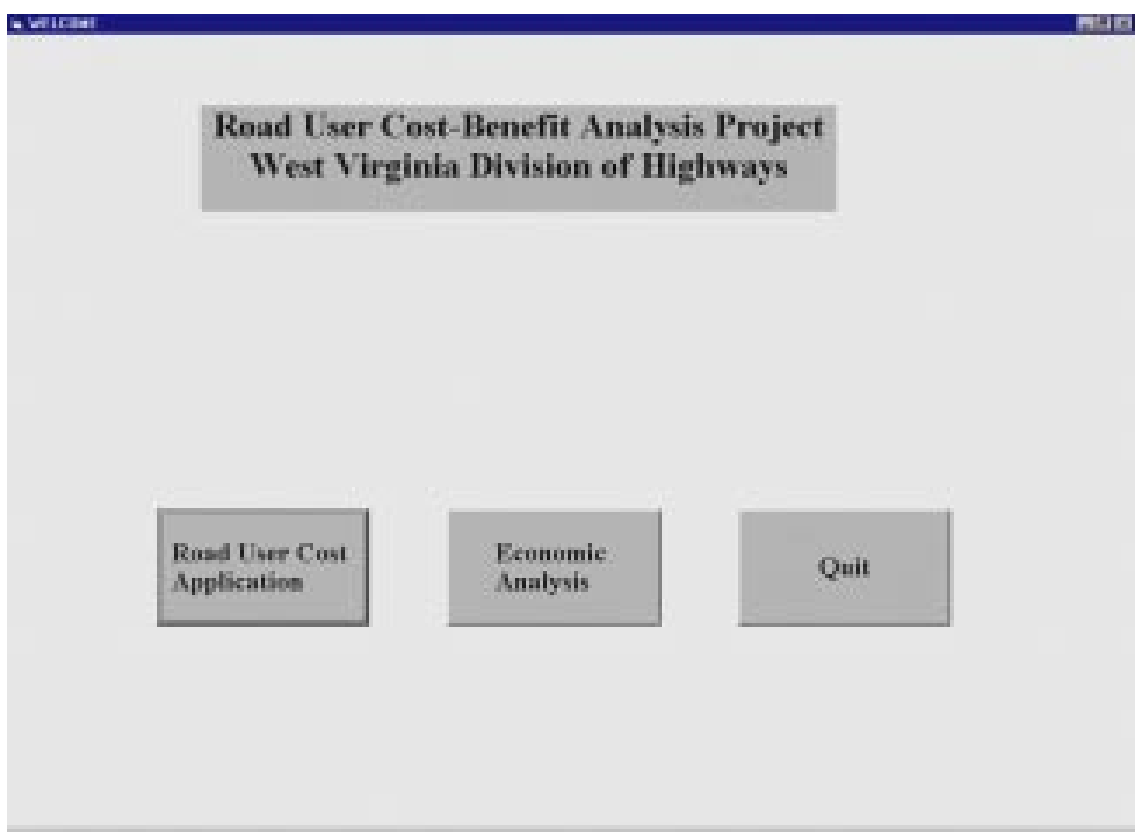

\section{Figure 4.1 The Welcome Screen (Welcome.frm)}

This screen has three buttons. The first button invokes a screen entitled "Road User

Cost Application" as shown in Figure 4.2. The "Economic Analysis" button is used to 
perform economic calculations for a single project or comparisons of two alternative projects. Clicking on the third button, "Quit" ends the program.

\section{- The Road User Cost Application Screen (Frmroad.frm)}

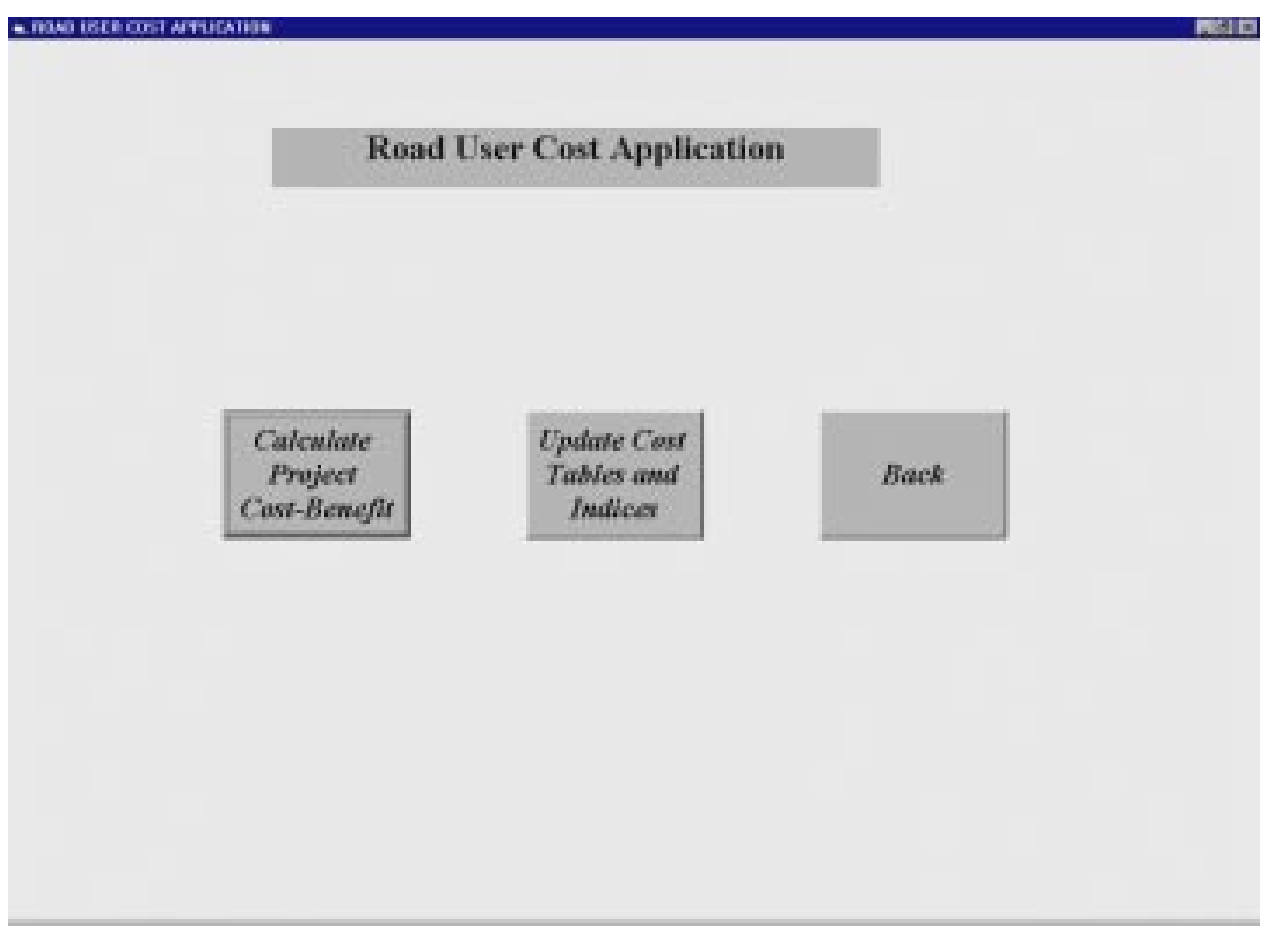

\section{Figure 4.2: The Road User Cost Application Screen (Frmroad.frm)}

The "Road User Cost Application" screen has three command buttons. The first button, labeled "Calculate Project Cost-Benefit", is used to calculate road user cost for a project having different sections of varying characteristics. The calculated costs, in dollars per thousand vehicles, are those incurred by the road users.

The middle command button which is labeled "Update Cost Tables and Indices" is used to update the cost tables and consumer price indices for various cost components. This is a task that must be done on an annual basis. The method of updating costs is explained in subsequent sections. The "Back" button will take the user to the previous screen. 
Clicking on the "Calculate Project Cost-Benefit" button will invoke a new screen, entitled "Startup", as shown in Figure 4.3. This screen is used for both new projects and existing projects that have already been saved.

\section{- The Startup Screen (Startup.frm)}

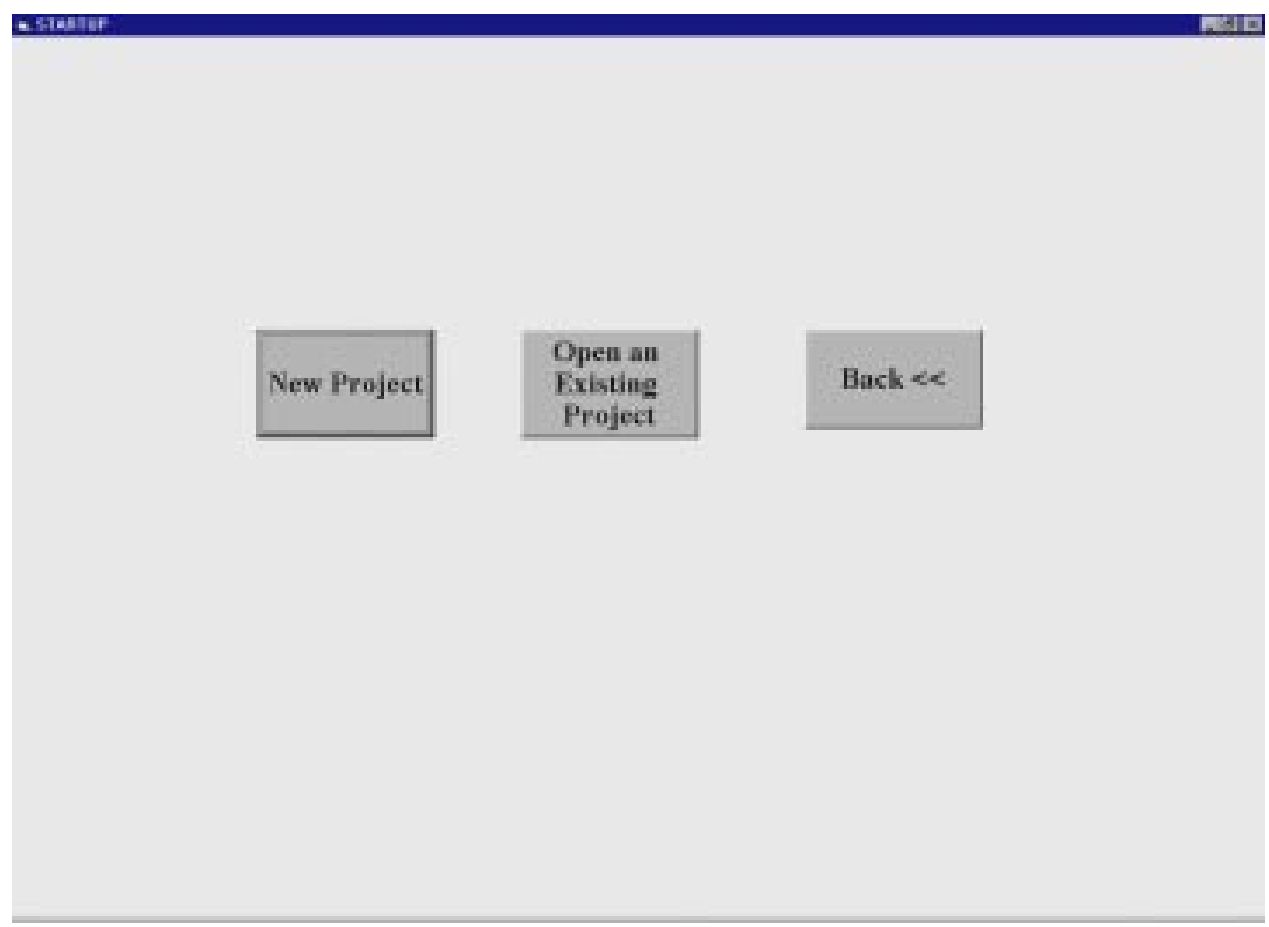

\section{Figure 4.3: The Startup Screen (Startup.frm)}

Clicking on the "New Project" button brings up the "Number of Sections" screen, shown in Figure 4.4. The "Open an Existing Project" button leads the user to a different screen titled "Opening an Existing Project". The "Back" button returns the user to the previous screen. 


\section{- The Number of Sections Screen (Noofsection.frm)}

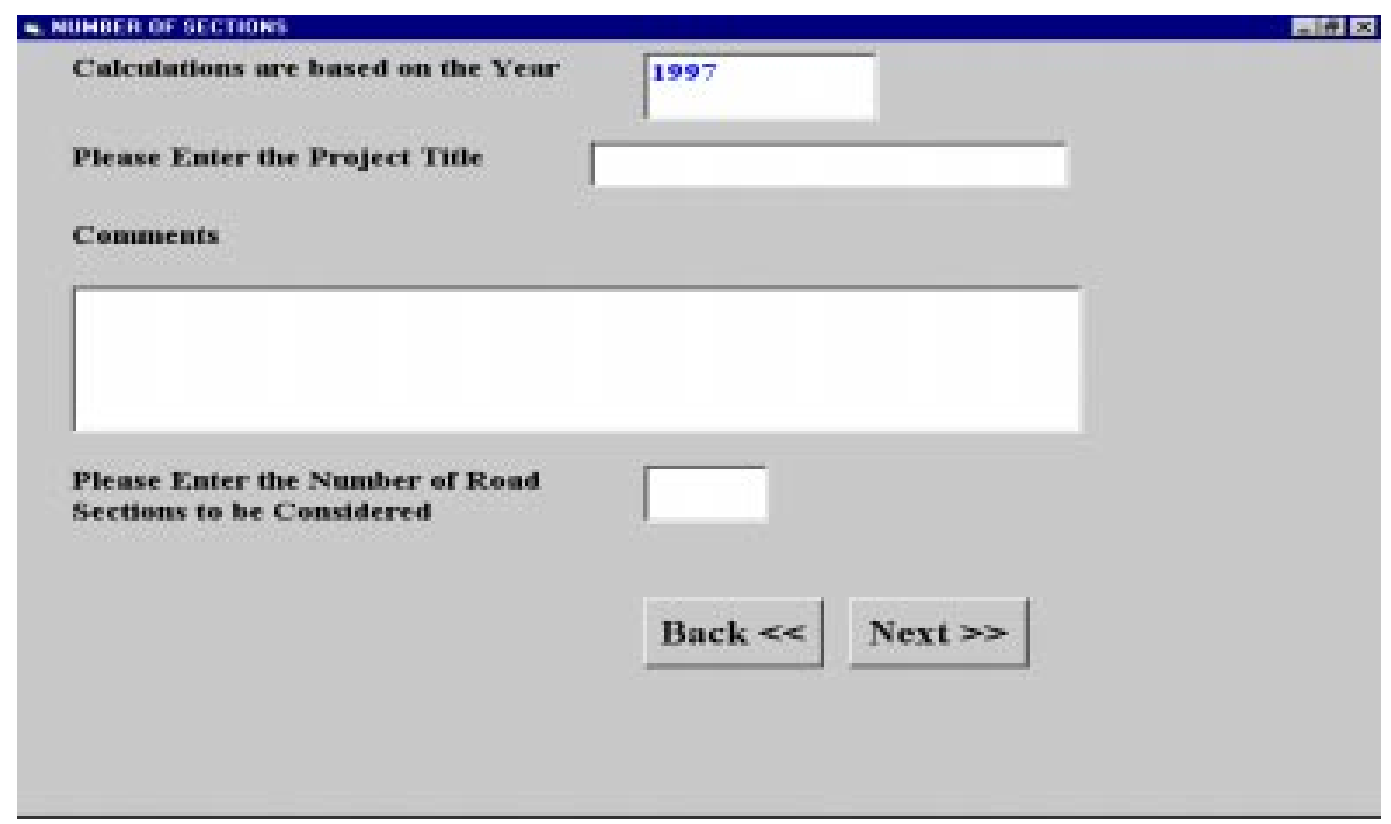

Figure 4.4: The Number of Sections Screen (Noofsection.frm)

The user can see the year for the cost figures in the top display box of this screen. If the year displayed is not the most recent year for which the consumer price indices are available, the user must go back to the screen shown in Figure 4.2 and proceed first to update the cost tables based on the latest indices. The second input is an alphanumeric title for the project. An example of the name of the project is "Morgantown-Grafton Route 22". A brief description of the project and some notes can be entered into the "Comments" section. The next required input is the box where the user has to enter the number of sections.

The software allows a maximum of fifty sections to be included in each project. After entering all the information in the input boxes, the user clicks on the "Next" button which will invoke the screen labeled "Main Screen", as shown in Figure 4.5. 


\section{- The Main Screen (Mainscreen.frm)}

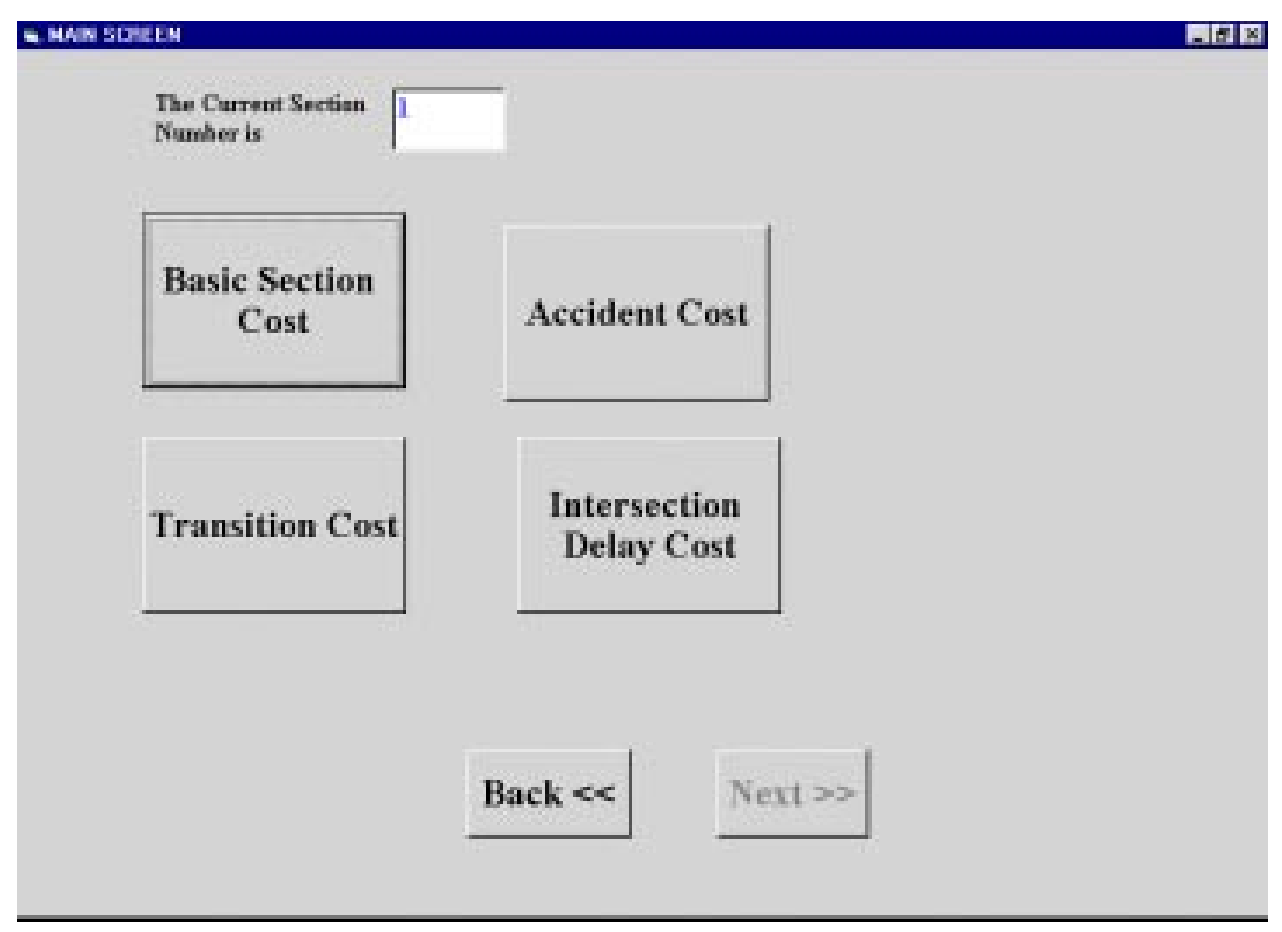

Figure 4.5: The Main Screen (Mainscreen.frm)

This screen has four command buttons, namely "Basic Section Cost", "Accident Cost", "Intersection Delay Cost" and "Transition Cost." The current section number is displayed at the top of the screen. It starts with section 1 and is automatically updated. This ensures that the user completes analysis for all the sections one after another.

A helpful feature of the software is the color of the four buttons, which is gray at the outset. Once a button is pressed and all calculations for that component are completed, the button changes color to white. After all the cost components are calculated, and all the buttons have changed colors to white, a button labeled "Next" appears, which the user must press to go to the next screen. 


\section{- The Vehicle Mix Screen (Fmrvehiclemix.frm)}

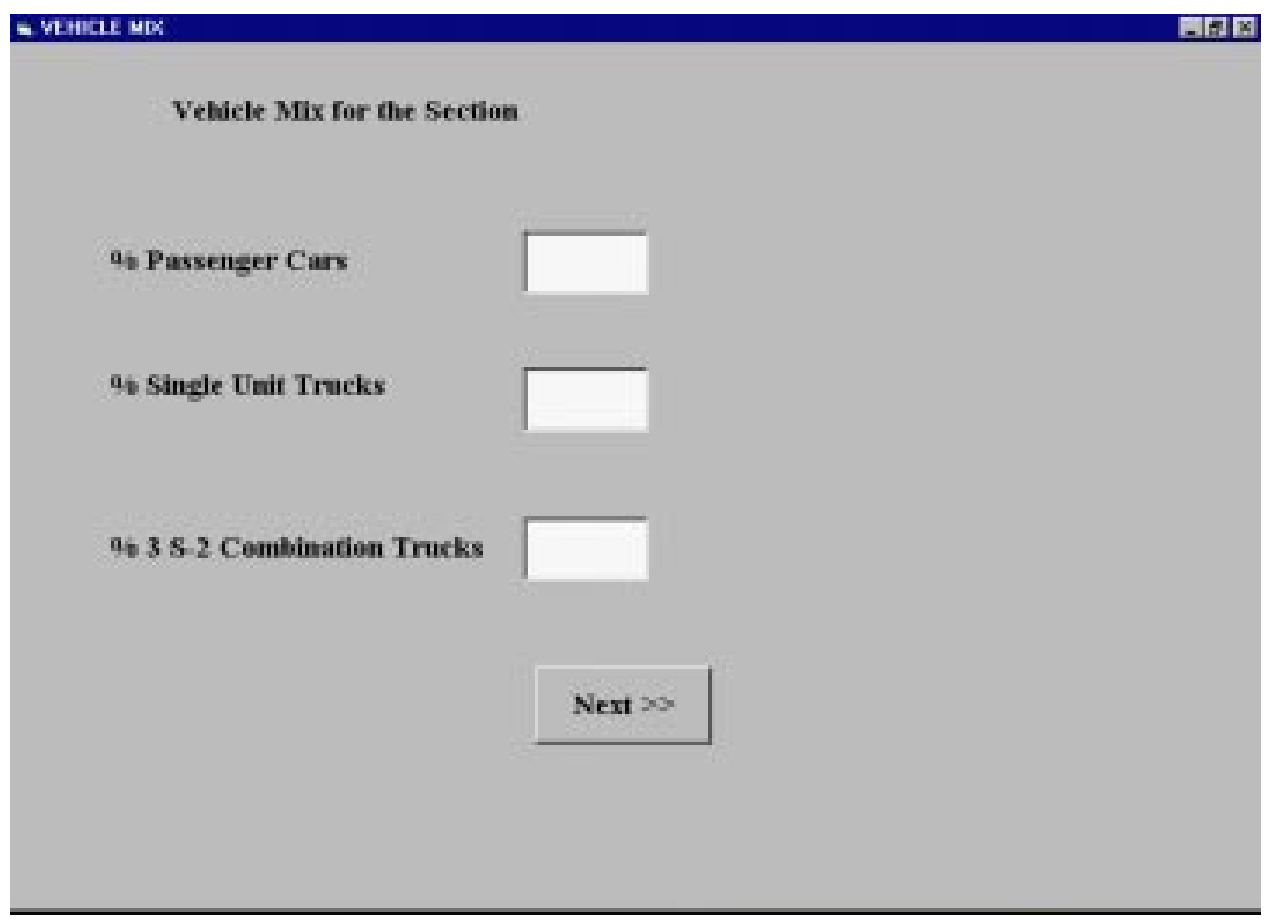

Figure 4.6: The Vehicle Mix Screen (Fmrvehiclemix.frm)

Pressing the "Basic Section Cost" button invokes a screen entitled "Vehicle Mix", shown in Figure 4.6. The user is required to enter the percentages of "Passenger cars", "Single Unit Trucks" and " 3 S-2 Combination Trucks" that make up the vehicle mix for the section. If the volume of any of these vehicle types is considered to be negligible, a value of zero must be entered for that type. The sum of the percentages must equal to 100; otherwise an error message will be displayed. When all the percentages are entered, the user clicks on "Next" button to go to the next screen entitled "Basic Section Costs for Passenger Cars". 


\section{- The Basic Section Cost for Passenger Cars Screen (Frmbasicsection.frm)}

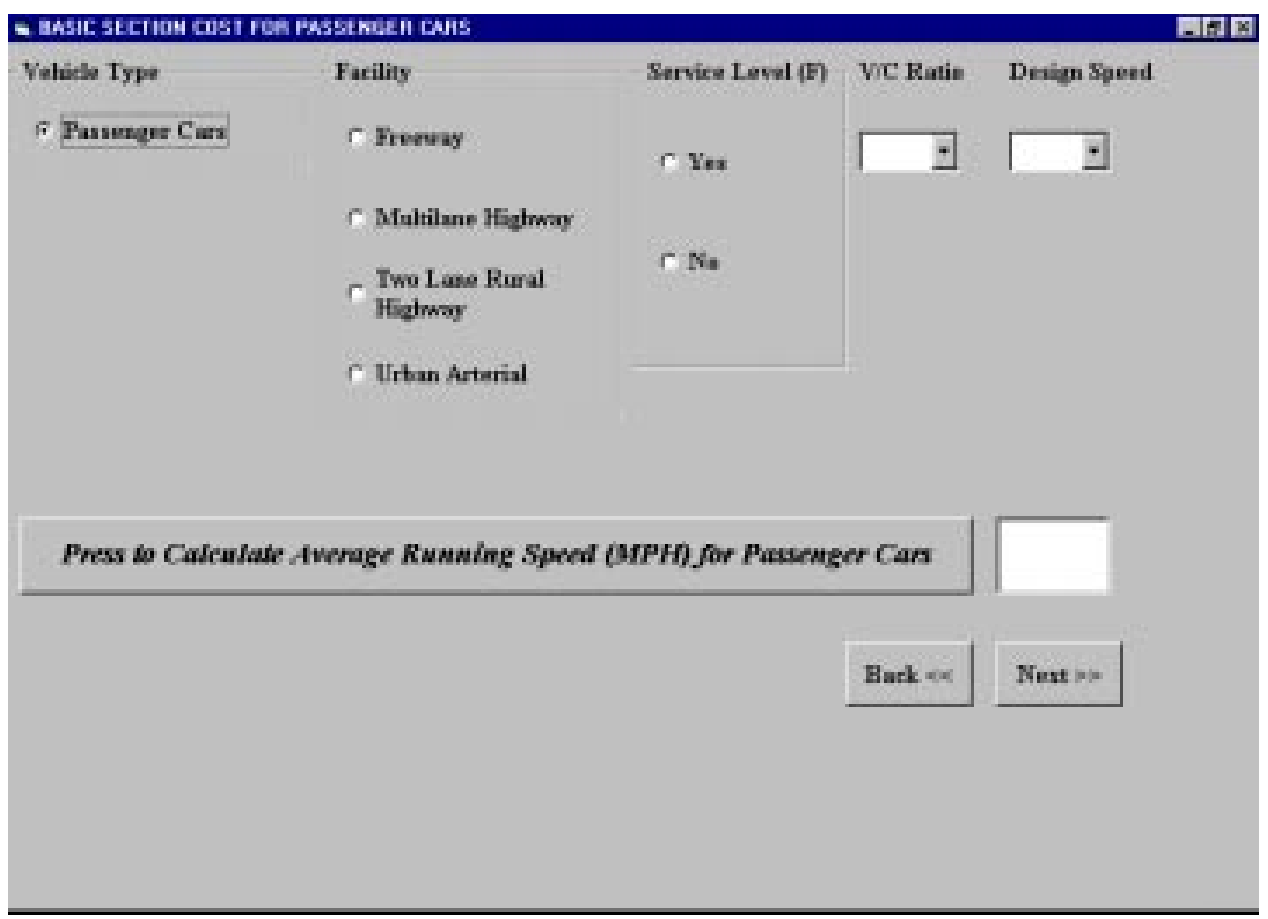

\section{Figure 4.7: The Basic Section Cost for Passenger Cars Screen (Frmbasicsection.frm)}

The screen entitled "Basic Section Cost for Passenger Cars" is shown in Figure 4.7.

The user is prompted to enter the type of highway under consideration. The possible choices are "Freeway", "Multi-lane Highway", "Two-Lane Rural Highway" and "Urban Arterial". These buttons are called "option buttons" since only one choice is accepted from the user. The next input is whether the level of service (F) or queuing is present or not. The user must click on either "Yes" or "No." The next required input is the volume to capacity (V/C) ratio. A drop-down menu appears that shows all acceptable V/C ratios. The next input is for the design speed, which must be selected from one of the values shown in the drop-down menu.

The average running speed is calculated on the basis of the given inputs with the press of the button "Press to Calculate Average Running Speed". The user must then click on 
the "Next" button to go to a new screen entitled "Travel Time Cost for Passenger Cars", as shown in Figure 4.8.

- The Travel Time Cost for Passenger Cars Screen (Traveltime.frm)

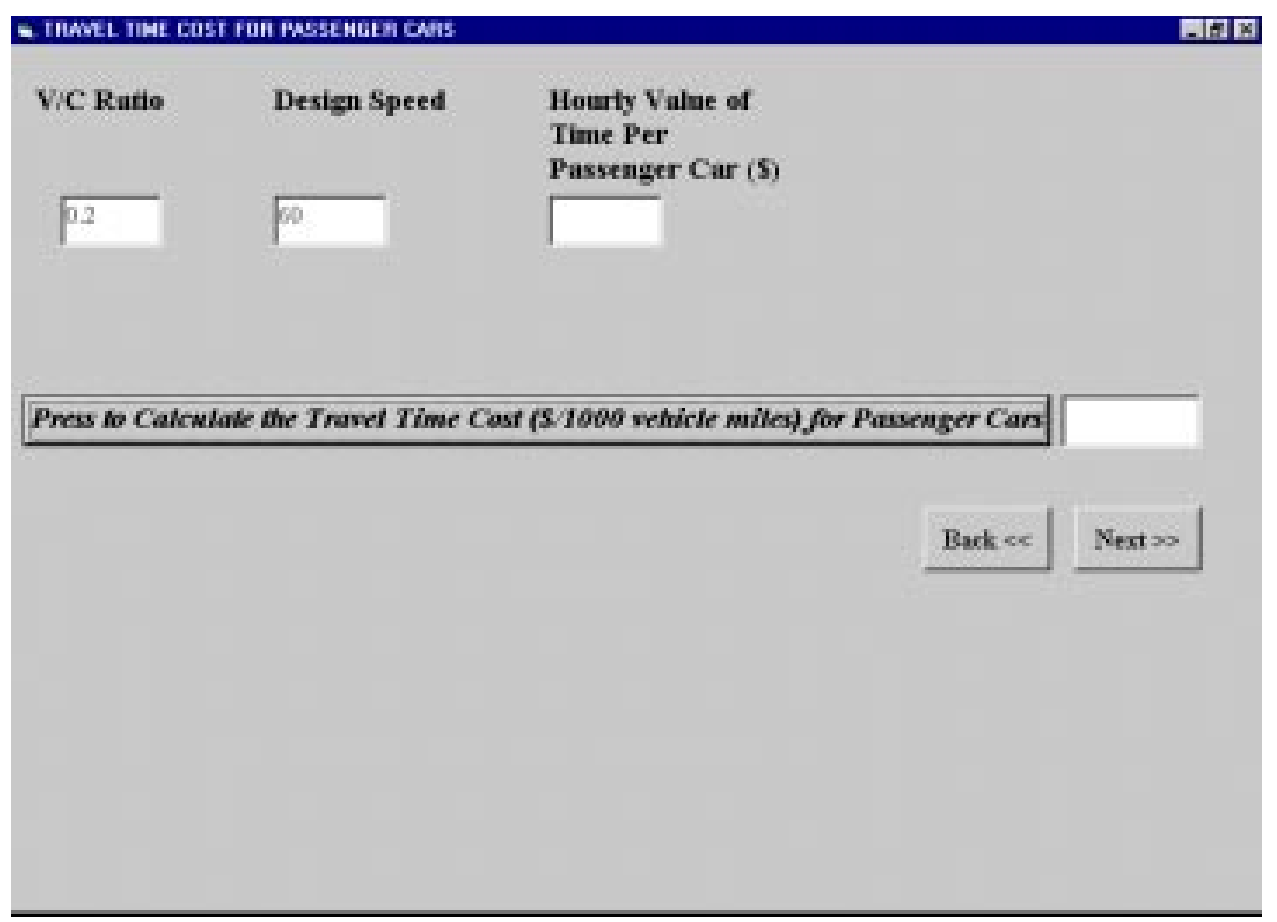

Figure 4.8: The Travel Time Cost for Passenger Cars Screen (Traveltime.frm)

The travel time cost screen requires only one input: the hourly value of time per passenger car. Using this input, the travel time cost is calculated with the clicking of the button "Press to Calculate the Travel Time Cost for Passenger Cars". 


\section{- The Grade Cost for Passenger Cars Screen (Gradecost.frm)}

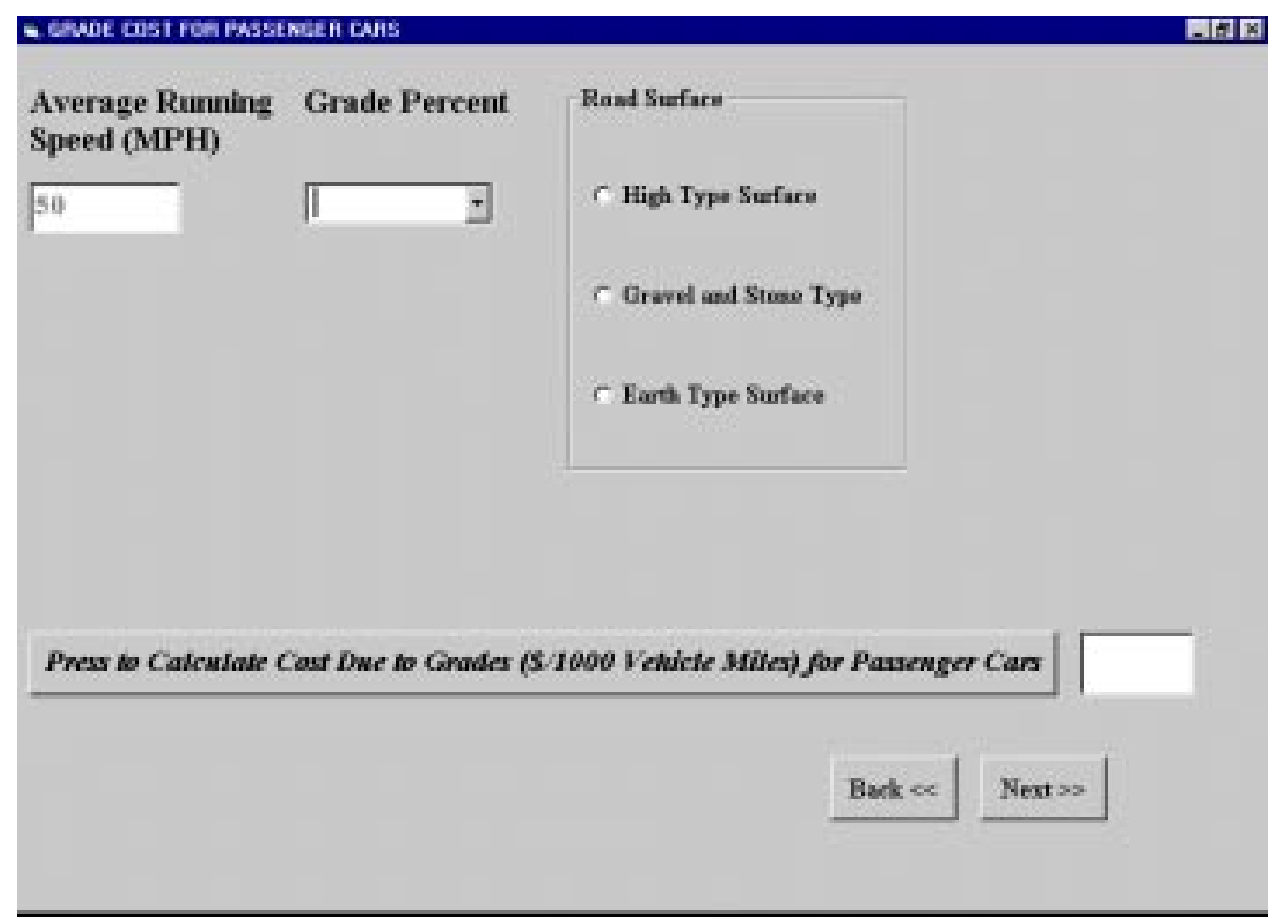

Figure 4.9: The Grade Cost for Passenger Cars Screen (Gradecost.frm)

The next screen is the "Grade Cost for Passenger Cars" (Figure 4.9), where the software calculates the grade cost for the section under consideration. The input to this screen is the grade percentage and the type of road surface. The former can be selected from the dropdown menu, which displays a list of grades ranging from negative 8 to positive 8 . The road surface can be high type, gravel and stone, or earth type. The grade cost is displayed in the output box. There may be certain inputs (e.g. the calculated average running speed) for which values are not available in the database. In this case, the following message "Warning! The average speed (old) has been replaced by the (new average speed)." is promptly displayed. The new value used is the nearest value obtained from the database, keeping all other inputs (e.g. grade percentage) constant and changing the variable for which no corresponding value was found. The new average running speed is displayed "Basic 
Section Cost for Passenger Cars" screen (Figure 4.7). The user has to repeat the calculations for the grade and curve costs once again as these values are affected by the new average running speed.

\section{- The Curve Cost for Passenger Cars Screen (Curveform.frm)}

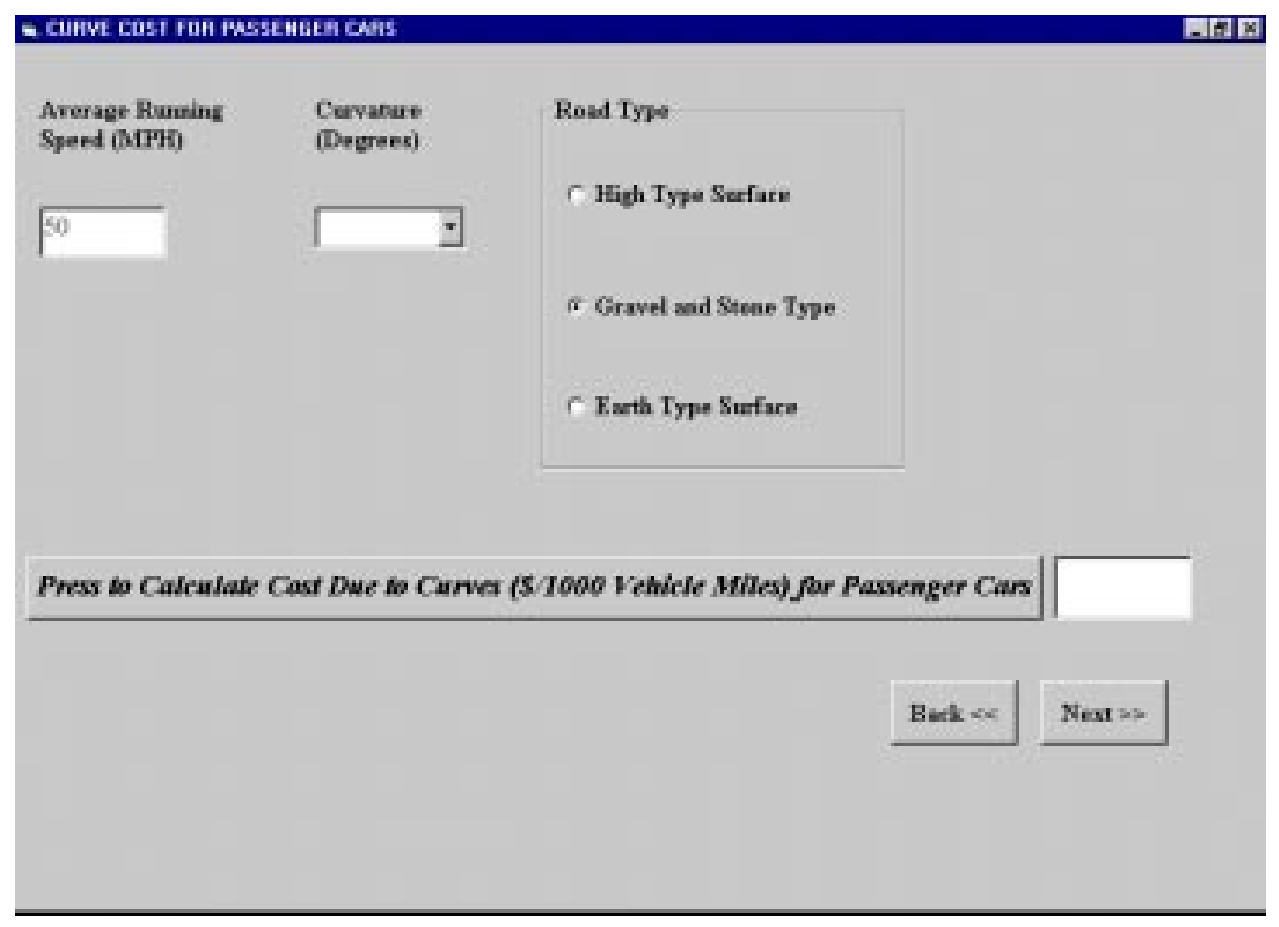

\section{Figure 4.10: The Curve Cost for Passenger Cars Screen (Curveform.frm)}

The next screen is the "Curve Cost for Passenger Cars" (Figure 4.10). The user has to input the curve angle. The type of road surface selected in the "Grade Cost for Passenger Cars" screen is carried over to this screen. On clicking the button labeled "Press to Calculate the Cost Due to Curves", the curve cost is displayed in the output box. If the value for a set of inputs is not available in the database, the nearest value is used as described earlier. 


\section{- The Speed Change Cost for Passenger Cars Screen (Speedchange.frm)}

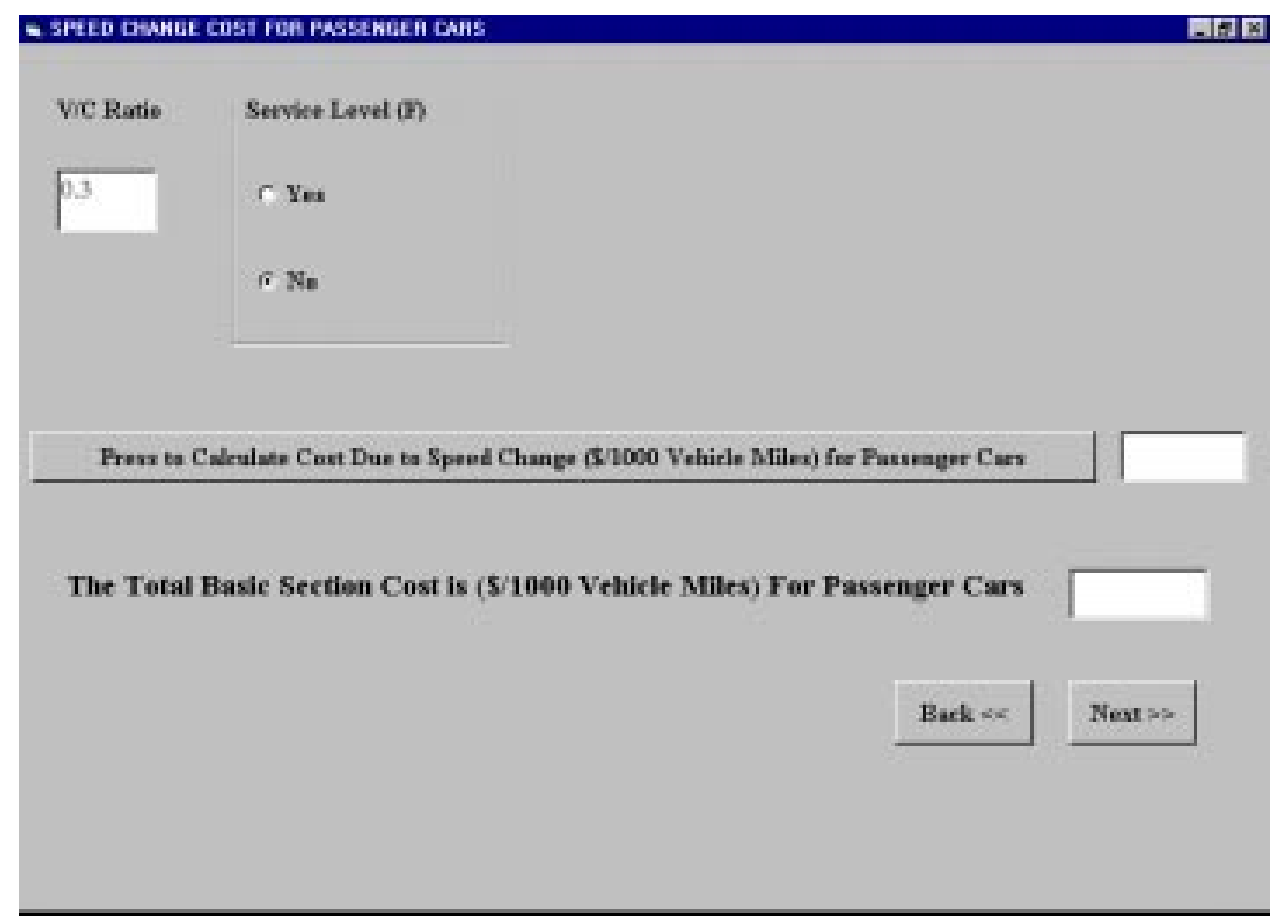

\section{Figure 4.11: The Speed Change Cost for Passenger Cars Screen (Speedchange.frm)}

The speed change cost and the total Basic Section cost for the passenger cars are calculated in the next screen entitled "Speed Change Cost for Passenger Cars" (Figure 4.11).

The next screen to be displayed depends on the vehicle mix entered previously. If the percentages of the Single Unit Truck and Combination truck are zero, the next screen that appears is the "Basic Section Cost for the Total Vehicle Mix" (Figure 4.12).

However, if the percentage entered for Single Unit Truck or for Combination truck is not zero, the software displays additional screens labeled "Basic Section Cost for Single Unit Trucks" and/or "Basic Section Cost for 3 S-2 Combination Truck". The user is led to new screens to calculate the Basic Section cost for single unit trucks and combination trucks, which are similar in appearance as that of the screens used for calculating Basic Section cost for passenger cars. Names of such forms are Sutbasicsection.frm, Ctbasicsection.frm, 
Sutcurveform.frm, Ctcurveform.frm, Sutgrade.frm, Ctgrade.frm, Suttraveltime.frm, Cttraveltime.frm, Sutspeedchangecost.frm and Ctspeedchangecost.frm.

- The Basic Section Cost for the Total Vehicle Mix Screen

(Frmcumulativebasicsection.frm)

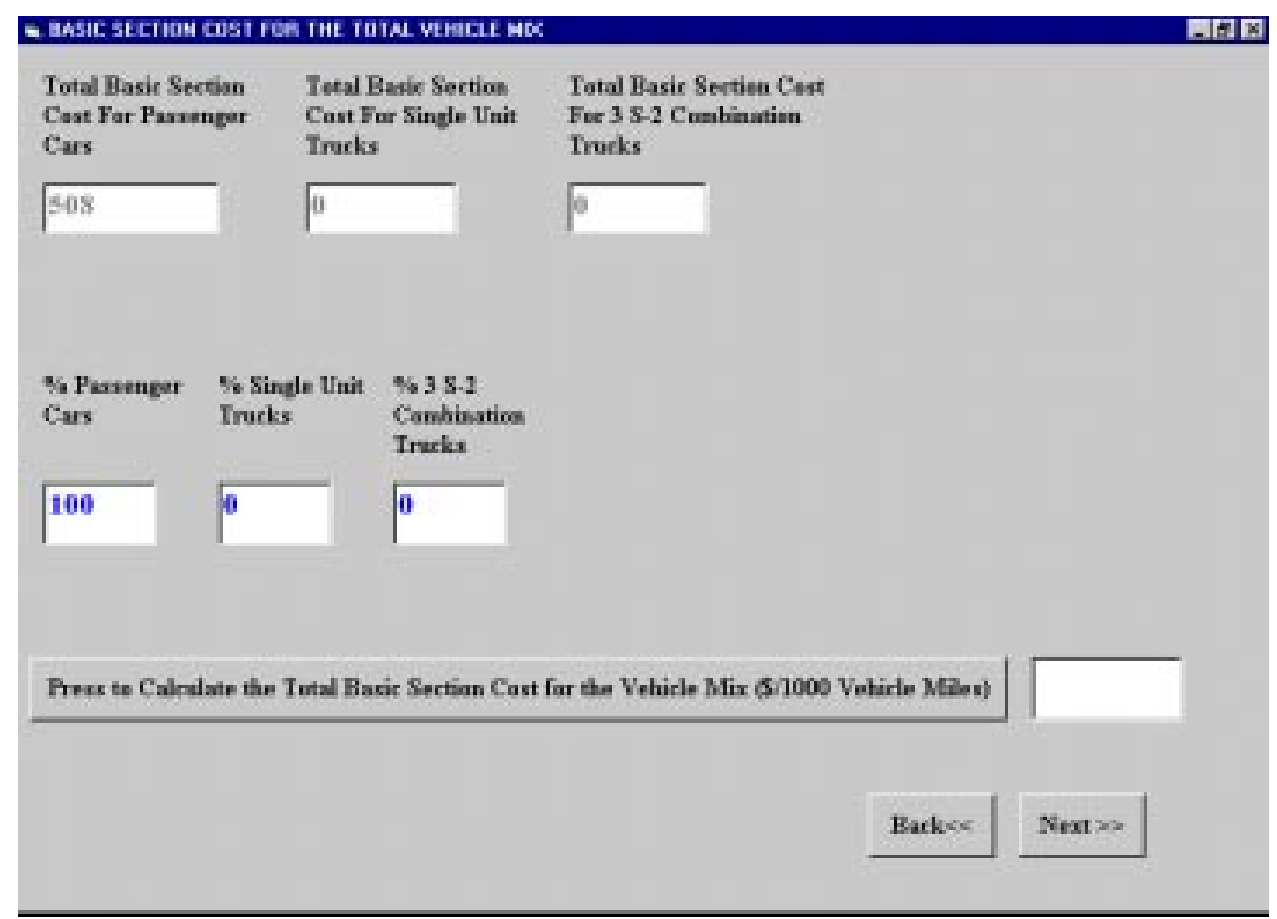

Figure 4.12: The Basic Section Cost for the Total Vehicle Mix Screen (Frmcumulativebasicsection.frm)

The screen entitled "Basic Section Cost for the Total Vehicle Mix" has the output box for the total Basic Section cost which is displayed when the user clicks on the button labeled "Press to Calculate the Total Basic Section Cost". This concludes the calculation of the Basic Section Cost. 
- The Accident Cost Screen (Accident.frm)

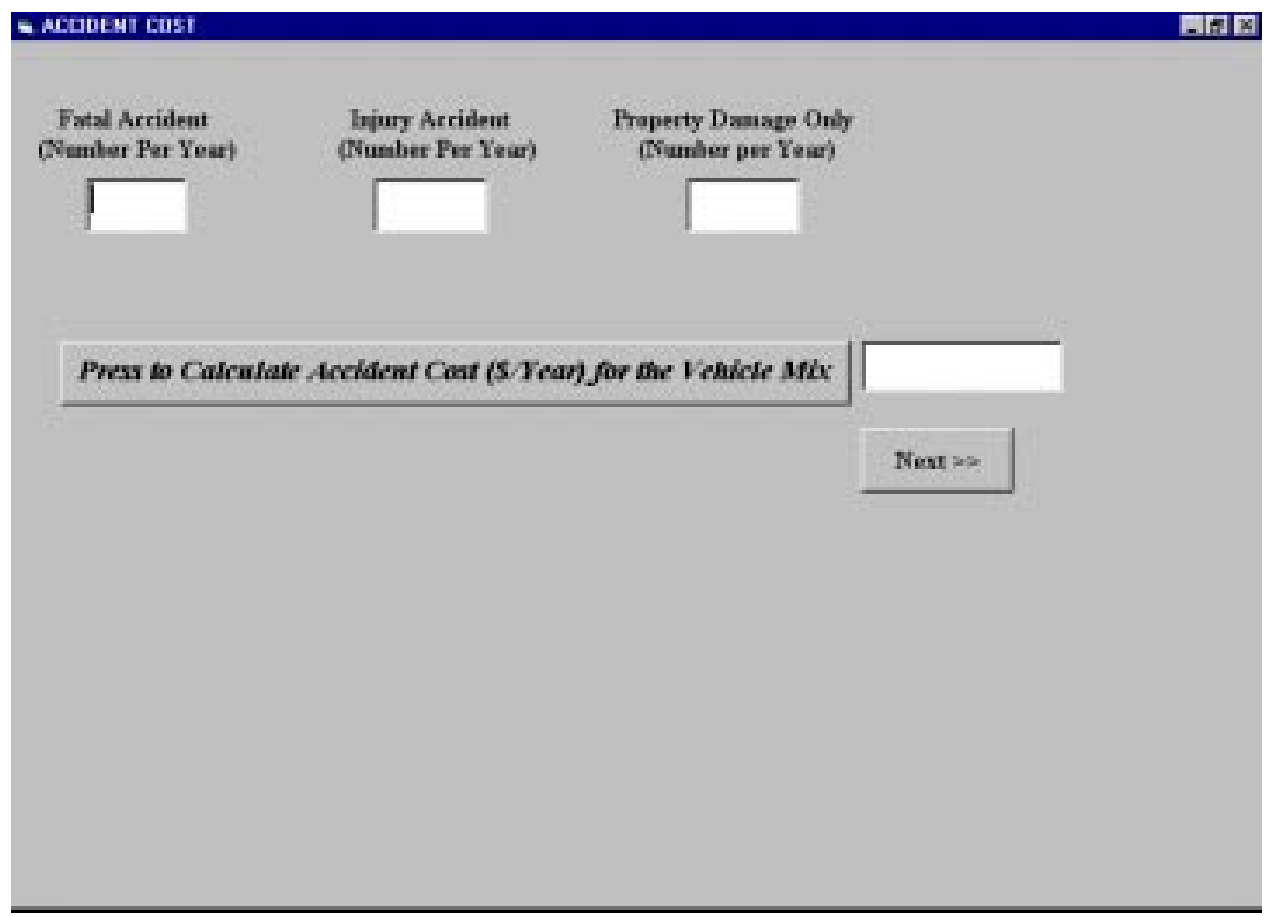

Figure 4.13: The Accident Cost Screen (Accident.frm)

The user is returned back to the "Main Screen" (Figure 4.5) as soon as the "Next" command button is pressed. The user then clicks on one of the other three buttons to calculate the other cost components.

If the user clicks on the "Accident Cost" command button, the software asks the question "Does the section require the calculation of Accident Cost". On clicking the "Yes" button the user is taken to the "Accident Cost" screen. If "No" is chosen, the color of the Accident Cost button changes to white and no further action is taken here. The "Accident Cost" screen (Figure 4.13) requires inputs for the number of Fatal accidents, Injury accidents and Property Damage Only accidents. 
If any of these accident results is considered to be negligible, a value of zero must be entered for that component. On the click of the button "Press to Calculate the Accident Cost", the annual accident cost is displayed in the output box.

\section{- The Transition Cost Screen (Transition.frm)}

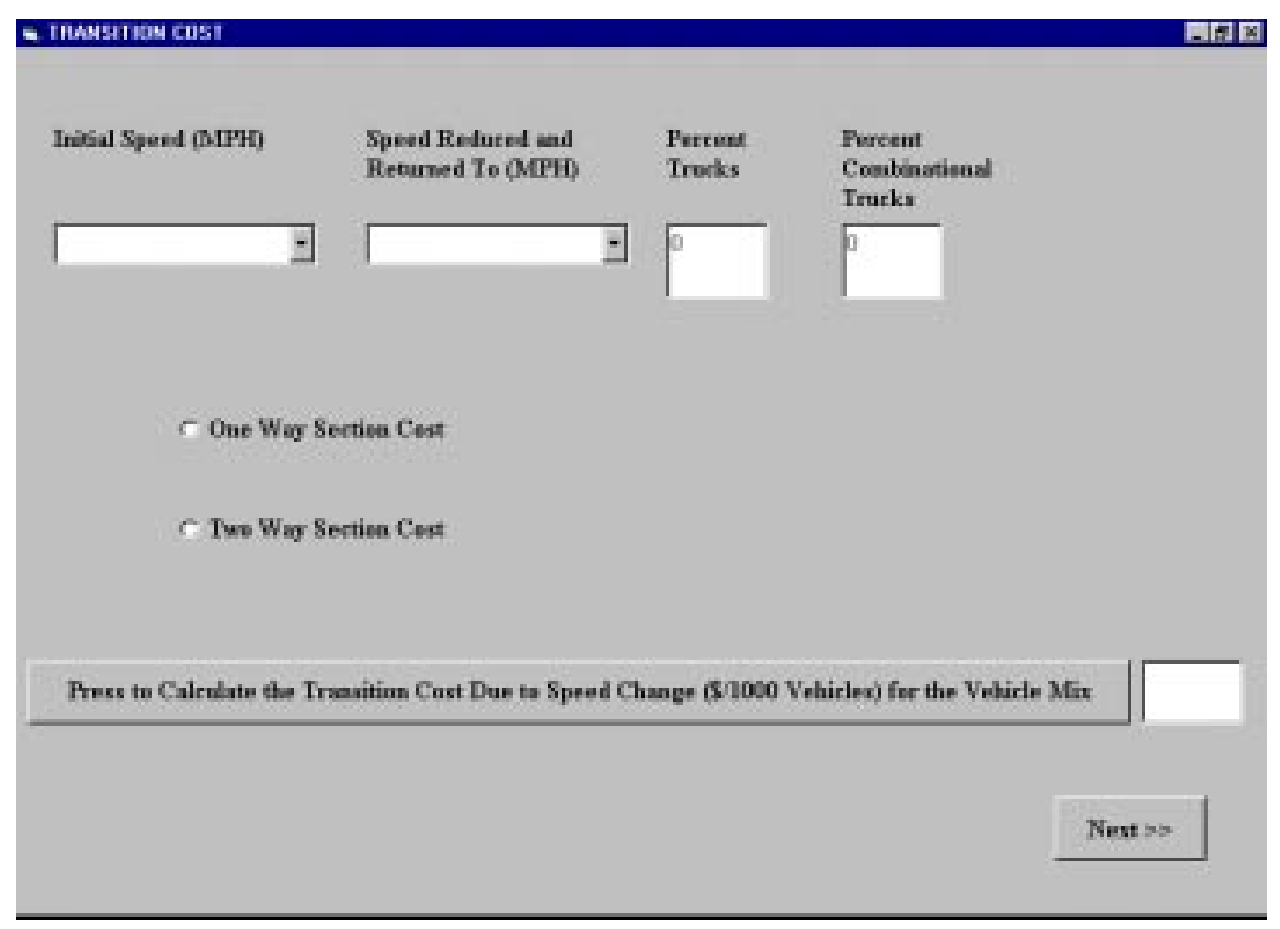

Figure 4.14: The Transition Cost Screen (Transition.frm)

Next, if the "Transition Cost" button is pressed, the question "Does the section require the calculation of Transition Cost?" will be displayed. If the answer is "Yes", the “Transition Cost" screen will be displayed (Figure 4.14).

The "Transition Cost" screen requires the following inputs: the initial speed of the vehicle, the reduced speed, and whether the calculated cost is for a one-way or two-way section. The speed data are in the form of dropdown menus, in which the user has to select 
from a list and the number of ways is in the form of an option button. On clicking the button

"Press to Calculate the Transition Cost", the transition cost is displayed in the output box.

The "Next" button takes the user back to the "Main Screen".

\section{- The Intersection Delay Cost Due to Stopping Screen (Delaycosts.frm)}

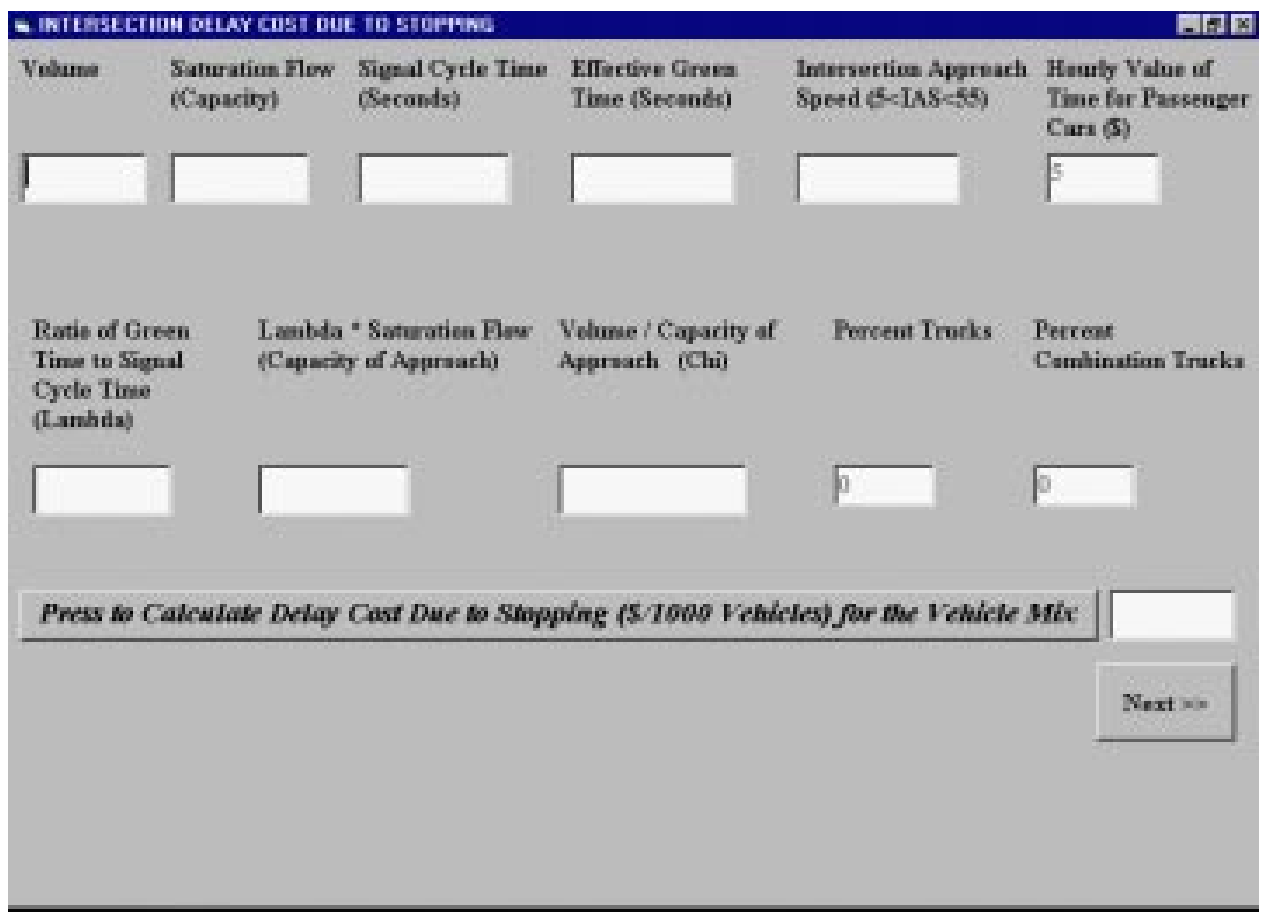

Figure 4.15: The Intersection Delay Cost Due to Stopping Screen (Delaycosts.frm)

The final cost component to be calculated is the intersection delay cost. If the user chooses to include the delay cost in the calculations, the "Delay Cost" screen (Figure 4.15) will be displayed. To calculate the Delay Cost, the following inputs are required: "Traffic Volume", "Road Capacity", "Signal Cycle Time (Seconds)", "Effective Green Time (Seconds)", "Intersection Approach Speed". "Hourly Value of Time for Passenger Cars", "Percent Single Unit Trucks" and "Percent Combination Trucks" are the inputs already 
known when the Basic Section cost is calculated. The intermediate components of green time to cycle time ratio (Lambda), capacity of approach and the volume to capacity ratio of approach are calculated when the inputs are provided. The intersection delay cost due to stopping is calculated on the click of the button labeled "Press to Calculate the Delay Cost".

\section{- The Intersection Delay Cost Due to Idling Screen (Idlingcosts.frm)}

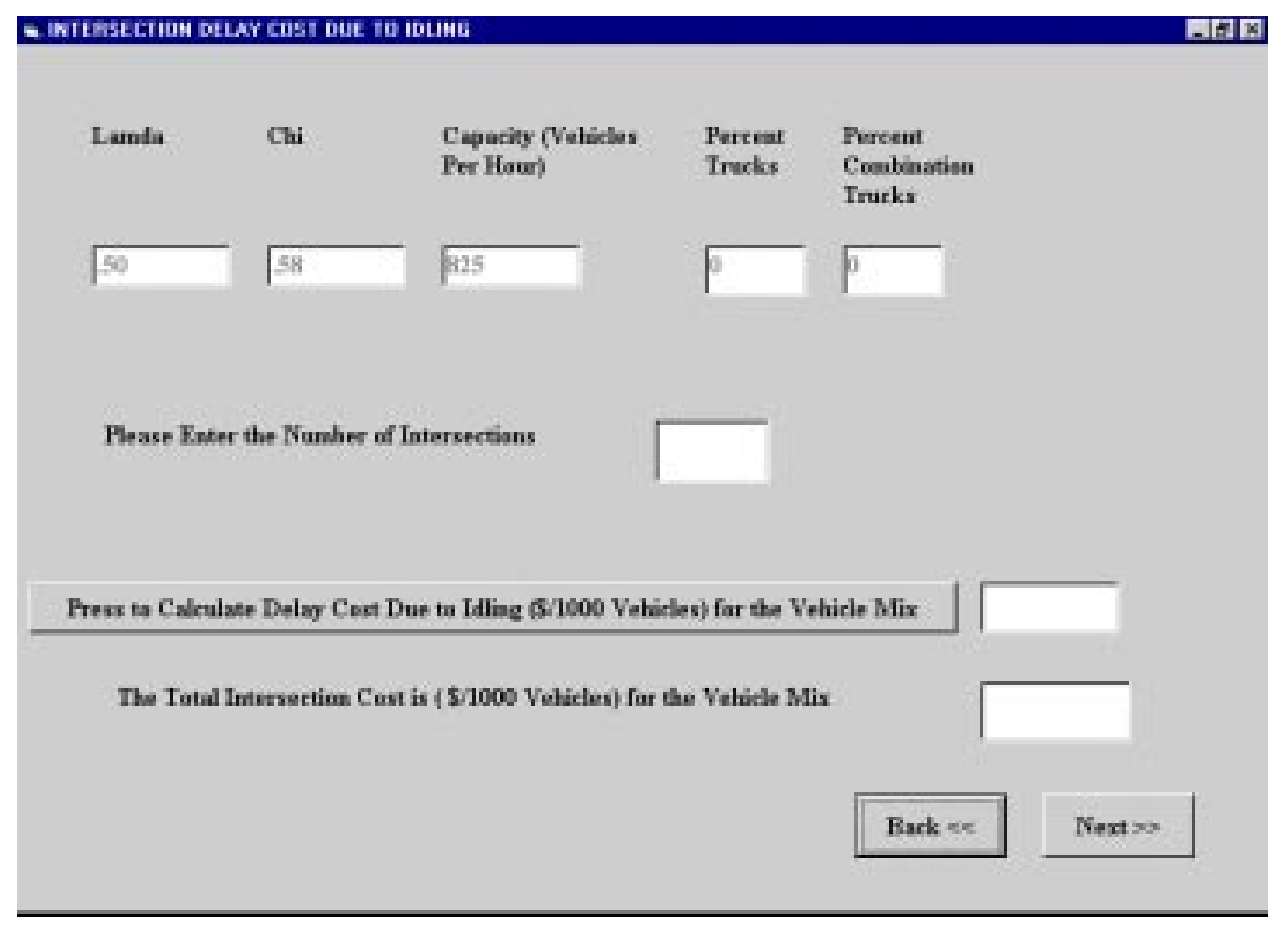

\section{Figure 4.16 The Intersection Delay Cost Due to Idling Screen (Idlingcosts.frm)}

The next screen is entitled "Intersection Delay Cost Due to Idling" (Figure 4.16) where the intersection delay cost due to idling is computed. The input data are the same as for the Delay Costs due to stopping and are displayed here for the user's information. The user needs to enter only the "Number of Intersections". The Total Intersection Cost (Intersection Delay Cost due to Stopping + Intersection Delay Cost due to Idling) is calculated and displayed in this screen. The user then goes back to the "Main Screen." If at 
this time the color of all four buttons has changed to white, the "Next" button will appear on the Main Screen. This button leads to the screen labeled "Total Cost" (Figure 4.17), where all the costs calculated so far is displayed.

\section{- The Total Cost Screen (Frmtotalcost.frm)}

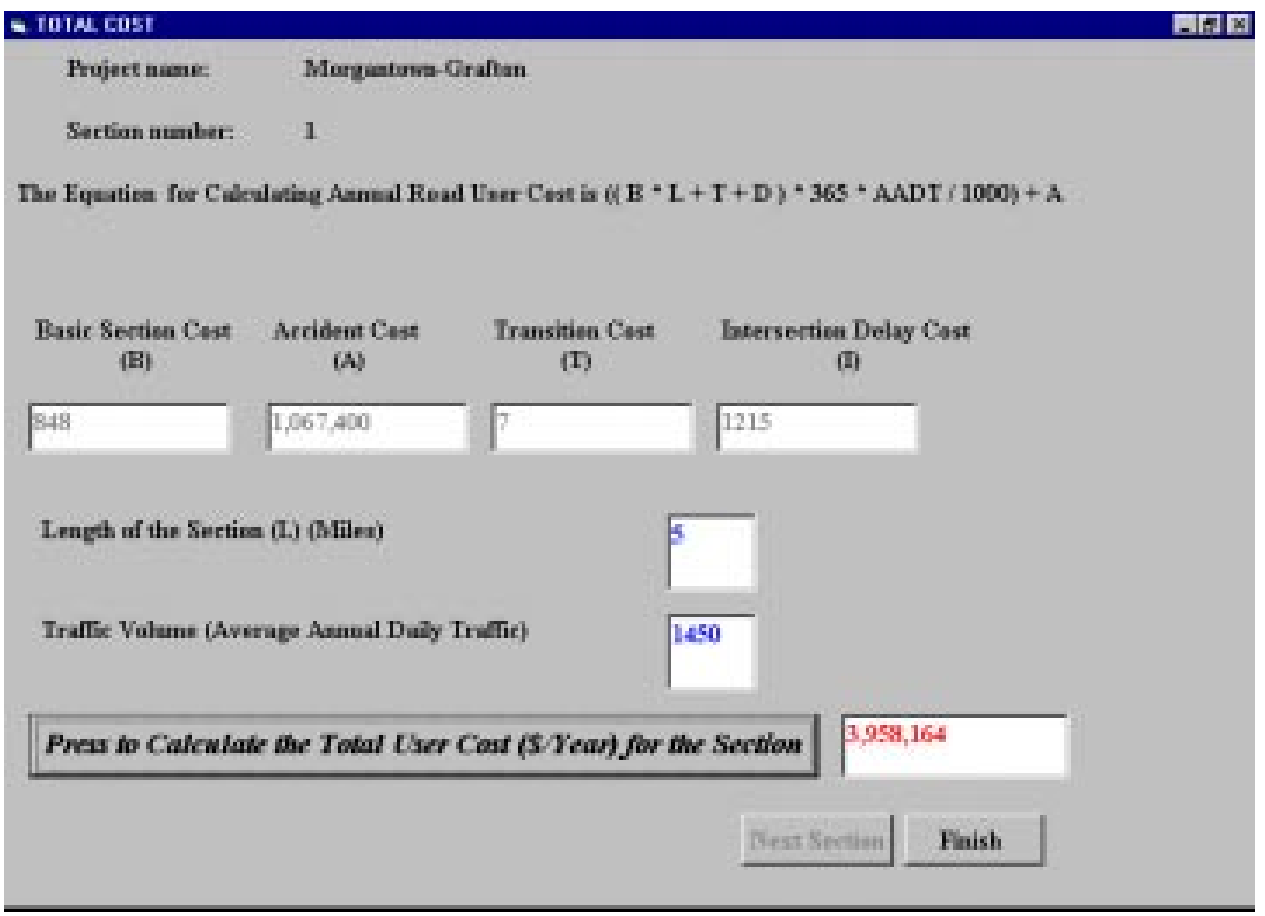

Figure 4.17: The Total Cost Screen (Frmtotalcost.frm)

The user is now required to enter the length of the section (in miles) and the traffic

volume (AADT) in this screen. The total cost is displayed as soon as the button "Press to Calculate the Total Cost" is clicked.

If there are still more sections to be analyzed, the user will click on the "Next Section" button which clears all the screens and displays the "Main Screen" (Figure 4.5) with the next section number displayed. The same procedure is repeated and costs are calculated for the new section. Once all calculations are completed for every section in the project, the 
"Next Section" button becomes disabled and the "Finish" button is activated. As all the sections are completed at this juncture, the user may wish to view all inputs and outputs on one screen. This can be achieved using the screen titled "View/Edit Results", shown in Figure 4.18 which is displayed when the "Finish" button (Figure 4.17) is pressed.

\section{- View/Edit Results Screen (Outputcosts.frm)}

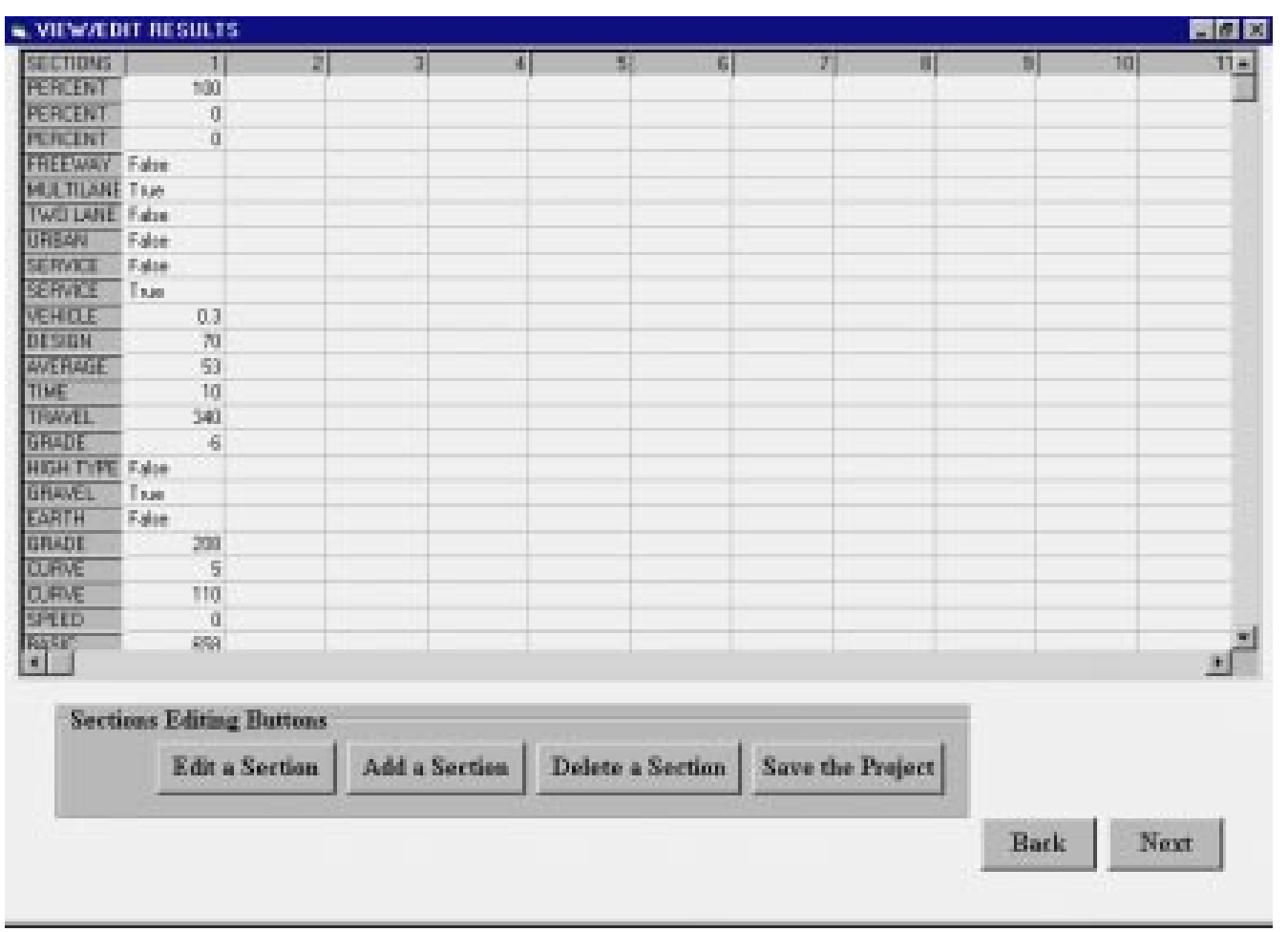

Figure 4.18: View/Edit Results Screen (Outputcosts.frm)

The table displayed in this screen is called a "Flexigrid." The user can widen the cells of the grid to view all the costs. The left most column shows the input labels and the top most row shows the section number. The user can perform a variety of operations by clicking on one the four "Section Editing Buttons" displayed. These buttons are "Edit a Section", "Add a Section", "Delete a Section" and "Save the Project". Edit a Section button 
is used to make modifications in a particular section. If the user clicks on this button, an input box will be displayed prompting the user for the section number to be edited, after which the "Main Screen" will be displayed. All calculations for that section can be repeated with the modified inputs.

If it is desired to add a new section to the project, clicking on the "Add a Section" button will take the user back to the "Main Screen". The number of sections in the project will be increased by one. However, if there are already 50 sections in the project, no more sections can be added. Attempts to increase the number of sections above 50 will result in an error message.

The "Delete a Section" button is useful if the user is no longer interested in a particular section and wants to remove it from the project. An input box will be displayed asking the user to enter the section number to be deleted. Once the section number is entered, it is automatically deleted from the project. Multiple sections can be deleted one by one.

Once the user is fully satisfied with the results, "Save the Project" button must be pressed. A window, as shown in Figure 4.19, will be displayed and the "View/Edit Results" screen will be disabled. The user has to press the "Save" button to save the project in a desired directory. The project is then saved in an ASCII text file in the harddrive (C:I) for future retrieval and the "View/Edit Results" screen is enabled once more. A message entitled "If you have not saved the file, Please do so" is displayed as soon as the "Next" button is pressed. It is the responsibility of the user to save the file in the desired directory. If the project is not saved at this juncture, the user may lose all information. On pressing the "Ok" button of the message box, the next screen titled "Inputs for the Project" screen (Figure 4.20) is displayed. 


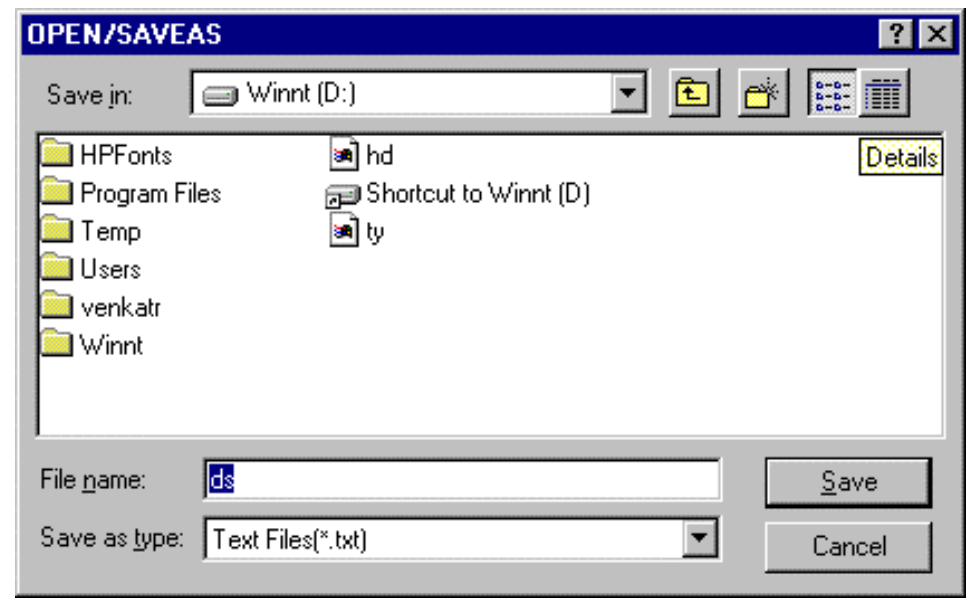

Figure 4.19: The Open/Saveas Dialog Box

- Inputs for the Project Screen (Inputresults.frm)

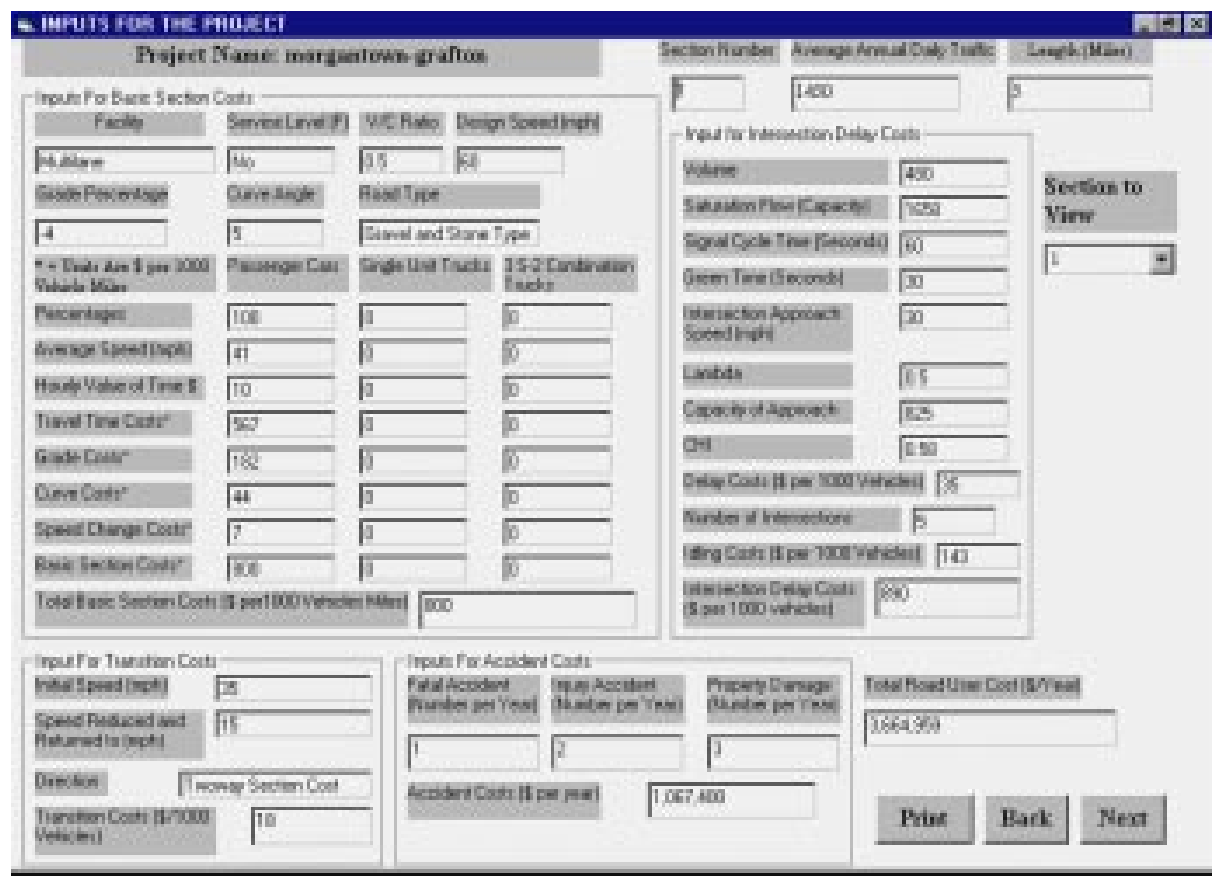

Figure 4.20: Inputs for the Project Screen (Inputresults.frm)

This screen summarizes the data for a section in a concise format ready to be printed for archival purposes. The user can select any individual section to view. The first section is 
displayed by default. Subsequent sections can be viewed by selecting the section number from the dropdown menu shown just below the "Section to View" label.

The user can also take printouts of the inputs by pressing the "Print" button. On clicking the "Print" button, a window entitled "Print Results" is displayed as shown in Figure 4.21.

\section{- The Print Results Screen (Frmprint.frm)}

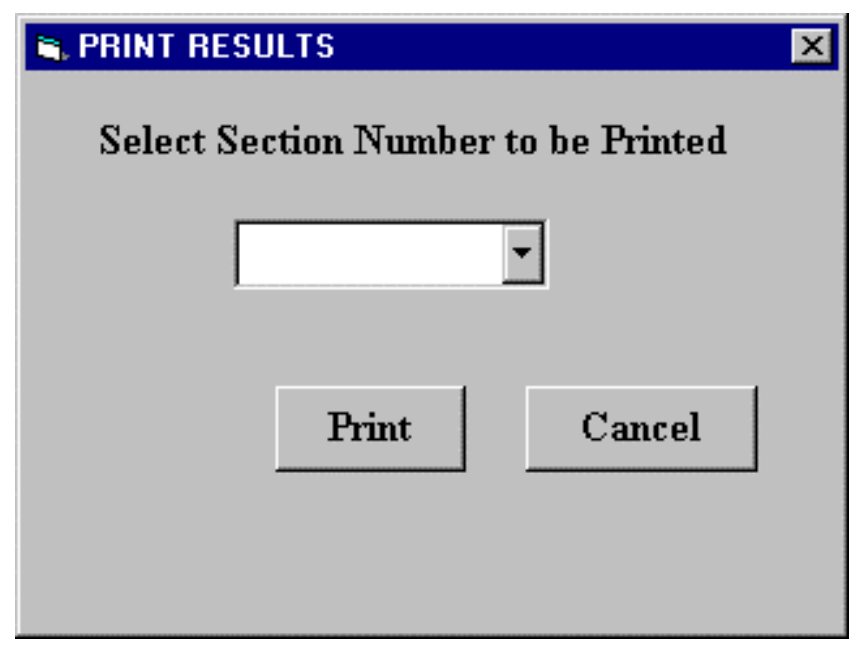

\section{Figure 4.21: The Print Results Screen (Frmprint.frm)}

The user has to select a section number to print in this screen. He can print individual sections by selecting a particular section number from the dropdown titled "Select Section Number to be Printed" or select "All" from the dropdown to print all sections in succession. Each section will be printed on a separate page.

Clicking on the "Next" button in Figure 4.20 will take the user to the "View Results" screen (Figure 4.22). 


\section{- The View Results Screen (Viewresults.frm)}

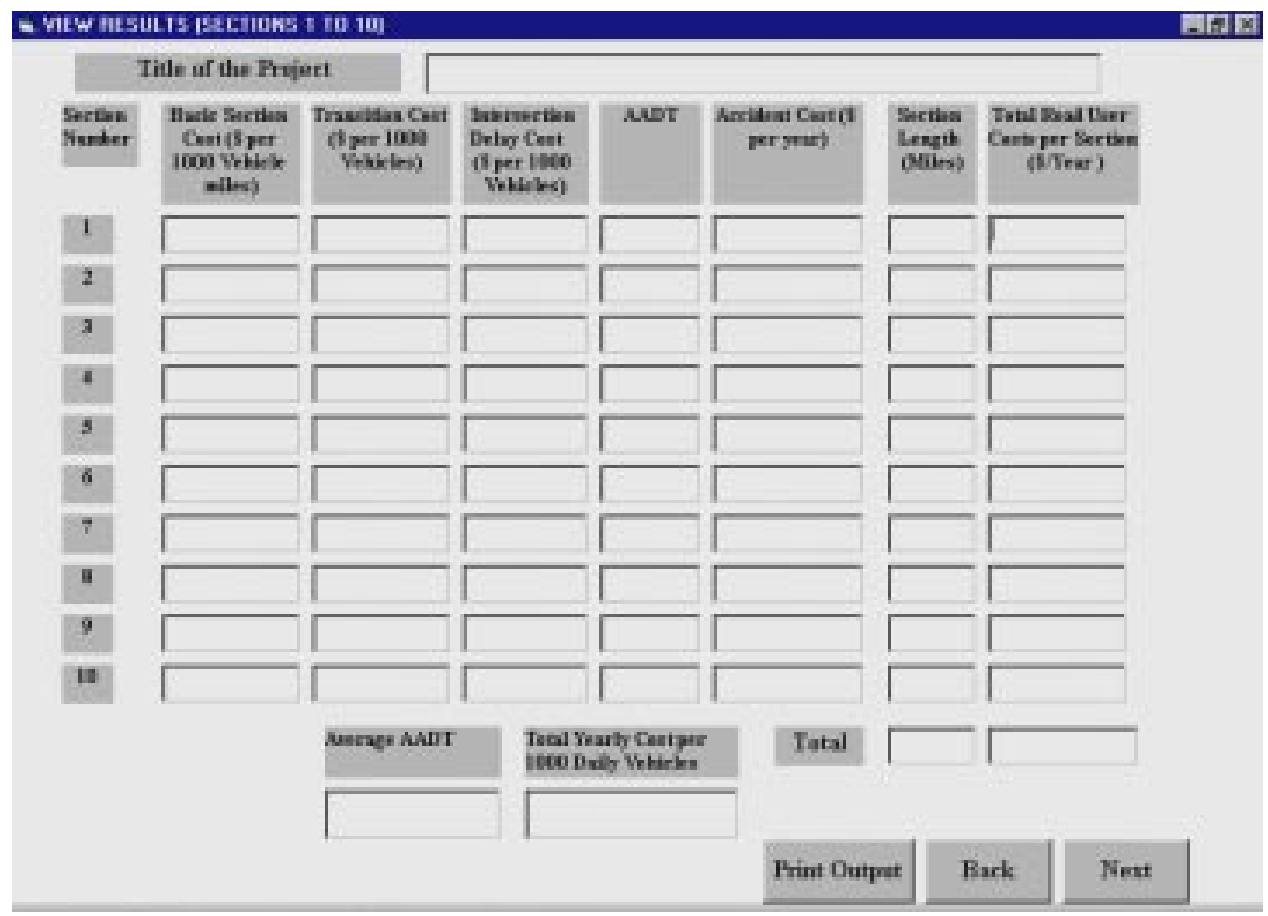

Figure 4.22: The View Results Screen (Viewresults.frm)

This screen display all cost components of each section (ten sections per screen) and total costs for the whole project. Viewresults1.frm, Viewresults2.frm, Viewresults3.frm and Viewresults4.frm are led to automatically if number of sections is more than ten. At this point the user can print the results for future reference. The "Back" button takes the user back to the previous screen. The "Next" button takes the user to the next screen in case there are more than ten sections. Otherwise, the "Next" button is replaced by the "End" button, which helps the user to exit the software. On pressing the "End" button, a window appears with a message "Do you want to go to a New Session?". If the user presses the "Yes" button, the screen in Figure 4.1 appears. The "No" button terminates the software. 


\section{- Opening an Existing File Screen (Open.frm)}

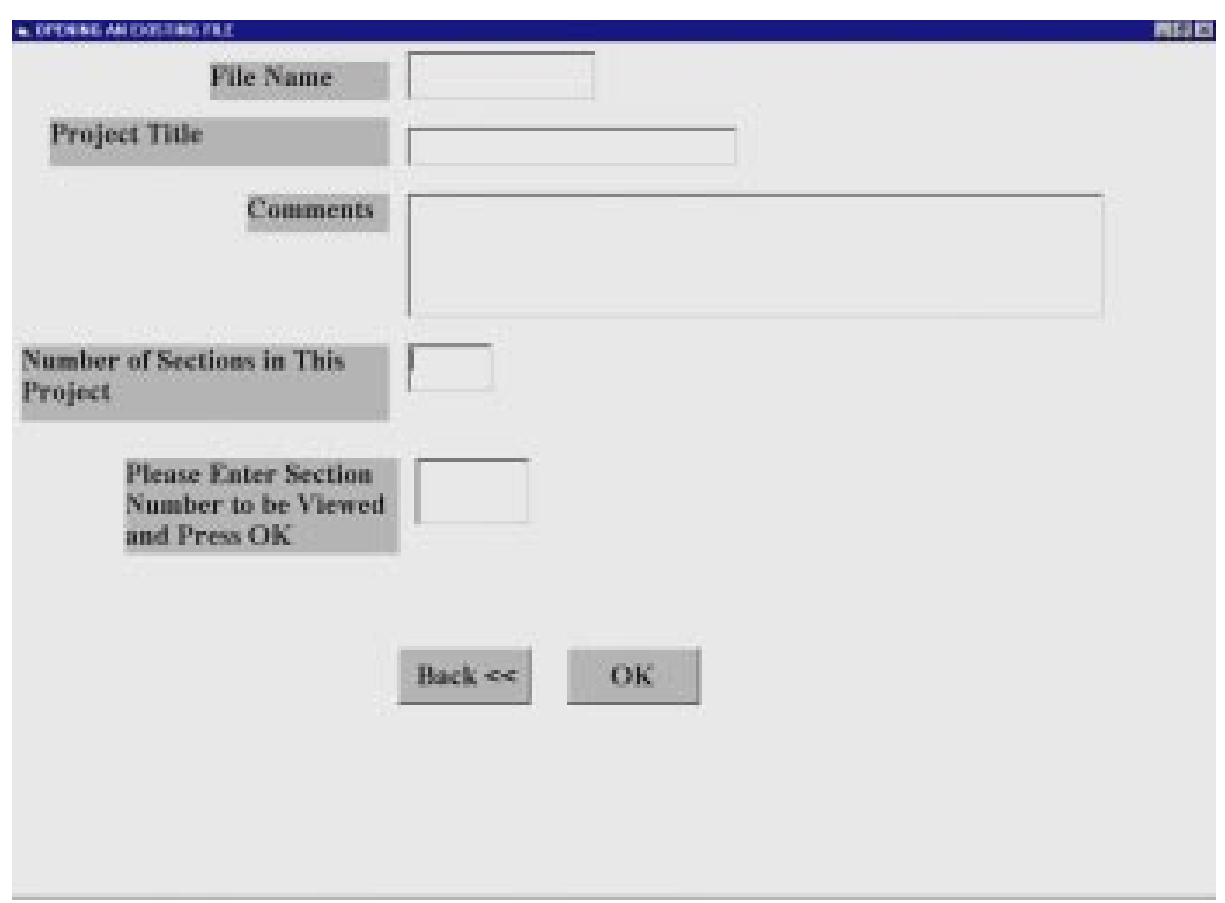

Figure 4.23: Opening an Existing File Screen (Open.frm)

To retrieve information saved in an existing file, the user must click on the "Opening an Existing File" button displayed in the "Startup" screen (Figure 4.3). This would bring up the open/saveas dialog box shown in Figure 4.19 from which the user selects the file to open. The user can also browse through all directories to find the desired file.

Once a file is selected, a new screen entitled "Opening an Existing File" (Figure 4.23) will be displayed. This screen shows the file name, the title of the project, brief comments on the project and the number of sections. An input box is also shown prompting the user for the section number to be viewed or edited. If the value entered for the section number to be viewed is larger than the number of sections in the project, an error message will be displayed. 
The user must enter a valid section number and press the "Ok" button to proceed to the "Main Screen". A label on top of the screen shows the section number being viewed. The "Basic Section Cost", "Accident Cost", "Intersection Delay Cost" and "Transition Cost" buttons are displayed on the screen. The user may press any one of them to view or make changes to the cost components.

Due to the fact that change in inputs in one screen may affect other screens, the user has to make sure that changes are reflected in all the required screens. If the user fails to do so, error messages will be displayed. As an example, if the user wants to change the grade percentage for passenger cars, he has to go to the "Grade Cost for Passenger Car" screen, select a new grade percentage from the dropdown menu and click on the button "Press to Calculate Grade Cost" to complete the calculation. The new grade cost also changes the total Basic Section cost, so the user has to proceed to the "Speed Change Cost for Passenger Cars" screen and click on "Press to Calculate the Speed Change Cost" to display the changed cost. Once all the necessary changes are made, the user clicks on the "Next" button on the "Main Screen" to move to the "Total Cost" screen. Here, the new costs are displayed in their respective output boxes. At this point it is also possible to change the length of the section. When the user is satisfied with the changes, the button "Press to Calculate the Total Cost for the Section" must be pressed to display the new total cost.

The user can go to the next screen titled "View/Edit Results" (Figure 4.18) where it is possible to use the various editing buttons available. The old costs may be revised either by viewing each section as in the screen "Opening an Existing File" (Figure 4.23) or by using the edit buttons in the screen "View/Edit Results" (Figure 4.18). After making all the 
changes needed, the user must save all the work for future retrieval. The user can proceed to obtain printouts of the projects after changes.

\section{- The View/Update Indices Screen (Frmupdateindices.frm)}

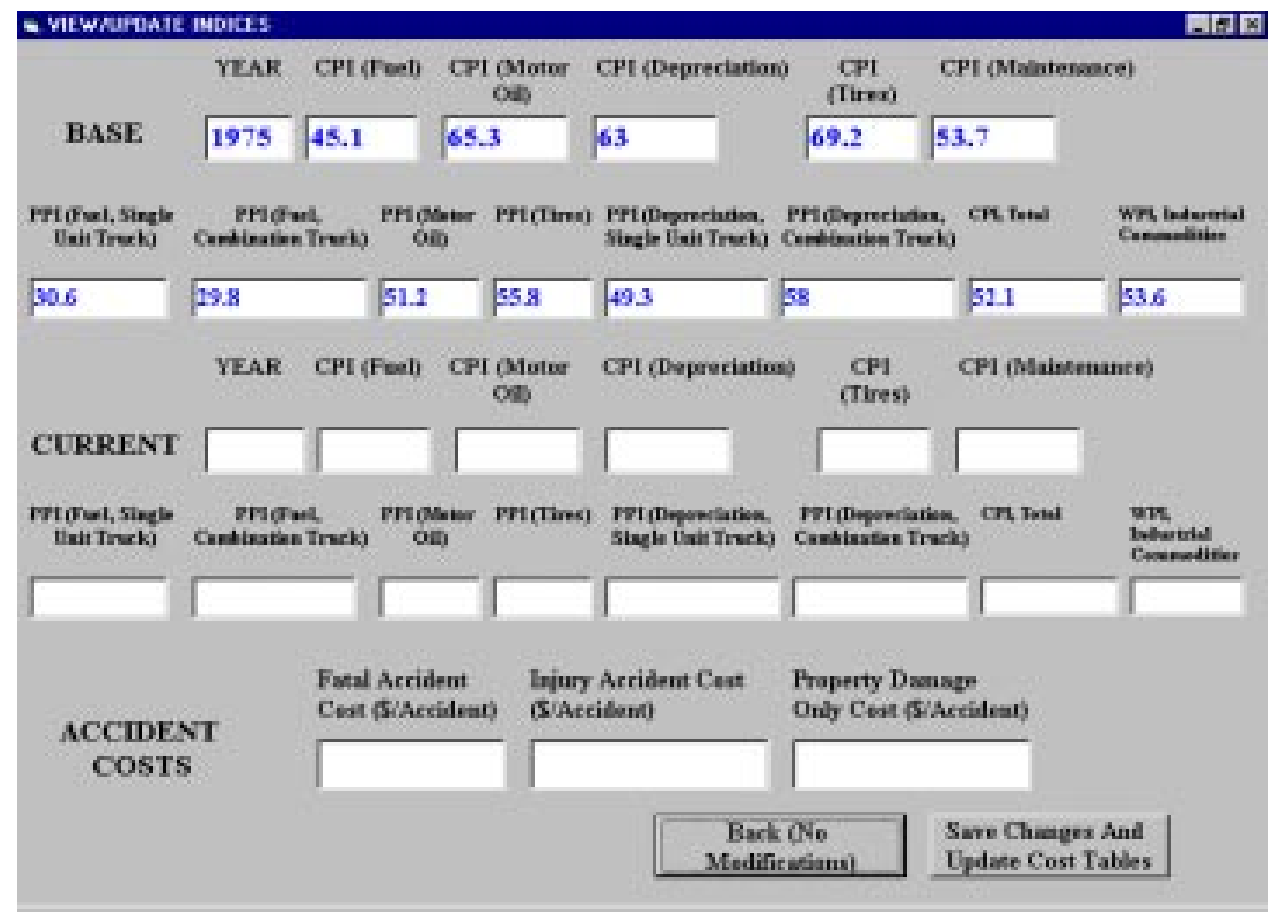

Figure 4.24: The View/Update Indices Screen (Frmupdateindices.frm)

All cost tables are stored in Excel worksheets. These tables must be updated annually so that calculated costs reflect the latest cost figures. The first step is to press the "Update Cost Tables and Indices" button on the "Road User Cost Application" screen, shown in Figure 4.2. Once this button is clicked, screen entitled "View/Update Indices" (Figure 4.24) is invoked. This screen opens and displays the base year, consumer price indices (CPI) and producer price indices (PPI), previously called wholesale price indices (WPI) for all price components: CPI (Fuel), CPI (Motor Oil), CPI (Depreciation), CPI (Tires) and CPI (Maintenance), PPI (Fuel, Single Unit Truck), PPI (Fuel, Combination Truck), PPI (Motor 
Oil), PPI (Tires), PPI (Depreciation, Single Unit Truck), PPI (Depreciation, Combination Truck), CPI (Total) and WPI (Industrial Commodities). The user must enter the current year and the latest CPI's, PPI's in the specified input boxes and click the "Save Changes and Update Cost Tables" button to update all the cost tables. The latest available vehicular accident costs, as published by the National Safety Council, must also be entered. Once the updating is finished, the user goes back to the "Road User Cost Application" screen. If the user does not want to save the changes made, he can go back to the "Road User Cost Application" screen by pressing the "Back (No Modifications)" button.

\section{- The Economic Analysis Screen (Frmeconomic.frm)}

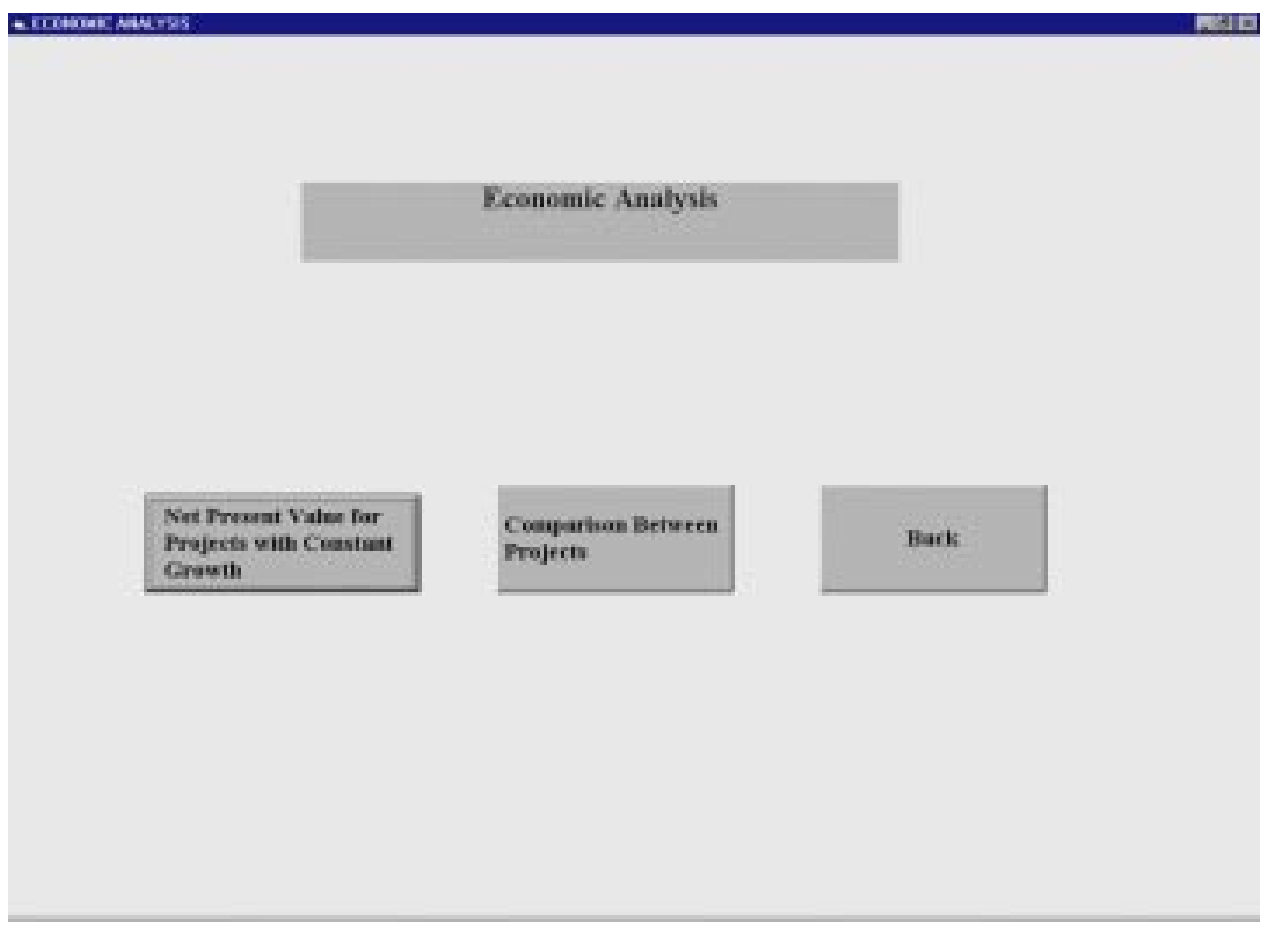

Figure 4.25: The Economic Analysis Screen (Frmeconomic.frm)

Another application of the software is to compute the present value of all the annual user benefits due to the improvement over the analysis period, and to compare this present 
value with the computed present value of the project costs associated with the improvement. A project (or project alternative) can be deemed economically justifiable if the present value of the project-related benefits exceeds the present value of all project-related costs. The user clicks on the "Economic Analysis" button displayed in the "Welcome" screen (Figure 4.1), to invoke the "Economic Analysis" screen, shown in Figure 4.25, which includes three buttons.

\section{- The Economic Analysis for Uniform Increase or Decrease Screen}

\section{(Frmuniformnpv.frm)}

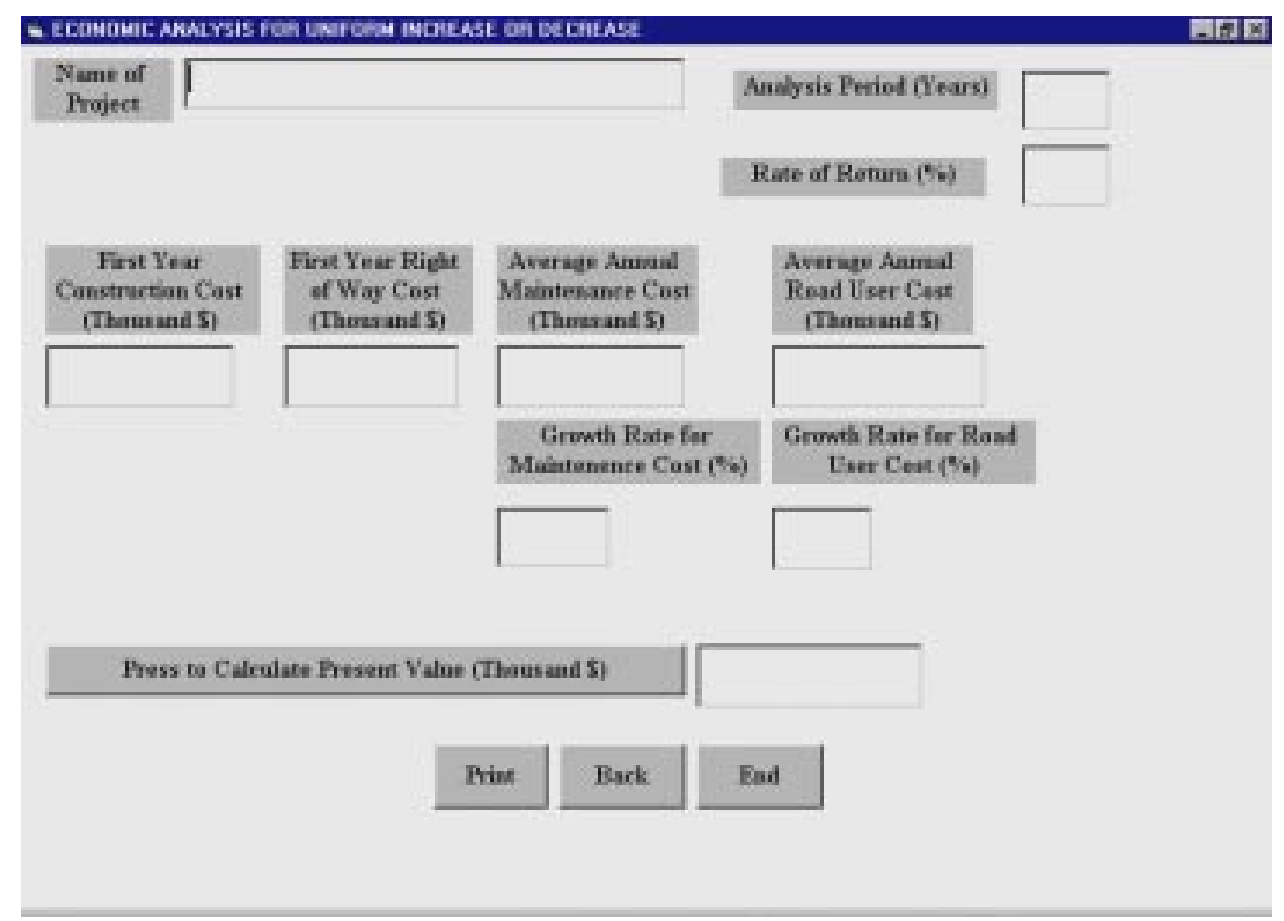

Figure 4.26: The Economic Analysis for Uniform Increase or Decrease Screen

\section{(Frmuniformnpv.frm)}

The "Net Present Value for Project with Constant Growth" button is used to calculate the present value for a project that has a constant anticipated annual growth rate for maintenance and user costs during the analysis period. On clicking this button, the screen 
entitled "Economic analysis for Uniform Increase or Decrease" (Figure 4.26) will be displayed.

The user must input the analysis period (in years), the growth rate for road user cost and maintenance cost, the rate of return, construction costs and right of way costs for the first year and average annual maintenance cost and average annual road user cost in the specified input boxes. On clicking the button entitled "Press to Calculate the Present Value", the present value is calculated and displayed on the screen. The user can also print the screen by pressing the button "Print".

- The Input Data for Economic Analysis Screen (Frminput.frm)

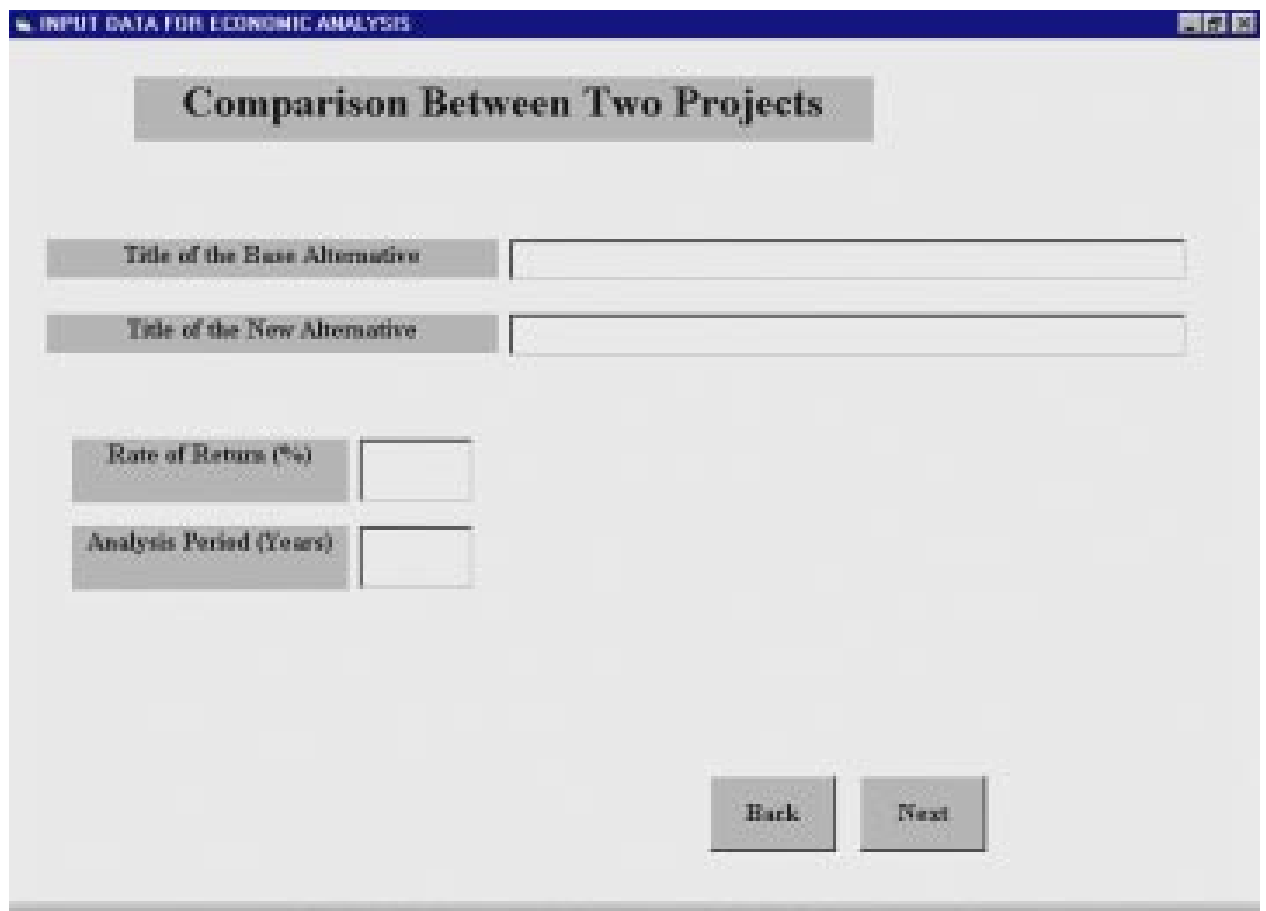

Figure 4.27: The Input Data for Economic Analysis Screen (Frminput.frm) 
To compare between two projects, the user has to click the button "Comparison Between Projects" in the "Economic Analysis" screen (Figure 4.25). A new screen entitled "Input Data for Economic Analysis" (Figure 4.27) will appear. The user must input the rate of return and analysis period in the input boxes and click on the "Next" button. The analysis period must not exceed forty years.

\section{- The Base or Alternative 0 Screen (Frmbase.frm)}

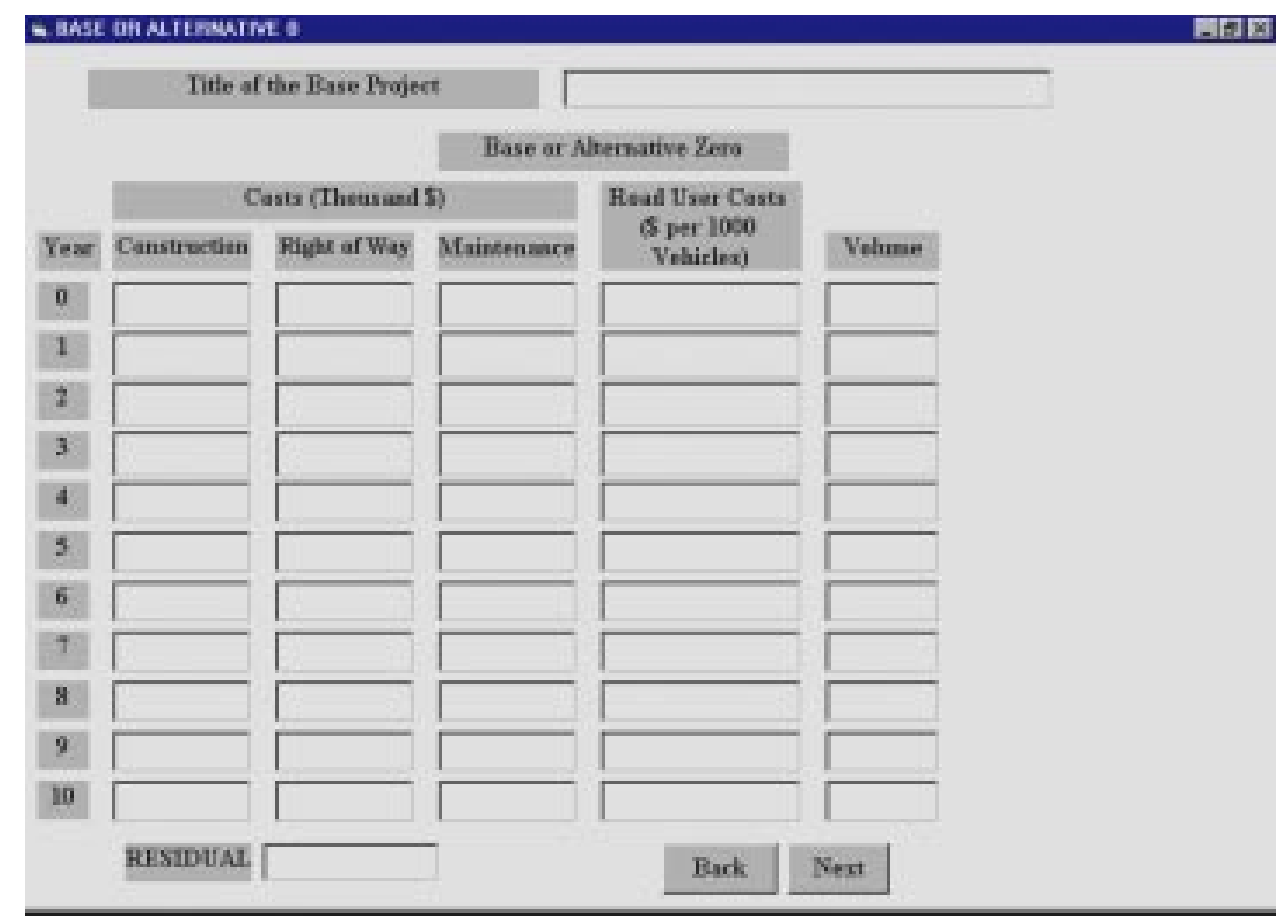

Figure 4.28: The Base or Alternative 0 Screen (Frmbase.frm)

"Base or Alternative 0" screen, Figure 4.28, displays input boxes for construction cost, right of way cost, maintenance cost, road user cost and volume of traffic (corresponding to the Total Yearly Cost per 1,000 Daily Vehicles and the AADT respectively, calculated in Figure 4.22) and the Residual Cost of the project. The input boxes appear dynamically depending on the analysis period, i.e. if the number of years is ten, then ten sets of input 
boxes appear. Frmbase1.frm, Frmbase2.frm and Frmbase3.frm, which are similar to Frmbase.frm, are led to automatically depending on the user input for analysis period.

- The New Alternative Screen (Frmcurrent.frm)

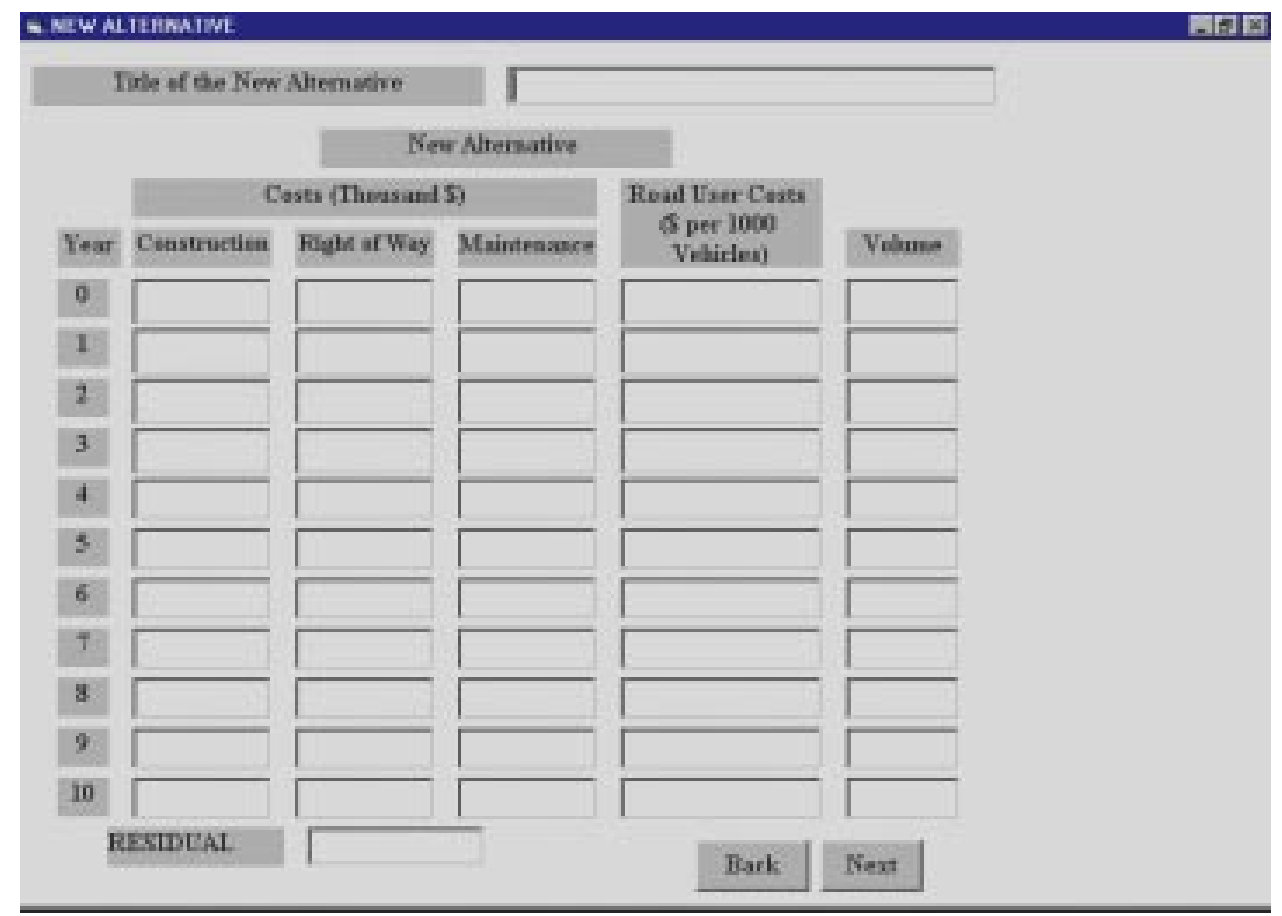

Figure 4.29: The New Alternative Screen (Frmcurrent.frm)

After inputting all data for the base and alternative, the user clicks on the "Next" button to go to a new screen entitled "The New Alternative", shown in Figure 4.29, which has the same display format as the previous screen. The data entered here pertains to the new alternative or the costs of making improvements to an existing roadway. After all inputs are complete, the user clicks on the "Next" button to go to the screen where the Net Present Value is calculated. Frmcurrent1.frm, Frmcurrent2.frm and Frmcurrent3.frm, which are similar to Frmcurrent.frm, are led to automatically depending on the user input for analysis period 


\section{- The Net Present Value Analysis Screen (Frmnpv.frm)}

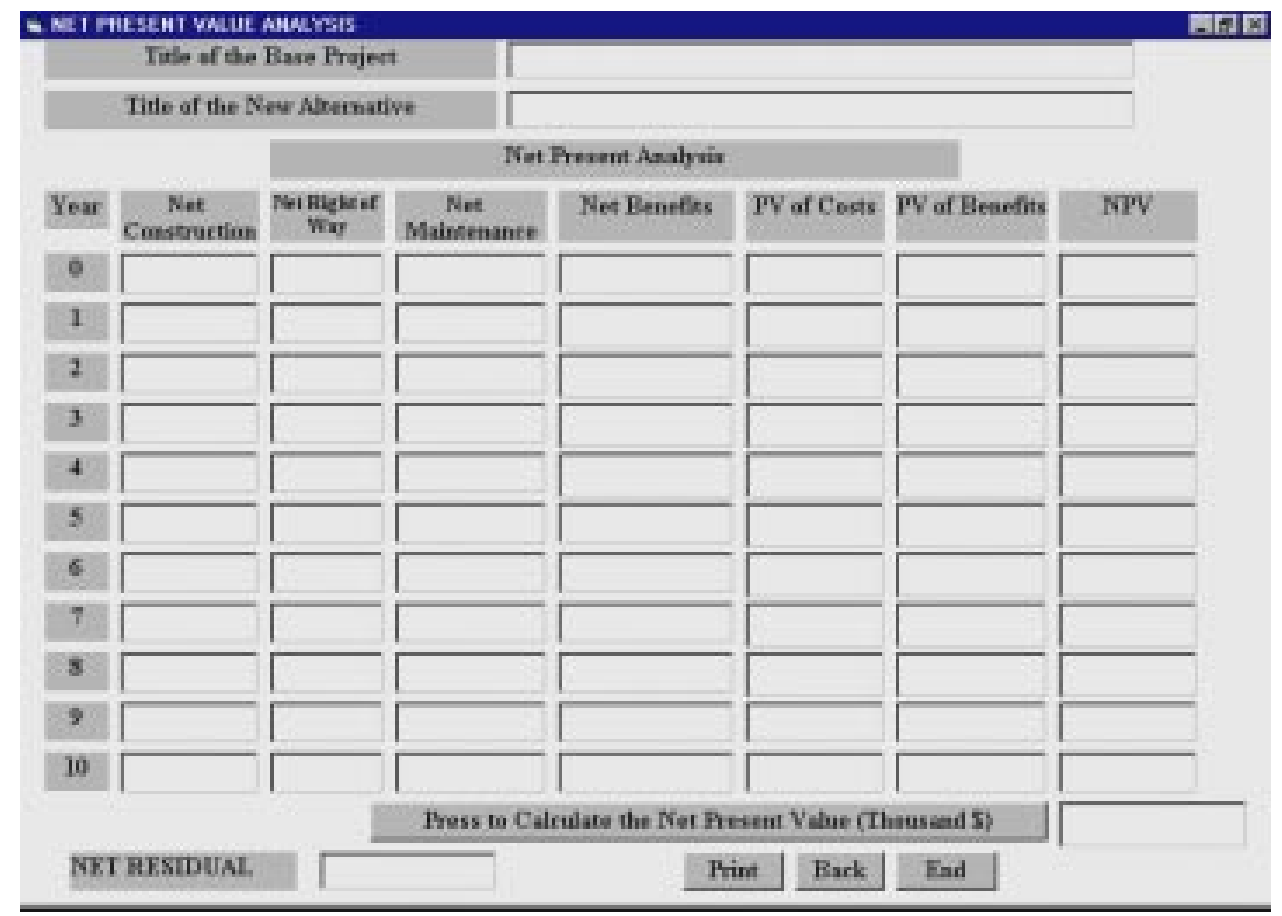

Figure 4.30: The Net Present Value Analysis Screen (Frmnpv.frm)

This screen is entitled "Net Present Value Analysis", Figure 4.30, which displays the net construction costs, net right of way costs, net maintenance costs, and net benefits. Frmnpv1.frm, Frmnpv2.frm and Frmnpv3.frm, which are similar to Frmnpv.frm, are led to automatically depending on the user input for analysis period.

There are also several boxes displayed in which the present value of the costs (construction cost + right of way cost + maintenance cost) and present value of the benefits are shown. The user must click on the "Press to Calculate the Net Present Value" button to calculate the present values of annual costs and benefits, the Net Present Value for each year and the overall Net Present Value.

The user can terminate this session by pressing the "End" button. This button is replaced by the "Next' button if the analysis period exceeds 10 years. The screen shown in 
Figure 4.30 had an analysis period of 10 years. In short, the last screen would have the "End" button required to terminate the session.

The code is written in BASIC and each and every form is associated with a code for carrying out the designated functions. The program code also has a module, which has all the global functions.

\subsection{Database Description}

The database having all the cost figures is stored in MS-Excel worksheets. There are two-database tables. One is named as base.xls and the other is current.xls. Each sheet has been given a name to identify the type of data stored in it. All the sheets that are present in the database table base.xls are listed below and the corresponding nomographs and tables referred from the Manual are described below. The current.xls also has the same sheet names, the only difference being the cost tables are the updated to the current year. TRANSITION: The "Transition" sheet holds the data for the transition costs computed by digitizing the nomograph (Figure 20, pp. 70) of the Manual. The transition cost figures are used to calculate the transition costs.

TRANADJUST: The "Tranadjust" sheet contains the data for adjusting the transition costs when trucks, both single unit trucks and 3 S-2 combination trucks are present in the vehicle mix. The percentages of the two types and the cost factor with which it shall be multiplied are listed. The table is listed in page 70 of the Manual.

GRADE: The "Grade" sheet contains the database on the grade costs for passenger cars. This database was constructed by digitizing the nomographs provided in the Manual. It is function of the grade percent and average running speed. The table is listed as Table B-4, Page 126 of the Manual. 
CURVE: The "Curve" sheet contains the costs incurred in negotiating curves on the analysis section by passenger cars. This cost is a function of the degree of curvature and the average running speed. The table is listed as Table B-7, Page 129 of the Manual.

PAVEDTOGRAVEL: This sheet contains adjustment factors multiplied to the grade and curve costs if the road is "Gravel and Stone" type. Figure 19 (pp. 62) of the Manual entitled "Multiplicative Factors To Convert Motor Vehicle Running Cost On Highway Type Pavements To Cost On Gravel And Stone Or To Earth Roadway Surfaces" was digitized for this purpose.

PAVEDTOEARTH: This sheet has the adjustment factors for "Earth" type surface and these factors are used to adjust the grade and curve costs according to the road type. Figure 19 (pp. 62) of the Manual entitled "Multiplicative Factors To Convert Motor Vehicle Running Cost On Highway Type Pavements To Cost On Gravel And Stone Or To Earth Roadway Surfaces" was digitized for this purpose.

ARTERIALSPEEDCHANGECOST: This sheet contains all the cost figures necessary to calculate the speed change cost for passenger cars in an Arterial type of highway. It includes the cost figures for a level of service present as well as absent. The nomograph listed on page 53 of the Manual entitled "Basic Section Costs (B) for Passenger Cars on Arterials" was digitized for this purpose.

TWOLANESPEEDCHANGECOST: This sheet contains data on the speed change cost for passenger cars in a two-lane or rural highway. It includes the cost figures for a level of service present as well as absent. The nomograph listed on page 52 of the Manual entitled "Basic Section Costs (B) for Passenger Cars on Two-Lane Highways" was digitized for this purpose. 
MULTILANESPEEDCHANGECOST: This sheet furnishes the data necessary to calculate the speed change cost for Multi-Lane facility for passenger cars. It includes the cost figures for a level of service present as well as absent. The nomograph listed on page 51 of the Manual entitled "Basic Section Costs (B) for Passenger Cars on Multi-Lane Highways" was digitized for this purpose.

FREEWAYSPEEDCHANGECOST: This sheet contains data on speed change cost for passenger cars on a Freeway. It includes the cost figures for a level of service present as well as absent. The nomograph listed on page 50 of the Manual entitled "Basic Section Costs (B) for Passenger Cars on Freeways" was digitized for this purpose.

TTCARTERIALSF: This sheet has the data for travel time cost for passenger cars on an Arterial facility with a level of service present. The nomograph listed on page 53 of the Manual entitled "Basic Section Costs (B) for Passenger Cars on Arterials" was digitized for this purpose.

TTCARTERIALNOSF: This sheet has the data for travel time cost for passenger cars on an Arterial facility where level of service is absent. The nomograph listed on page 53 of the Manual entitled "Basic Section Costs (B) for Passenger Cars on Arterials" was digitized for this purpose.

TTCTWOLANESF: This sheet contains data on travel time cost for passenger cars on a two-lane facility with a level of service present. The nomograph listed on page 52 of the Manual entitled "Basic Section Costs (B) for Passenger Cars on Two-Lane Highways" was digitized for this purpose.

TTCTWOLANENOSF: This sheet contains data on travel time cost for passenger cars on a two-lane facility with a level of service absent. The nomograph listed on page 52 of the 
Manual entitled "Basic Section Costs (B) for Passenger Cars on Two-Lane Highways" was digitized for this purpose.

TTCMULTISF: This sheet contains data on the travel time cost for passenger cars on a multi-lane highway with a level of service present. The nomograph listed on page 51 of the Manual entitled "Basic Section Costs (B) for Passenger Cars on Multi-Lane Highways" was digitized for this purpose.

TTCMULTINOSF: This sheet contains data on the travel time cost for passenger cars on a multi-lane highway without a level of service. The nomograph listed on page 51 of the Manual entitled "Basic Section Costs (B) for Passenger Cars on Multi-Lane Highways" was digitized for this purpose.

TTCFREEWAYSF: This sheet contains data for travel time cost for passenger cars on a Freeway having a level of service, F. The nomograph listed on page 50 of the Manual entitled "Basic Section Costs (B) for Passenger Cars on Freeways" was digitized for this purpose.

TTCFREEWAYNOSF: This sheet contains data for travel time cost for passenger cars on a Freeway with a level of service, $\mathrm{F}$ absent. The nomograph listed on page 50 of the Manual entitled "Basic Section Costs (B) for Passenger Cars on Freeways" was digitized for this purpose.

SPEEDARTERIALNOSF: This sheet contains the average running speed for a passenger cars on an Arterial facility without level of service. These costs are a function of the vehicle to capacity ratio and the design speed. The nomograph listed on page 53 of the Manual entitled "Basic Section Costs (B) for Passenger Cars on Arterials" was digitized for this purpose. 
SPEEDTWOLANENOSF: This sheet contains the average running speed for passenger cars utilizing a two-lane highway without a level of service. These costs are a function of the vehicle to capacity ratio and the design speed. The nomograph listed on page 52 of the Manual entitled "Basic Section Costs (B) for Passenger Cars on Two-Lane Highways" was digitized for this purpose.

SPEEDMULTINOSF: This sheet has cost figures for average running speed of passenger cars travelling on a Multi-Lane highway without a level of service. These costs are a function of the vehicle to capacity ratio and the design speed. The nomograph listed on page 51 of the Manual entitled "Basic Section Costs (B) for Passenger Cars on Multi-Lane Highways" was digitized for this purpose.

SPEEDFREEWAYNOSF: This sheet has data on average running speed for passenger cars on a Freeway without a level of service. These costs are a function of the vehicle to capacity ratio and the design speed. The nomograph listed on page 50 of the Manual entitled "Basic Section Costs (B) for Passenger Cars on Freeways" was digitized for this purpose.

SPEEDARTERIALSF: This sheet contains the average running speed for passenger cars on an Arterial facility with a level of service, F. These costs are a function of the vehicle to capacity ratio and the design speed. The nomograph listed on page 53 of the Manual entitled "Basic Section Costs (B) for Passenger Cars on Arterials" was digitized for this purpose.

SPEEDTWOLANESF: This sheet contains the average running speed for passenger cars utilizing a two-lane highway with a level of service, F. These costs are a function of the vehicle to capacity ratio and the design speed. The nomograph listed on page 52 of the Manual entitled "Basic Section Costs (B) for Passenger Cars on Two-Lane Highways" was digitized for this purpose. 
SPEEDMULTISF: This sheet includes cost figures for average running speed of passenger cars travelling on a Multi-Lane highway with a level of service, F. These costs are a function of the vehicle to capacity ratio and the design speed. The nomograph listed on page 51 of the Manual entitled "Basic Section Costs (B) for Passenger Cars on Multi-Lane Highways" was digitized for this purpose.

SPEEDFREEWAYSF: This sheet includes data on the cost based on average running speed for passenger cars on a Freeway with a level of service, F. These costs are a function of the vehicle to capacity ratio and the design speed. The nomograph listed on page 50 of the Manual entitled "Basic Section Costs (B) for Passenger Cars on Freeways" was digitized for this purpose.

AVJSTOPPERVEH: This sheet contains data on the average stops per vehicle (per signal) on an intersection. It is a function of chi and lambda. The nomograph listed as Figure 21 (pp. 72) of the Manual has been digitized for making this table.

ADDEDSTOPDELAY: This sheet contains figures on the added stopping delay cost per signal (Time Cost or cost due to Time Value of Money) in an intersection. It is a function of average length of stop in an intersection and the intersection approach speed. The nomograph listed as Figure 21 (pp. 72) of the Manual has been digitized for making this table.

DELAYTIMEADJUST: This sheet contains adjustment factors for delay time with respect to the presence of trucks, both single unit trucks and $3 \mathrm{~S}-2$ combination trucks, when the added stopping delay cost is computed. This table corresponds to the table listed in page 72 of the Manual.

ADDEDSTOPCOST: This sheet contains data on the added stopping cost per signal (Running Cost) in an intersection. It is a function of the average stop per vehicles and the 
approaching speed to a signal on an intersection. The nomograph listed as Figure 21 (pp. 72) of the Manual has been digitized for making this table.

DELAYCOSTADJUST: This sheet contains adjustment factors for delay time costs with respect to the presence of trucks, both single unit trucks and $3 \mathrm{~S}-2$ combination trucks, when the added stopping delay cost is computed. This table corresponds to the table listed in page 72 of the Manual.

IDLINGDELAY: This sheet has the data on the average delay per vehicle and is a function of chi and the capacity of the road on a signal of an intersection. The nomograph listed as Figure 22 (pp. 73) has been digitized for making this table.

CYCLETIME: This sheet contains data on the correction to the average delay per vehicle and is a function of lambda and Cycletime (Signal Cycle Time + Effective Green Time). The nomograph listed as Figure 22 (pp. 73) has been digitized for making this table.

IDLINGTIME: This sheet contains the time in seconds spent due to idling at intersections. The nomograph listed as Figure 22 (pp. 73) has been digitized for making this table.

IDLINGTIMECOST: This sheet has the data on cost (Delay Cost due to Time value of Money) for idling on a signal on an intersection and is a function of time (Idling time). The nomograph listed as Figure 22 (pp. 73) has been digitized for making this table.

IDLINGTIMEADJUST: This sheet contains adjustment factors for delay time costs with respect to the presence of trucks, both single unit trucks and $3 \mathrm{~S}-2$ combination trucks, when the delay cost is computed. This table corresponds to the table listed in page 73 of the Manual. 
IDLINGCOST: This sheet has the data on cost (Idling Cost) for idling on a signal on an intersection and is a function of time (Idling time at an Intersection). The nomograph listed as Figure 22 (pp. 73) has been digitized for making this table.

IDLINGCOSTADJUST: This sheet contains adjustment factors for delay time costs with respect to the presence of trucks, both single unit trucks and $3 \mathrm{~S}-2$ combination trucks, when the idling cost is computed. This table corresponds to the table listed in page 73 of the Manual.

ACCIDENTCOSTS: This sheet contains the latest vehicular accident costs for the Fatal Accident, Injury Accident and Property Damage Only type of accident.

CPIINDICES: This sheet has the consumer price indices and producer price indices on which the database is based upon. If the latest consumer price indices are available, the user must update the database based on the given provisions. The latest cost factors replaces the old factors once the update is done in current.xls.

SUTGRADE: This sheet contains the database on the grade costs for single unit trucks. This database was constructed by digitizing the nomographs provided in the Manual. It is function of the grade percent and average running speed. The table is listed as Table B-5, Page 127 of the Manual.

SUTCURVE: This sheet contain the costs due to curves incurred in negotiating curves on the analysis section by single unit trucks. This cost is a function of the degree of curvature and the average running speed. The table is listed as Table B-8, Page 130 of the Manual.

SUTARTERIALSPEEDCHANGECOST: This sheet contains all the cost figures necessary in calculating the speed change cost for single unit trucks in Arterial type of highway. It includes the cost figures for a level of service present as well as absent. The 
nomograph listed on page 57 of the Manual entitled "Basic Section Costs (B) for Single Unit Trucks on Arterials" was digitized for this purpose.

SUTTWOLANESPEEDCHANGECOST: This sheet contains data on the speed change cost for single unit trucks in a two-lane or rural highway. It includes the cost figures for a level of service present as well as absent. The nomograph listed on page 56 of the Manual entitled "Basic Section Costs (B) for Single Unit Trucks on Two-Lane Highways" was digitized for this purpose.

SUTMULTILANESPEEDCHANGECOST: This sheet furnishes the data necessary to calculate the speed change cost for Multi-Lane facility for single unit trucks. It includes the cost figures for a level of service present as well as absent. The nomograph listed on page 55 of the Manual entitled "Basic Section Costs (B) for Single Unit Trucks on Multi-Lane Highways" was digitized for this purpose.

SUTFREEWAYSPEEDCHANGECOST: This sheet contains data on speed change cost for single unit trucks on a Freeway. It includes the cost figures for a level of service present as well as absent. The nomograph listed on page 54 of the Manual entitled "Basic Section Costs (B) for Single Unit Trucks on Freeways" was digitized for this purpose.

SUTTTCARTERIALSF: This sheet has the data for travel time cost for single unit trucks on an Arterial facility with a level of service. The nomograph listed on page 57 of the Manual entitled "Basic Section Costs (B) for Single Unit Trucks on Arterials" was digitized for this purpose.

SUTTTCARTERIALNOSF: This sheet has the data for travel time cost for single unit trucks on an Arterial facility without a level of service. The nomograph listed on page 57 of 
the Manual entitled "Basic Section Costs (B) for Single Unit Trucks on Arterials" was digitized for this purpose.

SUTTTCTWOLANESF: This sheet contains data on travel time cost for single unit trucks on a two-lane facility with a level of service, F. The nomograph listed on page 56 of the Manual entitled "Basic Section Costs (B) for Single Unit Trucks on Two-Lane Highways" was digitized for this purpose.

SUTTTCTWOLANENOSF: This sheet contains data on travel time cost for single unit trucks on a two-lane facility without a level of service. The nomograph listed on page 56 of the Manual entitled "Basic Section Costs (B) for Single Unit Trucks on Two-Lane Highways" was digitized for this purpose.

SUTTTCMULTISF: This sheet contains data on the travel time cost for single unit trucks on a Multi-Lane highway with a level of service, F. The nomograph listed on page 55 of the Manual entitled "Basic Section Costs (B) for Single Unit Trucks on Multi-Lane Highways" was digitized for this purpose.

SUTTTCMULTINOSF: This sheet contains data on the travel time cost for single unit trucks on a Multi-Lane highway without a level of service. The nomograph listed on page 55 of the Manual entitled "Basic Section Costs (B) for Single Unit Trucks on Multi-Lane Highways" was digitized for this purpose.

SUTTTCFREEWAYSF: This sheet contains data for travel time cost for single unit trucks on a Freeway having a level of service, F. The nomograph listed on page 54 of the Manual entitled "Basic Section Costs (B) for Single Unit Trucks on Freeways" was digitized for this purpose. 
SUTTTCFREEWAYNOSF: This sheet contains data for travel time cost for single unit trucks on a Freeway having a level of service. The nomograph listed on page 54 of the Manual entitled "Basic Section Costs (B) for Single Unit Trucks on Freeways" was digitized for this purpose.

SUTSPEEDARTERIALNOSF: This sheet contains the average running speed for single unit trucks on an Arterial facility without level of service. These costs are a function of the vehicle to capacity ratio and the design speed. The nomograph listed on page 57 of the Manual entitled "Basic Section Costs (B) for Single Unit Trucks on Arterials" was digitized for this purpose.

SUTSPEEDTWOLANENOSF: This sheet contains the average running speed for a single unit trucks utilizing the Two-Lane highway without a level of service. These costs are a function of the vehicle to capacity ratio and the design speed. The nomograph listed on page 56 of the Manual entitled "Basic Section Costs (B) for Single Unit Trucks on Two-Lane Highways" was digitized for this purpose.

SUTSPEEDMULTINOSF: This sheet has cost figures for average running speed of single unit trucks travelling on a Multi-Lane highway without a level of service. These costs are a function of the vehicle to capacity ratio and the design speed. The nomograph listed on page 55 of the Manual entitled "Basic Section Costs (B) for Single Unit Trucks on Multi-Lane Highways" was digitized for this purpose.

SUTSPEEDFREEWAYNOSF: This sheet has data on average running speed single unit trucks on a Freeway without a level of service. These costs are a function of the vehicle to capacity ratio and the design speed. The nomograph listed on page 54 of the Manual entitled "Basic Section Costs (B) for Single Unit Trucks on Freeways" was digitized for this purpose. 
SUTSPEEDARTERIALSF: This sheet contains the average running speed for single unit trucks on an Arterial facility with a level of service, F. These costs are a function of the vehicle to capacity ratio and the design speed. The nomograph listed on page 57 of the Manual entitled "Basic Section Costs (B) for Single Unit Trucks on Arterials" was digitized for this purpose.

SUTSPEEDTWOLANESF: This sheet contains the average running speed for a single unit trucks utilizing the Two-Lane highway with a level of service, F. These costs are a function of the vehicle to capacity ratio and the design speed. The nomograph listed on page 56 of the Manual entitled "Basic Section Costs (B) for Single Unit Trucks on Two-Lane Highways" was digitized for this purpose.

SUTSPEEDMULTISF: This sheet has cost figures for average running speed of single unit trucks travelling on a Multi-Lane highway with a level of service, F. These costs are a function of the vehicle to capacity ratio and the design speed. The nomograph listed on page 55 of the Manual entitled "Basic Section Costs (B) for Single Unit Trucks on Multi-Lane Highways" was digitized for this purpose.

SUTSPEEDFREEWAYSF: This sheet has data on average running speed single unit trucks on a Freeway with a level of service, F. These costs are a function of the vehicle to capacity ratio and the design speed. The nomograph listed on page 54 of the Manual entitled "Basic Section Costs (B) for Single Unit Trucks on Freeways" was digitized for this purpose.

CTGRADE: This sheet contains the database on the grade costs for $3 \mathrm{~S}-2$ combination trucks. This database was constructed by digitizing the nomographs provided in the Manual. It is function of the grade percent and average running speed. The table is listed as Table B-6, Page 128 of the Manual. 
CTCURVE: This sheet contains the costs due to curves incurred in negotiating curves on the analysis section by $3 \mathrm{~S}-2$ combination trucks. This cost is a function of the degree of curvature and the average running speed. The table is listed as Table B-9, Page 131 of the Manual.

CTARTERIALSPEEDCHANGECOST: This sheet contains all the cost figures necessary in calculating the speed change cost for a $3 \mathrm{~S}-2$ combination trucks in Arterial type of highway. It includes the cost figures for a level of service present as well as absent. The nomograph listed on page 61 of the Manual entitled "Basic Section Costs (B) for 3-S2 Combination Trucks on Arterials" was digitized for this purpose.

CTTWOLANESPEEDCHANGECOST: This sheet contains data on the speed change cost for a $3 \mathrm{~S}-2$ combination trucks in a two-lane or rural highway. It includes the cost figures for a level of service present as well as absent. The nomograph listed on page 60 of the Manual entitled "Basic Section Costs (B) for 3-S2 Combination Trucks on Two-Lane Highways" was digitized for this purpose.

CTMULTLANESPEEDCHANGECOST: This sheet furnishes the data necessary to calculate the speed change cost for Multi-Lane facility for 3 S-2 combination trucks. It includes the cost figures for a level of service present as well as absent. The nomograph listed on page 59 of the Manual entitled "Basic Section Costs (B) for 3-S2 Combination Trucks on Multi-Lane Highways" was digitized for this purpose.

CTFREEWAYSPEEDCHANGECOST: This sheet contains data on speed change cost for 3 S-2 combination trucks on a Freeway. It includes the cost figures for a level of service present as well as absent. The nomograph listed on page 58 of the Manual entitled "Basic Section Costs (B) for 3-S2 Combination Trucks on Freeways" was digitized for this purpose. 
CTTTCARTERIALSF: This sheet has the data for travel time cost for $3 \mathrm{~S}-2$ combination trucks on an Arterial facility with a level of service. The nomograph listed on page 61 of the Manual entitled "Basic Section Costs (B) for 3-S2 Combination Trucks on Arterials" was digitized for this purpose.

CTTTCARTERIALNOSF: This sheet has the data for travel time cost for 3 S-2 combination trucks on an Arterial facility without a level of service. The nomograph listed on page 61 of the Manual entitled "Basic Section Costs (B) for 3-S2 Combination Trucks on Arterials" was digitized for this purpose.

CTTTCTWOLANESF: This sheet contains data on travel time cost for $3 \mathrm{~S}-2$ combination trucks on a two-lane facility with a level of service, F. The nomograph listed on page 60 of the Manual entitled "Basic Section Costs (B) for 3-S2 Combination Trucks on Two-Lane Highways" was digitized for this purpose.

CTTTCTWOLANENOSF: This sheet contains data on travel time cost for 3 S-2 combination trucks on a two-lane facility without a level of service. The nomograph listed on page 60 of the Manual entitled "Basic Section Costs (B) for 3-S2 Combination Trucks on Two-Lane Highways" was digitized for this purpose.

CTTTCMULTISF: This sheet contains data on the travel time cost for 3 S-2 combination trucks on a multi-lane highway with a level of service, F. The nomograph listed on page 59 of the Manual entitled "Basic Section Costs (B) for 3-S2 Combination Trucks on Multi-Lane Highways" was digitized for this purpose.

CTTTCMULTINOSF: This sheet contains data on the travel time cost for $3 \mathrm{~S}-2$ combination trucks on a multi-lane highway without a level of service. The nomograph listed 
on page 59 of the Manual entitled "Basic Section Costs (B) for 3-S2 Combination Trucks on Multi-Lane Highways" was digitized for this purpose.

CTTTCFREEWAYSF: This sheet contains data for travel time cost for $3 \mathrm{~S}-2$ combination trucks on a freeway having a level of service, F. The nomograph listed on page 58 of the Manual entitled "Basic Section Costs (B) for 3-S2 Combination Trucks on Freeways" was digitized for this purpose.

CTTTCFREEWAYNOSF: This sheet contains data for travel time cost for 3 S-2 combination trucks on a Freeway having a level of service. The nomograph listed on page 58 of the Manual entitled "Basic Section Costs (B) for 3-S2 Combination Trucks on Freeways" was digitized for this purpose.

CTSPEEDARTERIALNOSF: This sheet contains the average running speed for a $3 \mathrm{~S}-2$ combination trucks on an Arterial facility without level of service. These costs are a function of the vehicle to capacity ratio and the design speed. The nomograph listed on page 61 of the Manual entitled "Basic Section Costs (B) for 3-S2 Combination Trucks on Arterials" was digitized for this purpose.

CTSPEEDTWOLANENOSF: This sheet contains the average running speed for 3 S-2 combination trucks utilizing the Two-Lane highway without a level of service. These costs are a function of the vehicle to capacity ratio and the design speed. The nomograph listed on page 60 of the Manual entitled "Basic Section Costs (B) for 3-S2 Combination Trucks on Two-Lane Highways" was digitized for this purpose.

CTSPEEDMULTINOSF: This sheet has cost figures for average running speed of $3 \mathrm{~S}-2$ combination trucks travelling on a Multi-Lane highway without a level of service. These costs are a function of the vehicle to capacity ratio and the design speed. The nomograph 
listed on page 59 of the Manual entitled "Basic Section Costs (B) for 3-S2 Combination Trucks on Multi-Lane Highways" was digitized for this purpose.

CTSPEEDFREEWAYNOSF: This sheet has data on average running speed 3 S-2 combination trucks on a Freeway without a level of service. These costs are a function of the vehicle to capacity ratio and the design speed. The nomograph listed on page 58 of the Manual entitled "Basic Section Costs (B) for 3-S2 Combination Trucks on Freeways" was digitized for this purpose.

CTSPEEDARTERIALSF: This sheet contains the average running speed for 3 S-2 combination trucks on an Arterial facility with a level of service, F. These costs are a function of the vehicle to capacity ratio and the design speed. The nomograph listed on page 61 of the Manual entitled "Basic Section Costs (B) for 3-S2 Combination Trucks on Arterials" was digitized for this purpose.

CTSPEEDTWOLANESF: This sheet contains the average running speed for a 3 S-2 combination trucks utilizing the Two-Lane highway with a level of service, F. These costs are a function of the vehicle to capacity ratio and the design speed. The nomograph listed on page 60 of the Manual entitled "Basic Section Costs (B) for 3-S2 Combination Trucks on Two-Lane Highways" was digitized for this purpose.

CTSPEEDMULTISF: This sheet has cost figures for average running speed of 3 S-2 combination trucks travelling on a Multi-Lane highway with a level of service, F. These costs are a function of the vehicle to capacity ratio and the design speed. The nomograph listed on page 59 of the Manual entitled "Basic Section Costs (B) for 3-S2 Combination Trucks on Multi-Lane Highways" was digitized for this purpose. 
CTSPEEDFREEWAYSF: This sheet has data on average running speed for 3 S-2 combination trucks on a Freeway with a level of service, F. These costs are a function of the vehicle to capacity ratio and the design speed. The nomograph listed on page 58 of the Manual entitled "Basic Section Costs (B) for 3-S2 Combination Trucks on Freeways" was digitized for this purpose.

\subsection{Internal Working and the File Structure}

This section describes the internal working of the software. The Visual Basic ${ }^{\circledR} 5$ project is stored in a file named HighwayCosts.vbp. This file is converted to an executable file titled "HighwayCosts.exe". This is an executable file meaning that the source code is not available for editing. The executable file includes all the system files (.sys files), dynamic link library files (.dll files) and ActiveX control files (.ocx files). All of the files needed to install the software are available in the Setup.exe. Once the Setup.exe file is run, the setup wizard is activated. It tells in a systematic manner how to install the software and dependent files including the database. The database is stored in two files. The 1975 cost tables are stored in a file named base.xls and the latest cost tables after updating from 1975 cost tables

are stored in current.xls. The base.xls and the current.xls files are stored in a directory labeled "Database". The setup files are located in the directory called "Setup". These files are already installed on the West Virginia Division of Highway server.

The software works when the HighwayCosts.vbp file (The Visual Basic ${ }^{\circledR} 5$ Project file) which has all the forms and module binds to the database using the Data Control Objects. These establish a link between the user and the database. Different tables are accessed according to the input characteristics. Sets of interpolation are carried out to 
compute the costs when the inputs are intermediate between two points in the nomographs. Extrapolation is strictly avoided because the characteristic of the graph is unknown beyond the end points. The software source code and its various components are included in the appendices.

Updating technique is based on the formulas described in Chapter 3. Updating is always done with the 1975 cost tables as the base to minimize round off errors. This is the reason base.xls file (the file having the 1975 cost tables) is present along with the current price table (current.xls). When the user chooses to update the cost tables, a connection is established with the base.xls file. Costs are updated according to the formulas described in Chapter 3. As soon as the updating is done, the base.xls is saved as current.xls dynamically by the code written. This ensures that the base.xls file stays unchanged and a new current.xls is created and ready for referral.

\subsection{Valid Ranges for Inputs and Parameters}

User inputs have to be consistent and valid for the proper functioning of the software. Also, calculations can be completed only if all the required inputs are entered. Several displays and error messages are designed to alert the user in case of missing or inconstitent inputs. In the following, a number of possible inconsistencies are discussed.

The set of valid inputs to the software and their ranges are described in this section. It is important that the inputs be within the ranges specified in order to produce correct results. If the inputs are out of range, a warning message will be displayed as "Inputs Out of Range". At this point the user is asked to reenter a valid input before the user can proceed.

The maximum number of sections that can be analyzed for a project is limited to 50 . This limit has been determined in consultation with the WVDOH officials. Entering a project 
title is mandatory. The vehicle mix must consist of passenger cars. Percentages of Single Unit Trucks and 3 S-2 Combination Trucks must be entered even if they are equal to zero.

The Basic Section Cost starts with computing the average running speed. The user must select a unique facility and a corresponding service level $(\mathrm{F})$ of yes (Service Level F is present) or no (Service Level $\mathrm{F}$ is not present). The volume to capacity ratio ranges from 0 to 1 in increments of 0.10 . The design speed for Freeway facility is $70 \mathrm{mph}, 60 \mathrm{mph}$ and 50 mph. This is the same for a Multi-Lane highway facility. The design speed for two-lane highway ranges from $40 \mathrm{mph}$ to $70 \mathrm{mph}$ in increments of $10 \mathrm{mph}$. An Arterial facility has a range of $25 \mathrm{mph}$ to $45 \mathrm{mph}$ in increments of $10 \mathrm{mph}$. These values are the same for single unit trucks and $3 \mathrm{~S}-2$ combination trucks.

To compute the travel time cost, the user must enter the hourly value of time in dollars. The grade costs are a function of the average running speed and grade percentages. The grade percentage ranges from -8 to 8 in increments of one unit. That means that a grade percent of 0.5 would be a wrong input.

The curve costs is a function of the average running speed and degree of curvature. The curve ranges from 1 to 30 . This range of values applies also to single unit trucks and 3S-2 combination trucks.

Transition costs depend on the initial speed and speed reduced and returned to. Valid values for the initial speed range from $80 \mathrm{mph}$ to $5 \mathrm{mph}$ in increments of $5 \mathrm{mph}$. The reduced and returned to speed ranges from $75 \mathrm{mph}$ to $0 \mathrm{mph}$ (complete stop) in increments of $5 \mathrm{mph}$.

Intersection delay cost depends on the volume of the traffic on the road at the intersection, capacity of the road, signal cycle time, effective green time and the intersection approach speed (the range is from $5 \mathrm{mph}$ to $55 \mathrm{mph}$ ). Intermediate values such as lambda, 
capacity of approach and chi are computed depending on the above inputs. These inputs must be such that the intermediate values computed fall in specific ranges. The value of computed lambda must be between 0.2 and 0.8 . The value of capacity of approach is between 200 and 4,400. The value of chi is between 0.1 and 0.8 .

The above mentioned ranges conform to the nomographs given in the Manual and must be strictly followed.

In most cases, the user is required to enter a value for a variable or choose from a drop-down menu. If the value entered is not included in the drop-down menu, the software will not respond. For example, valid choices for the design speed for a Freeway are 70 miles per hour, 60 miles per hour and 50 miles per hour. Any speed other than the abovementioned values, such as 65 miles per hour, will result in the software not responding to the input. Another example is the user input for vehicle to capacity ratio. It has a range from 0 to 1 in steps of 0.1 . An input of 0.25 would be considered inconstitent. The software also assumes that percentage of cars is greater than zero for every section of a project. An input of zero percent for cars will cause an error message to be displayed.

\subsection{Example}

The following example illustrates the use of the software. The software essentially does three tasks, namely calculating the user costs for a highway project, update the costs so that the most recent cost tables are used, and perform an economic analysis to determine project feasibility and comparison of alternatives.

The user enters the number of section in the screen shown in Figure 4.4. In this example, the title of the project is Morgantown-Grafton and the number of section is 1 . Inputs for Basic Section cost shown in Table 4.2 are common for all type of vehicles 
irrespective of the vehicle mix. The inputs for a particular vehicle type belonging to the vehicle mix are shown in the Table 4.3.

\begin{tabular}{|l|l|}
\hline \multicolumn{1}{|c|}{ Inputs } & \\
\hline Facility & Freeway \\
\hline Service Level & No \\
\hline V/C Ratio & 0.6 \\
\hline Design Speed (mph) & 70.0 \\
\hline Grade (\%) & -3.0 \\
\hline Curve Angle & 4.0 \\
\hline Road Type & High Type Surface \\
\hline
\end{tabular}

Table 4.2: Inputs for Basic Section Cost.

\begin{tabular}{|l|l|l|l|}
\hline Inputs for Section 1 & $\begin{array}{l}\text { Passenger } \\
\text { Cars }\end{array}$ & $\begin{array}{l}\text { Single Unit } \\
\text { Trucks }\end{array}$ & $\begin{array}{l}\text { 3 S-2 Combination } \\
\text { Trucks }\end{array}$ \\
\hline Percentages & 100 & 0 & 0 \\
\hline Average Speed (mph) & 50 & 0 & 0 \\
\hline Hourly value of Time (\$) & 10 & 0 & 0 \\
\hline Travel Time Cost & 616 & 0 & 0 \\
\hline Grade Cost & 174 & 0 & 0 \\
\hline Curve Cost & 37 & 0 & 0 \\
\hline Speed Change Cost & 5 & 0 & 0 \\
\hline Basic Section Cost & 832 & 0 & 0 \\
\hline Total Basic Section Cost (\$ per 1000 & & 832 \\
\hline Vehicle Miles) & & & \\
\hline
\end{tabular}

Table 4.3: Inputs for Basic Section Cost for the Vehicle Mix. 
Table 4.4 shows the input for the accident cost. The three inputs for the accident costs are the number of fatal accidents, the number of Injury Accidents and number of Property Damage Accidents per year.

\begin{tabular}{|l|l|}
\hline FATAL ACCIDENT & 1 \\
\hline INJURY ACCIDENT & 2 \\
\hline PROPERTY DAMAGE & 3 \\
\hline ACCIDENT COST (\$ PER YEAR) & $1,067,400$ \\
\hline
\end{tabular}

Table 4.4: The Accident Cost Table

Table 4.5 and Table 4.6 show the input for the Transition Costs and Intersection Delay Costs respectively.

\begin{tabular}{|l|l|}
\hline \multicolumn{1}{|c|}{ Inputs for Transition Cost } & \\
\hline Initial Speed (mph) & 40 \\
\hline Final Speed (mph) & 30 \\
\hline Direction & Two-Way Section Cost \\
\hline Transition Cost (\$/ 1000 Vehicles) & 8 \\
\hline
\end{tabular}

Table 4.5: Inputs for Transition Cost 


\begin{tabular}{|l|l|}
\hline \multicolumn{1}{|c|}{ Inputs for Intersection Delay Cost } & \\
\hline Volume & 480 \\
\hline Saturation Flow & 1650 \\
\hline Signal Cycle Time & 60 \\
\hline Green Time & 30 \\
\hline Intersection Approach Speed & 30 \\
\hline Lambda & 0.5 \\
\hline Capacity of Approach & 825 \\
\hline Chi & 0.58 \\
\hline Delay Cost (\$ per 1000 Vehicles) & 49 \\
\hline Number of Intersections & 5 \\
\hline Idling Cost (\$ per 1000 Vehicles) & 198 \\
\hline Intersection Delay Cost (\$ per 1000 Vehicles) & 1,235 \\
\hline
\end{tabular}

Table 4.6: Inputs for the Intersection Delay Cost

The length of the section is 5 miles and the annual daily traffic is 1,450 . The formula for the Total Road User Cost is executed and the calculated value is $\$ 3,926,938$ per year. The average AADT is also 1,450 and the Total yearly cost per 1000 daily vehicles $\$ 2,708$. 


\section{Chapter 5: Conclusions and Recommendations for Future Research}

\subsection{Conclusions}

“A Manual on User Benefit Analysis of Highway and Bus-Transit Improvements " published in 1977 by AASHTO provides guidelines for road user cost. Unfortunately, the use of the Manual is cumbersome and error-prone. In order to address this problem, an application software was developed based on the 1977 Manual. The 1977 Manual is a product of research sponsored by NCHRP. The project entitled "Highway User Economic Analysis" was performed under NCHRP Project 2-12 and formed the basis for the cost tables and nomographs in the Manual.

The application software reported here was been developed for the WVDOH to facilitate the computation of road-user cost, which forms one of the most important components of the highway transportation costs. Federal regulations require all state departments of transportation to conduct an economic analysis for all projects costing over twenty five million dollars.

This software provides highway planners with easy to use capabilities to perform benefit-cost analysis for individual projects as well as compare various alternatives based on several engineering economy criteria. This software can be used to compute the road user cost for a project with up to fifty sections with varying characteristics. The road user cost are calculated as annualized costs. Provisions are made for updating the cost tables as the latest consumer price indices and producer price indices become available. Net Present Value analysis has been used as an engineering economy tool to conduct the economic analysis. All components of costs that are incurred over the life cycle of a project are included in the 
economic analysis. These include construction costs, maintenance costs, right of way costs, residual costs and road user cost.

Visual Basic $^{\circledR} 5$ has proved to be an effective front-end tool interacting with the database tables stored in Microsoft Excel. The software can be used to perform analysis on new projects as well as those which have been analyzed previously and saved in a file. The user can also add, delete, or modify a section as and when required.

\subsection{Recommendations for Future Research}

A lot of research is going on in the field of Engineering Economy. New concepts are born that can be used to further enhance the basis for economic justification of a project. Net Present Value method can be used to decide whether a project is economically feasible or not; but it alone cannot justify economic decisions. Enhanced version of the Net Present Value techniques, which may include probabilistic approaches and risk factor analysis, can be incorporated in future research.

New software application can be developed to integrate the current application with other highway evaluation applications. Various manuals such as the Highway Capacity Manual can be consulted dynamically. The current application can be further developed into a full-fledged decision support system. As an extension of this project, it is also recommended to make this application web-based so that other state DOT's can use it. 


\section{References}

1. American Association of State Highway Officials. (1952). Road User Cost Benefit Analysis Improvements. Washington, DC.

2. Anderson, D. G., Curry, D. A., and Pozdena, R. J. (1977). User Benefit Analysis for Highway and Bus Transit Improvements. Final Report NCHRP Project 2-12, Stanford Research Institute, Meleno Park, CA. (Published as A Manual on User Benefit Analysis of Highway and Bus-Transit Improvements, 1977 by the American Association of State Highway and Transportation Officials).

3. Bureau of Labor Statistics. [On-Line]. Available: http://www.bls.gov

4. Claffey, P. J. (1971). Running Costs of Motor Vehicles as Affected by Road Design and Traffic, National Cooperative Highway Research Program (NCHRP) Report No. 111.

5. Curry, D. A., and Anderson, D. G. (1972). Procedures for Estimating Highway User Costs, Air Pollution, and Noise Effects, National Cooperative Highway Research Program (NCHRP) Report No. 133. pp.127.

6. DeCorla-Souza, P., Cohen, H., Haling, D., and Hunt, J. (1997). Using Steam for BenefitCost Analysis of Transportation Alternatives, Prepared for Consideration for presentation at the 1998 Annual Meeting of the Transportation Research Board, Paper No. 980083. pp.1-7.

7. Dell' Isola, A. J. and Kirk, S. J. (1981). Life Cycle Costing for Design Professionals. New York. McGraw-Hill.

8. Douglas H. (1997). Visual Basic ${ }^{\circledR} 5$ Bible. CA. IDG Books Worldwide, Inc.

9. Federal Highway Administration (1994). Highway Economy Requirements System (HERS)-Overview. Volume 2. 
10. Federal Highway Administration (1995). Highway Economy Requirements System (HERS)-User's Guide. Volume 3.

11. Federal Highway Administration (1996). Highway Economy Requirements System (HERS)-Technical Report. Volume 4.

12. Federal Highway Administration Policy Memorandum (1996). National Highway System Designation Act. Life-Cycle Cost Analysis Requirements. [On-Line]. Available: http://www.fhwa.dot.gov/legsreg/directives/policy/lcca.htm

13. Frye, F. F. (1973). Alternative Multimodal Passenger transportation Systems-A Comparative Analysis. National Cooperative Highway Research Program (NCHRP). Report 146. pp.68.

14. Hickling Lewis Brod, Inc. StratBENCOST. [On-Line]. Available: http://www.hlbecon.com/web1/prod02.htm

15. Lindow, E. S. (1978). Systems Approach to Life-Cycle Design of Pavements, Vol 1, Life 2 Users Manual, Report No. CERL-TR-M-253, Construction Engineering Research Laboratory, Dept of Army.

16. National Cooperative Highway Research Program (1993). MicroBENCOST User's Manual. Project 7-12, Texas Transportation Institute, The Texas A\&M University System. College Station, Texas.

17. National Cooperative Highway Research Program. Microcomputer Evaluation of Highway User Benefits. Project 7-12. [On-Line]. Available: http://www2.nas.edu/trbcrp/25a2.html 
18. National Cooperative Highway Research Program. Research Strategies for Improving Highway User Cost-Estimating Methodologies. Project 2-18. [On-Line]. Available: http://www2.nas.edu/trbcrp/689a.html

19. National Cooperative Highway Research Program. Development of an Innovative Highway User-Cost Estimation Procedure. Project 2-18/3. [On-Line]. Available: http://www2.nas.edu/trbcrp/68fa.html

20. National Cooperative Highway Research Program (1998). Summary of Progress, Transportation Research Board, National Research Council. Washington, DC.

21. National Safety Council (1997). Estimating the Cost of Unintentional Injuries. [On-Line]. Available: http://www.nsc.org/lrs/statinfo/estcost7.htm

22. Oglesby, C. H. and Hicks, R. G. (1982). Highway Engineering. (4th Edition). New York. Wiley.

23. Peterson, D. E. (1985). Life-Cycle Cost Analysis of Pavements, National Cooperative Highway Research Program Synthesis of Highway Practice, Highway Research Board, National Research Council.

24. Stanford Research Institute (1961). Economics of Asphalt and Concrete for Highway Construction. Report No. SRI Project IE-3153, American Petroleum Institute, New York.

25. Thomas, E. N. and Schofer, J. L. (1970). Strategies for the Evaluation of the Alternative Transportation Plans. National Cooperative Highway Research Council (NCHRP). Report 96. pp.111.

26. Winfrey, R., and Zellner, C. (1971). Summary and Evaluation of Economic Consequences of Highway Improvements, National Cooperative Highway Research Program (NCHRP) Report No. 122. pp.324. 
27. Winfrey, R. (1968). Economic Analysis for Highways. Scranton, PA. International Textbook.

28. Wright, H. P (1996). Highway Engineering. (6th Edition). New York. John Wiley \& Sons, Inc. 


\section{Appendix A: Software Manual}

\section{West Virginia Department of Transportation Division of Highways}

Highway Cost-Benefit Analysis System Software User's Manual 


\section{INTRODUCTION}

The software described in this manual was developed to facilitate the use of the 1977 American Association of State Highway and Transportation Officials (AASHTO) manual entitled "A Manual on User Benefit Analysis of Highway and Bus Transit Improvements". It

performs all cost calculations stipulated in the Manual to compute road user cost for a highway construction or improvement project. In addition, the software can be used to perform cost-benefit analysis for a single project and comparison of various alternatives.

The software consists of the following two main modules:

1) User Cost-Benefit Application, and

2) Economic Analysis.

The first module is designed to calculate the road user cost for the construction or refurbishment of "uniform" highway sections. It is thus necessary to divide the project under consideration into sections of reasonably similar geometric characteristics and traffic conditions before using this module. This module is also used to update the road user cost tables.

The Economic Analysis module is designed to help determine whether a given project or certain project alternatives can be deemed economically justifiable.

Cost tables stored in this software must be updated annually so that project costs are calculated using the most up-to-date cost figures. 


\section{SOFTWARE OPERATION}

After clicking on the "Road User" icon in Windows, the "Welcome Screen", shown in Figure A1, will be displayed.

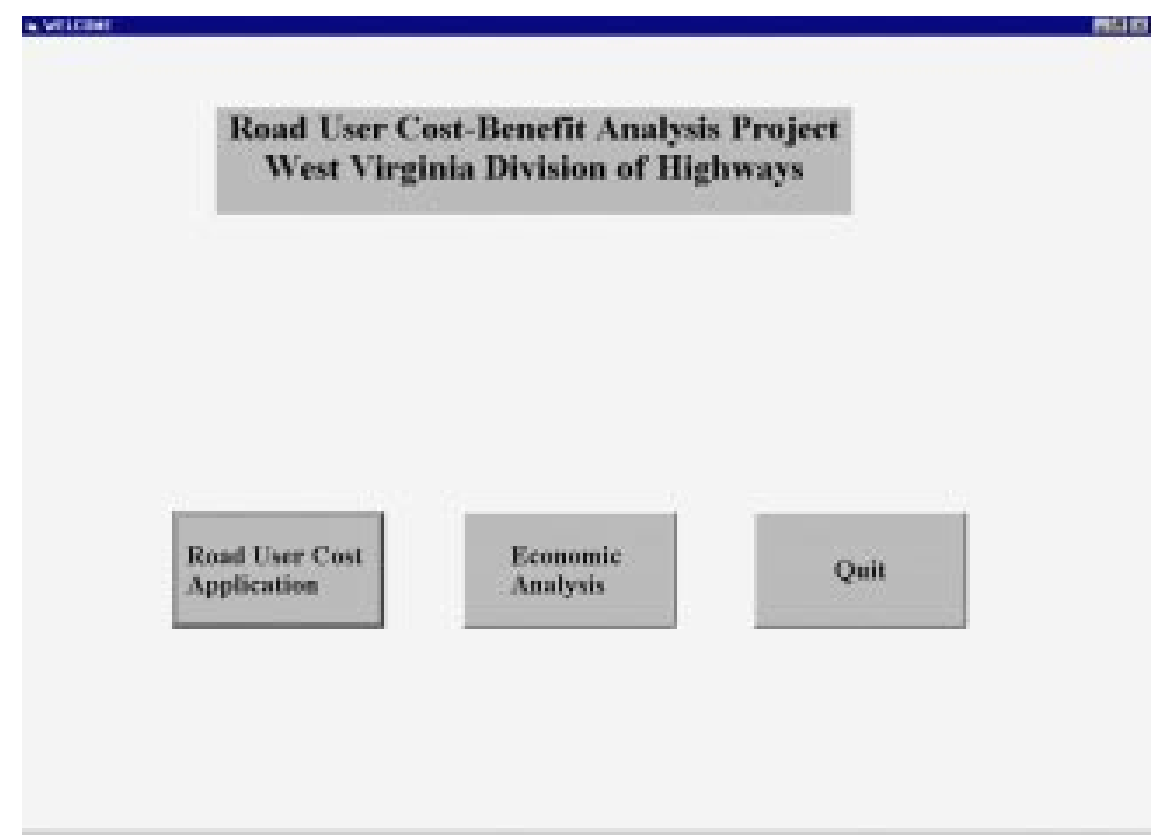

Figure A1: The Welcome Screen

This screen has three buttons. The first button invokes a screen entitled "Road User

Cost Application" as shown in Figure A2. The "Economic Analysis" button is used to perform economic calculations for a single project or comparisons of two alternative projects. Clicking on the third button, "Quit" ends the program.

The "Road User Cost Application" screen has three command buttons. The first button, labeled "Calculate Project Cost-Benefit", is used to calculate road user cost for a project having different sections of varying characteristics. The calculated costs, in dollars per thousand vehicles, are those incurred by the road users. 


\section{Road User Cost Application}
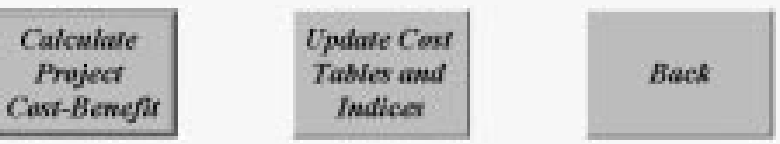

Figure A2: The Road User Cost Application Screen

The middle command button which is labeled "Update Cost Tables and Indices" is used to update the cost tables and consumer price indices for various cost components. This is a task that must be done on an annual basis. The method of updating costs is explained in subsequent sections. The "Back" button will take the user to the previous screen.

Clicking on the "Calculate Project Cost-Benefit" button will invoke a new screen, entitled "Startup", as shown in Figure A3. This screen is used for both new projects and existing projects that have already been saved. 


\section{Open an \\ Existing \\ Project}

Back ex

Figure A3: The Startup Screen

\subsection{Cost Calculations for a New Project}

Clicking on the "New Project" button brings up the "Number of Sections" screen, shown in Figure A4. The user can see the year for the cost figures in the top display box. If the year displayed is not the most recent year for which the consumer price indices are available, the user must go back to the screen shown in Figure A2 and proceed first to update the cost tables based on the latest indices. The second input is an alphanumeric title for the project. An example of the name of the project is "Morgantown-Grafton Route 22". A brief description of the project and some notes can be entered into the "Comments" section. The next required input is the box where the user has to enter the number of sections. A "section" is defined as a road segment that possesses characteristics considered to be fairly homogeneous; it may be considered as the average of its smaller subsections. 


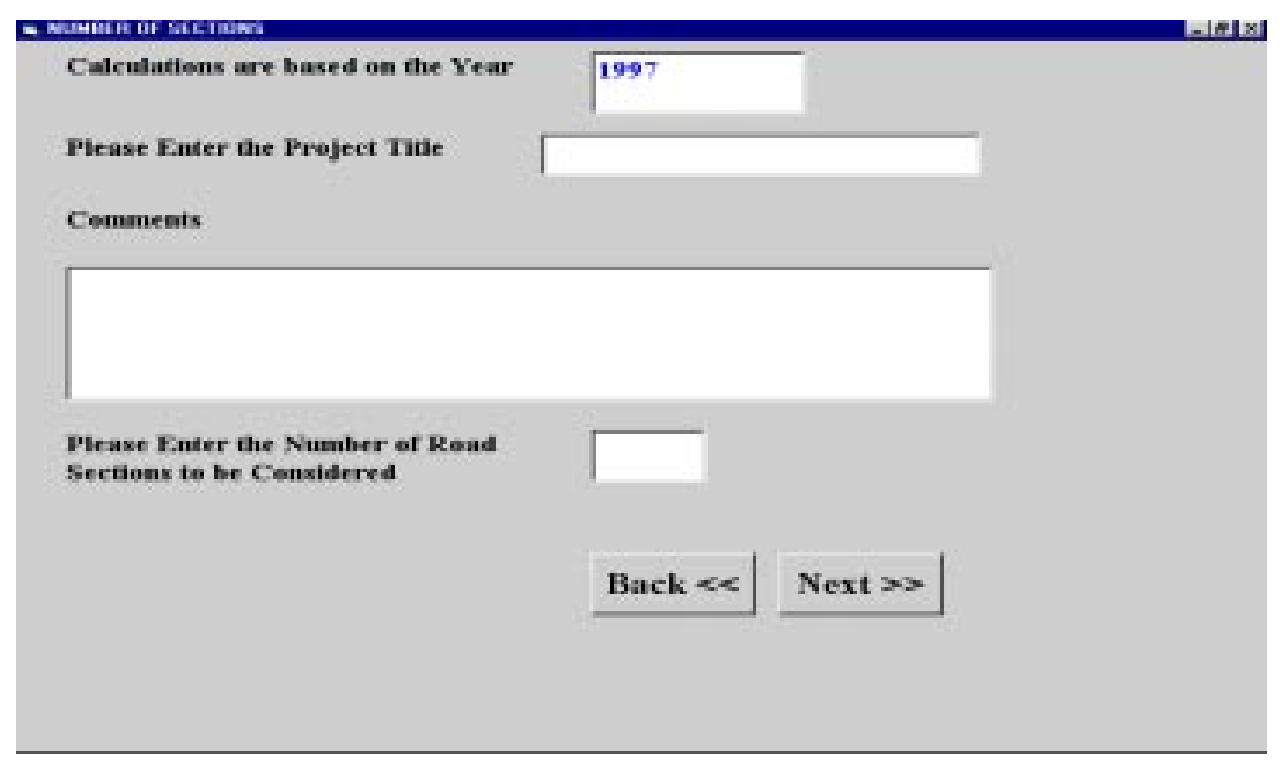

Figure A4: The Number of Sections Screen

The term "characteristic" is defined as the various attributes of a highway such as the grade percent or curve angle or the type of road surface. The software allows a maximum of fifty sections to be included in each project. After entering all the information in the input boxes, the user clicks on the "Next" button which will invoke the screen labeled "Main Screen", as shown in Figure A5. This screen has four command buttons, namely "Basic Section Cost", "Accident Cost", "Intersection Delay Cost" and "Transition Cost." The section number is displayed on the top of the screen. It starts with section 1 and is automatically updated. This ensures that the user completes all the sections one after another.

A helpful feature of the software is the color of the four buttons, which is gray at the outset. However, once a button is pressed and all calculations for that component are completed, the button changes color to white. After all the cost components are calculated, and all the buttons have changed colors to white, a button labeled "Next" appears, which the user must press to go to the next screen. 


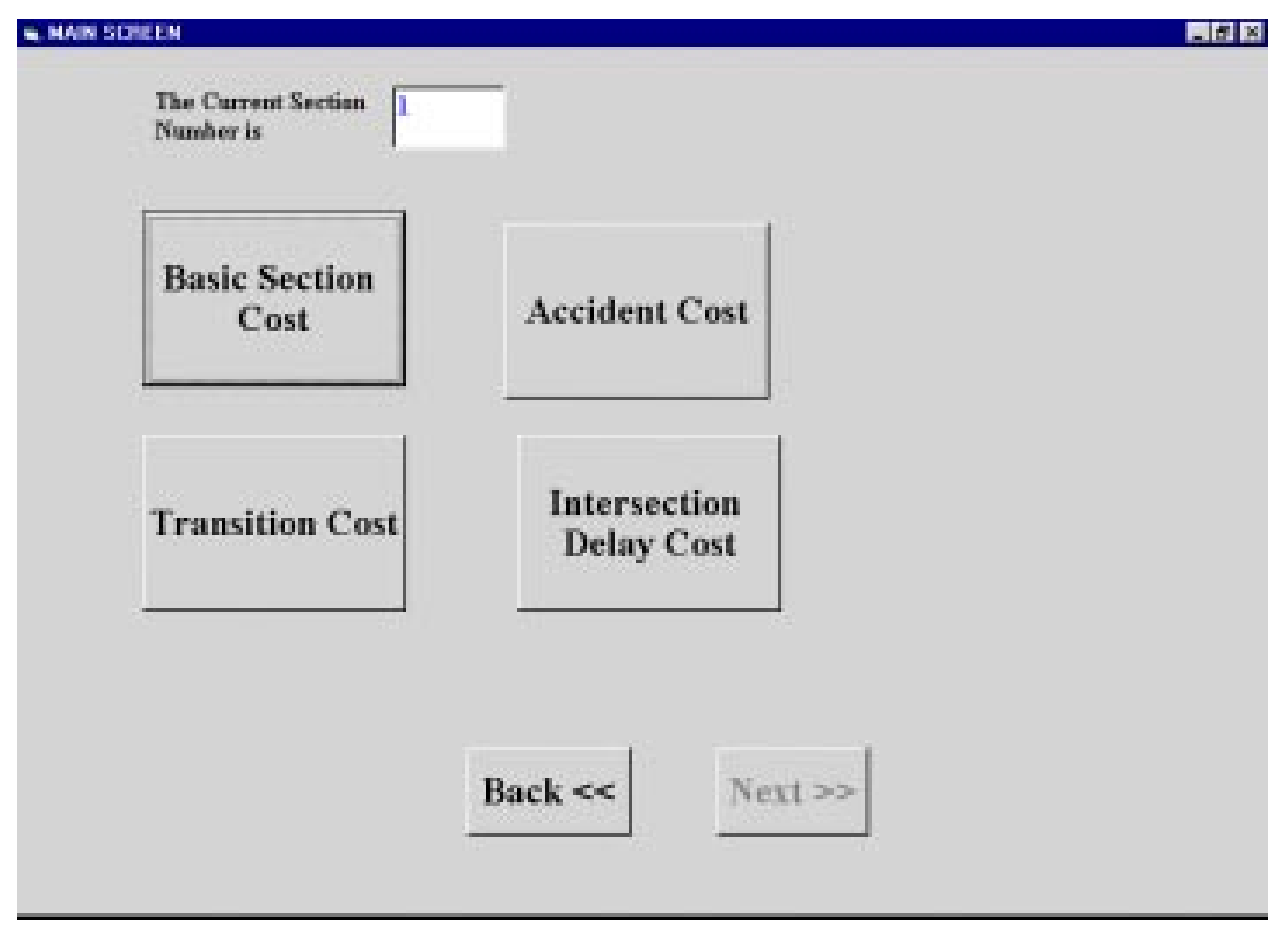

Figure A5: The Main Screen

Pressing the "Basic Section Cost" button invokes a screen entitled "Vehicle Mix", shown in Figure A6. The user is required to enter the percentages of "Passenger cars", "Single Unit Trucks" and " 3 S-2 Combination Trucks" that make up the vehicle mix for the section. If the volume of any of these vehicle types is considered to be negligible, a value of zero must be entered for that type. The sum of the percentages must equal to 100; otherwise an error message will be displayed. When all the percentages are entered, the user clicks on "Next" button to go to the next screen entitled "Basic Section Costs for Passenger Cars". 


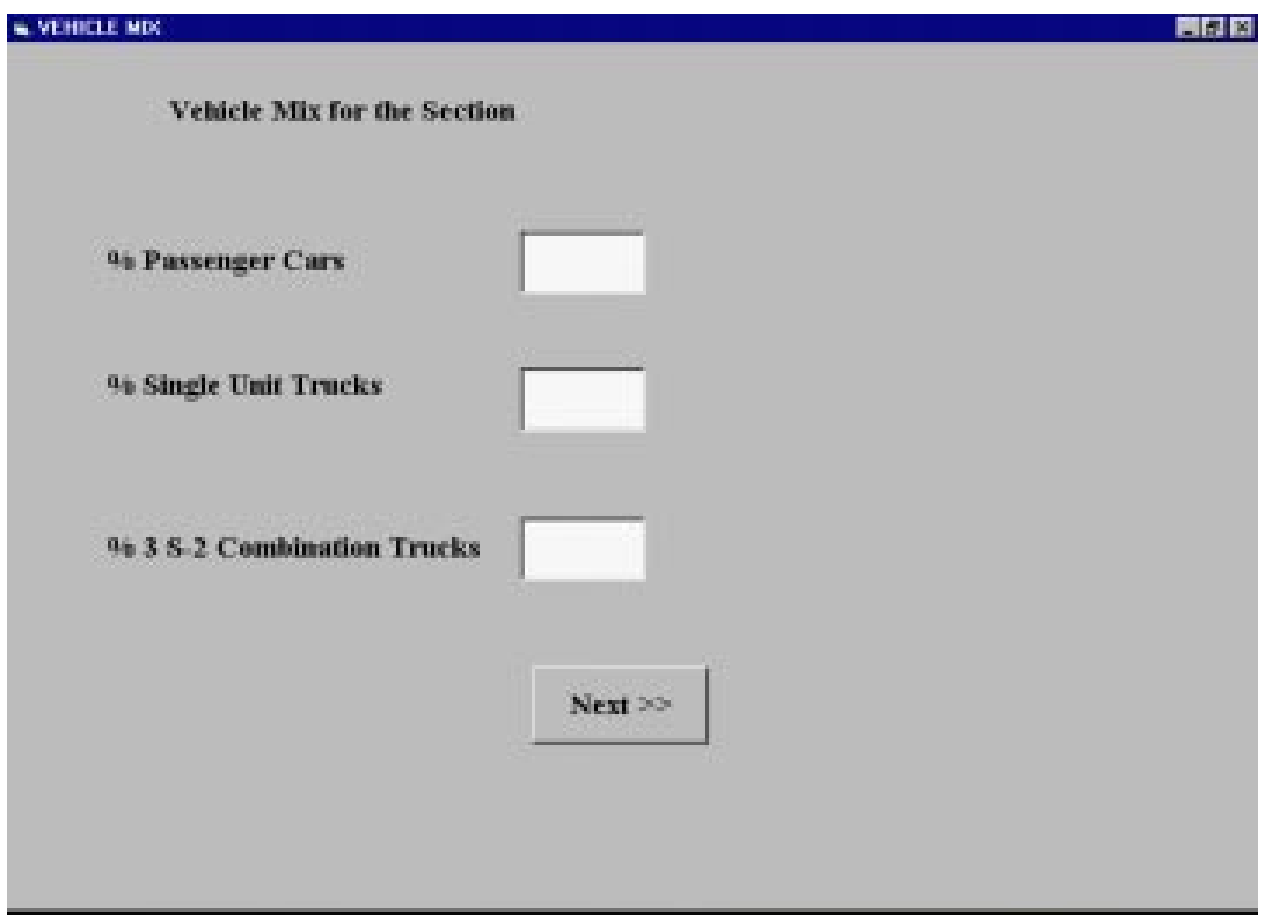

Figure A6: The Vehicle Mix Screen

The screen entitled "Basic Section Cost for Passenger Cars" is shown in Figure A7. The user is prompted to enter the type of highway under consideration. The possible choices are "Freeway", "Multi-lane Highway", "Two-Lane Rural Highway" and "Urban Arterial". These buttons are called "option buttons" since only one choice is accepted from the user. The next input is whether the level of service $(\mathrm{F})$ or queuing is present or not. The user must click on either "Yes" or "No." The next required input is the volume to capacity (V/C) ratio. A drop-down menu appears that shows all acceptable V/C ratios. The next input is for the design speed, which must be selected from one of the values shown in the drop-down menu. 


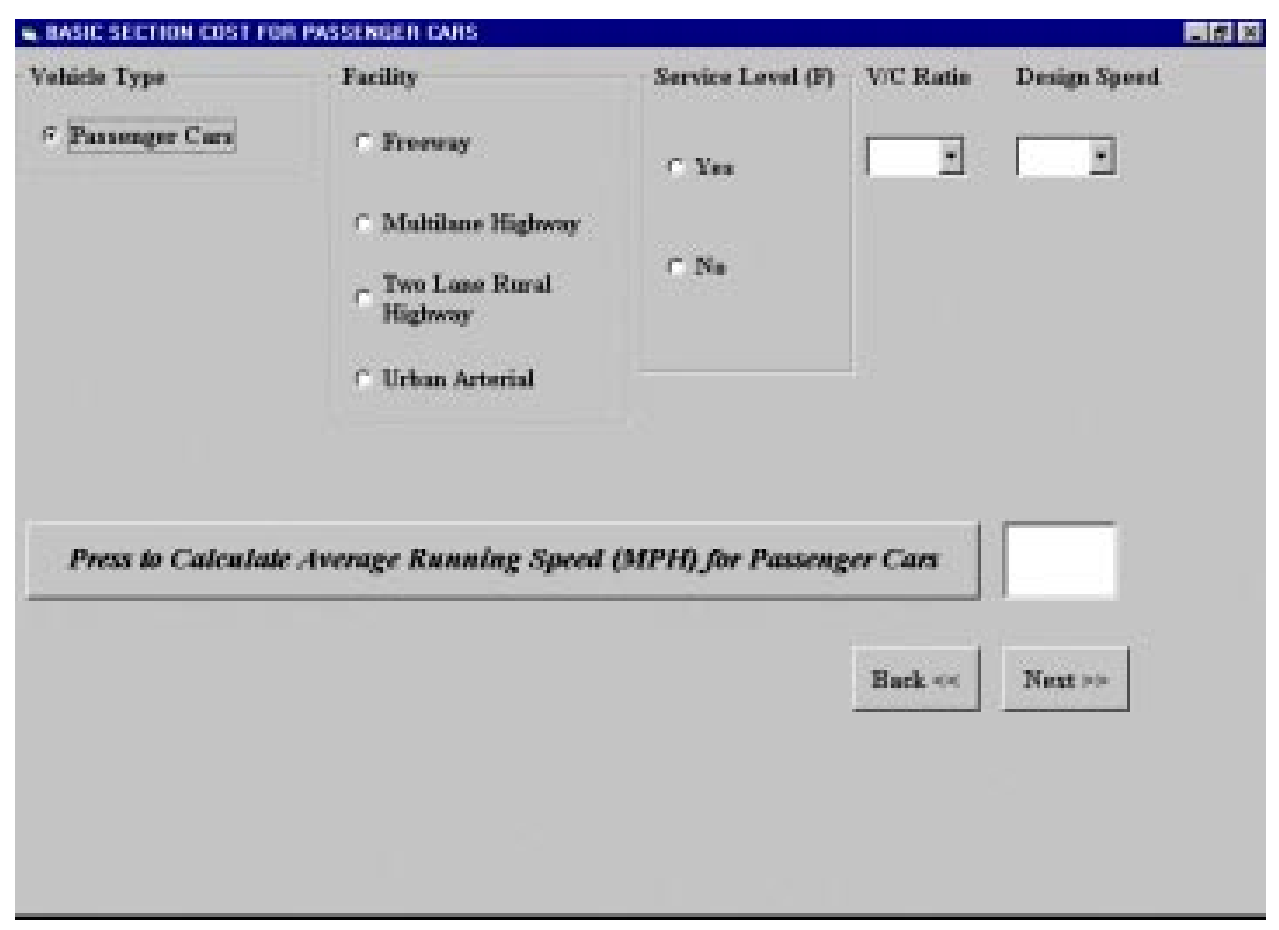

Figure A7: The Basic Section Cost for Passenger Cars Screen

Design speed is defined as the speed selected for the purposes of design in correlation with specific features of the highway, such as curvature, super-elevation, and sight distance, on which the safe operation of a vehicle depends. The average running speed is calculated on the basis of the given inputs with the press of the button "Press to Calculate Average Running Speed". The average running speed is defined as the summation of distance traveled by all vehicles or a specified class of vehicles over a given section of highway during a specified period of time, divided by the total travel time. The user must then click on the "Next" button to go to a new screen entitled "Travel Time Cost for Passenger Cars", as shown in Figure A8. For the convenience of the user, various components of the Basic Section Cost (i.e. travel time cost, grade cost, curve cost, and the speed change cost) are shown in different screens. The user is automatically led to each of these screens after clicking on the "Next" button. 


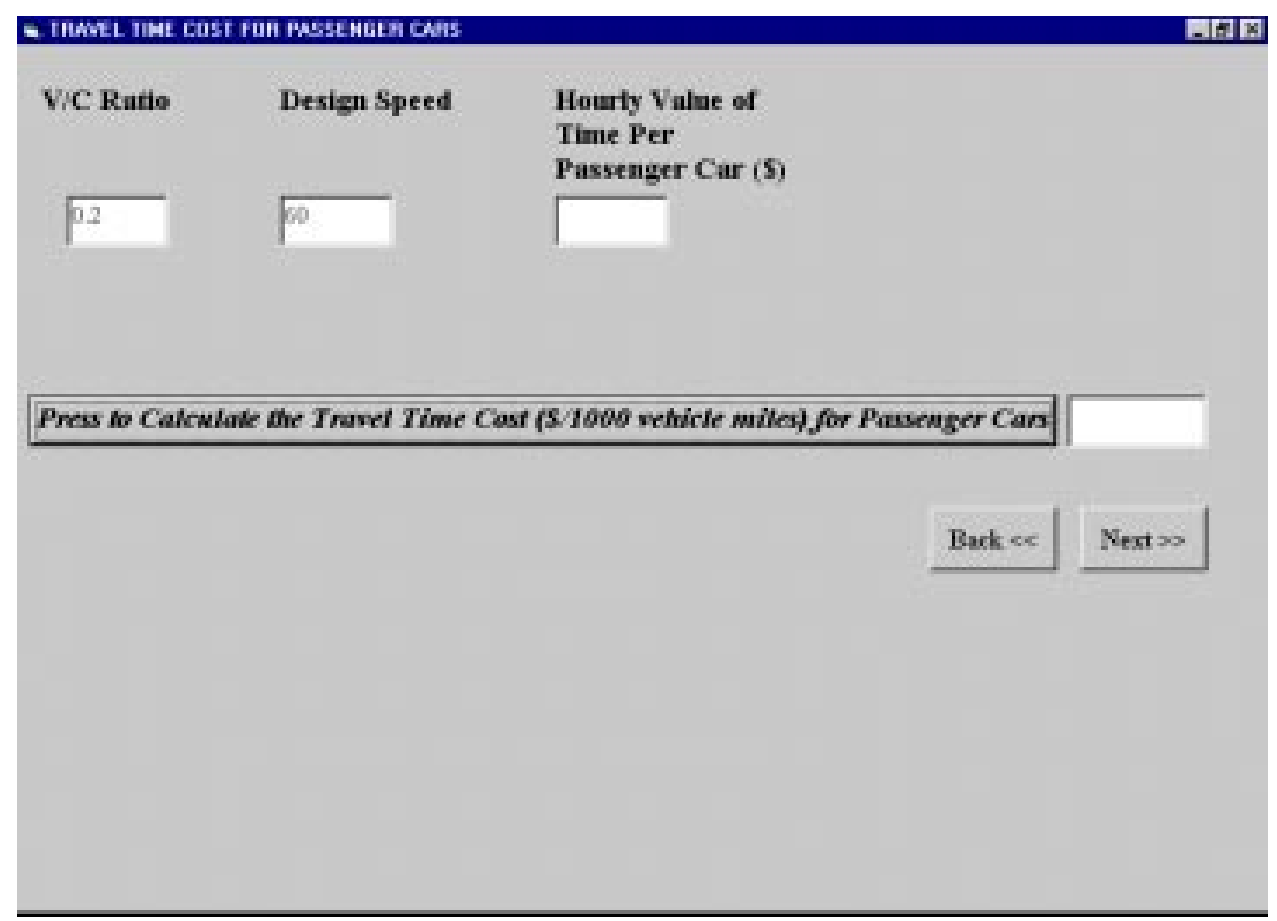

Figure A8: The Travel Time Cost for Passenger Cars Screen

The travel time cost screen requires only one input: the hourly value of time per passenger car. Using this input, the travel time cost is calculated with the clicking of the button "Press to Calculate the Travel Time Cost for Passenger Cars". The next screen is the "Grade Cost for Passenger Cars" (Figure A9), where the software calculates the grade cost for the section under consideration. The input to this screen is the grade percentage and the type of road surface. The former can be selected from the dropdown menu, which displays a list of grades ranging from negative 8 to positive 8 . The road surface can be high type, gravel and stone, or earth type. The grade cost is displayed in the output box. There may be certain inputs (e.g. the calculated average running speed) for which values are not available in the database. In this case, the following message "Warning! The average speed (old) has been replaced by the (new average speed)." is promptly displayed. The new value used is the nearest value obtained from the database, keeping all other inputs (e.g. grade percentage) 
constant and changing the variable for which no corresponding value was found. The new average running speed is displayed in the screen titled "Basic Section Cost for Passenger Cars" (Figure A7). The user has to repeat the calculations for the grade and curve costs once again as these values are affected by the new average running speed.

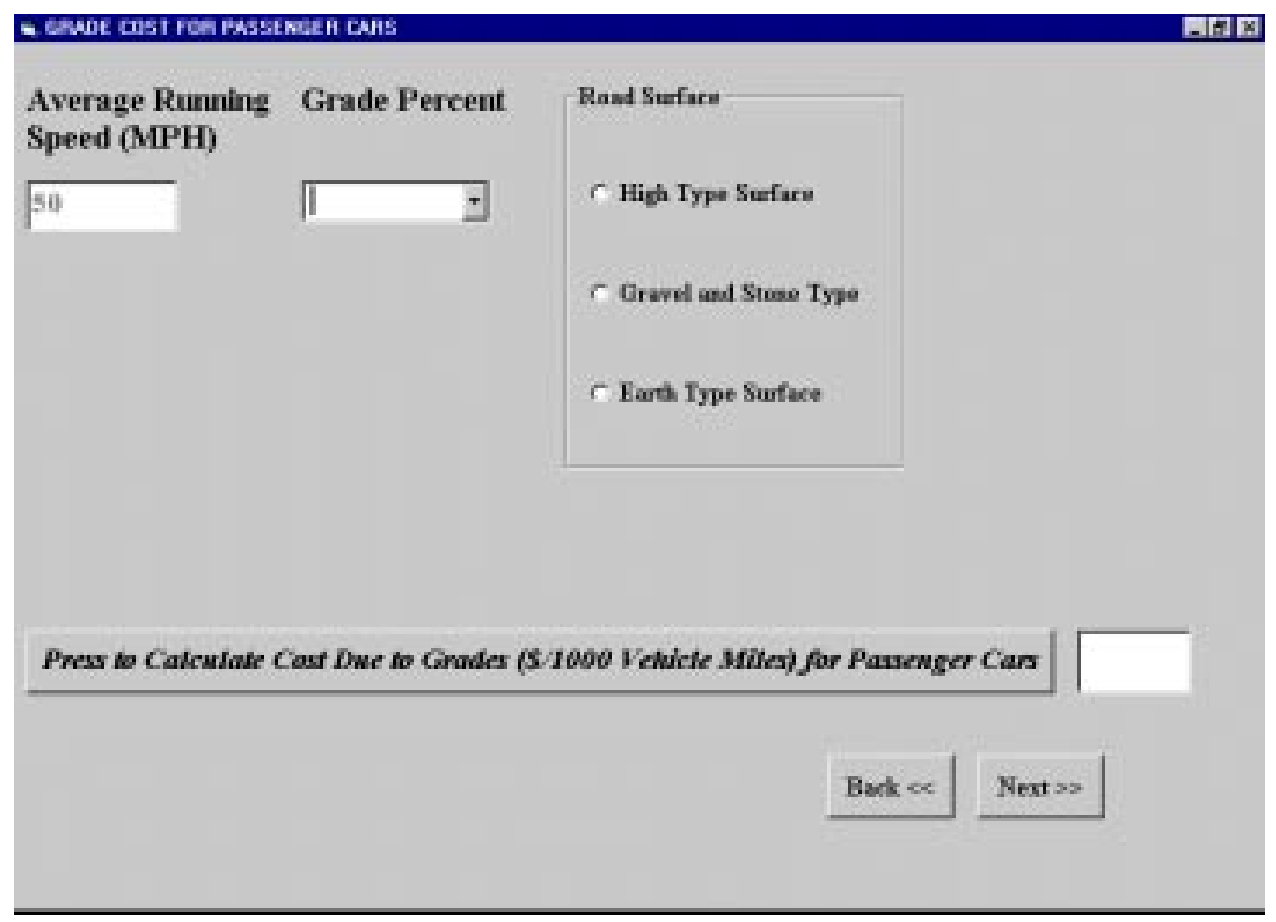

Figure A9: The Grade Cost for Passenger Cars Screen

The next screen is the "Curve Cost for Passenger Cars" (Figure A10). The user has to input the curve angle. The type of road surface selected in the "Grade Cost for Passenger Cars" screen is carried over to this screen. On clicking the button labeled "Press to Calculate the Cost Due to Curves", the curve cost is displayed in the output box. If the value for a set of inputs is not available in the database, the nearest value is used as described earlier. The speed change cost and the total Basic Section cost for the passenger cars are calculated in the next screen entitled "Speed Change Cost for Passenger Cars" (Figure A11). 


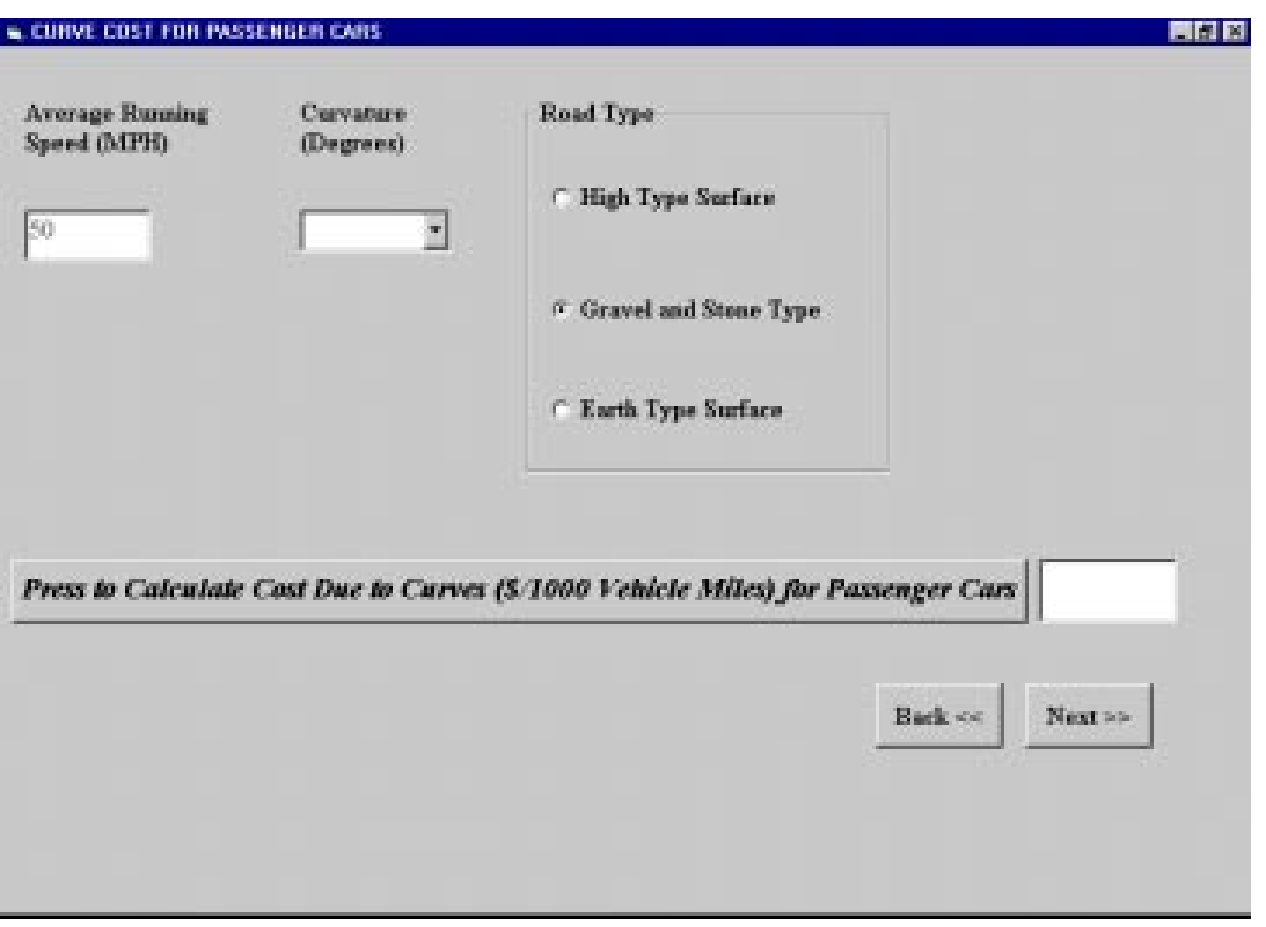

Figure A10: The Curve Cost for Passenger Cars Screen

The next screen to be displayed depends on the vehicle mix entered previously. If the percentages of the Single Unit Truck and Combination truck are zero, the next screen that appears is the "Basic Section Cost for the Total Vehicle Mix" (Figure A12). 


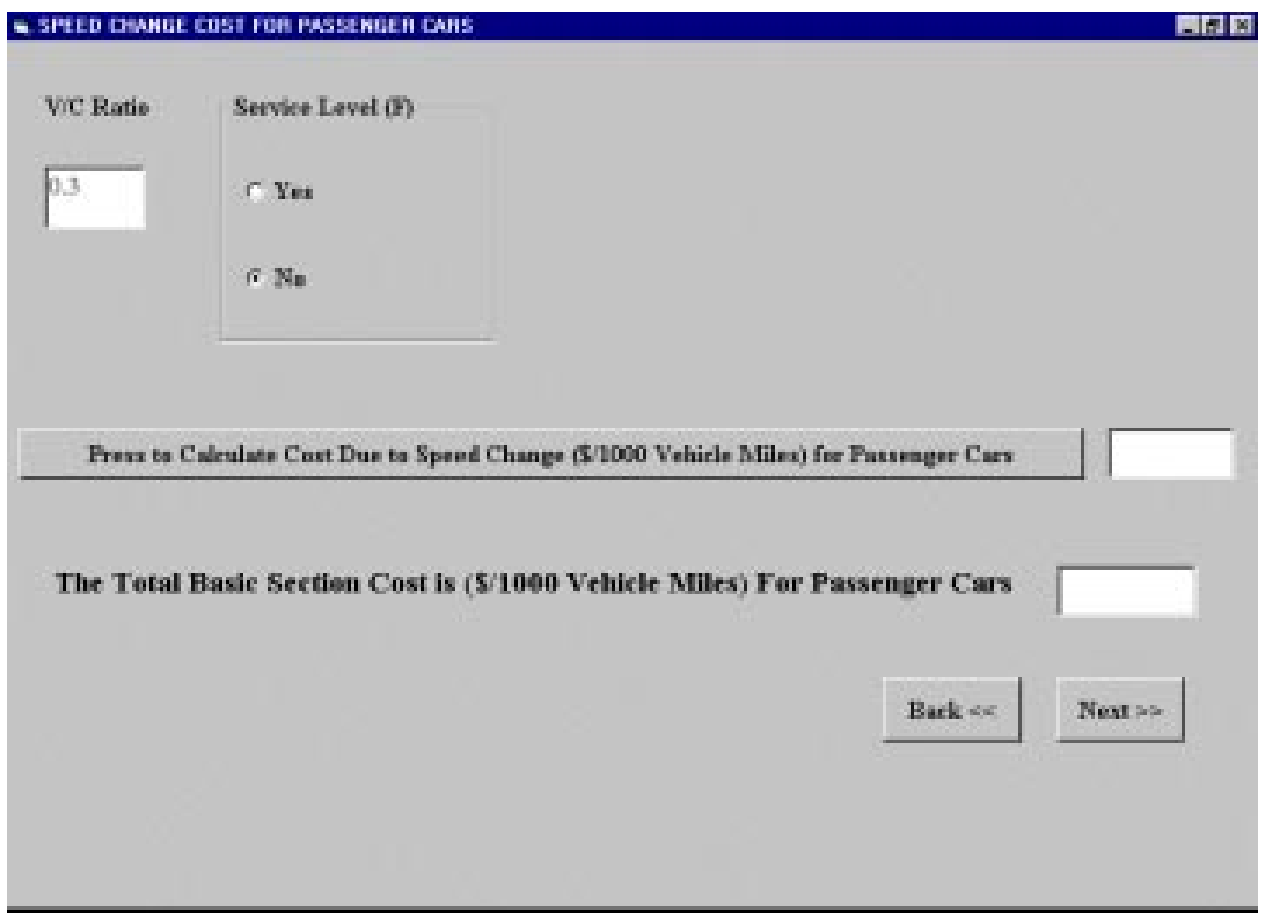

Figure A11: The Speed Change Cost for Passenger Cars Screen

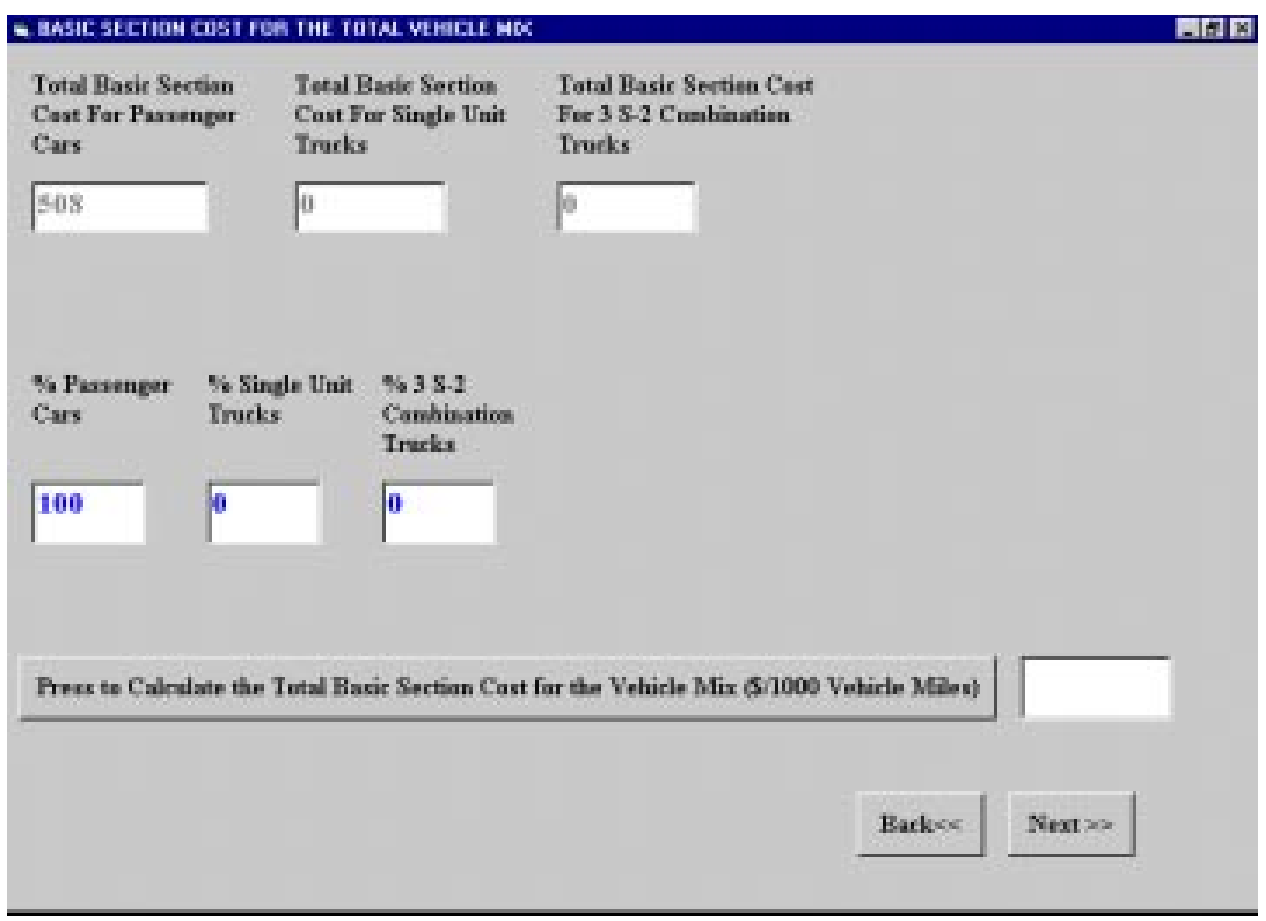

Figure A12: The Basic Section Cost for the Total Vehicle Mix Screen 
However, if the percentage entered for Single Unit Truck or for Combination truck is not zero, the software displays additional screens labeled "Basic Section Cost for Single Unit Trucks" and/or "Basic Section Cost for 3 S-2 Combination Truck". A series of calculations, similar to passenger cars, will be repeated. The screen entitled "Basic Section Cost for the Total Vehicle Mix" has the output box for the total Basic Section cost which is displayed when the user clicks on the button labeled "Press to Calculate the Total Basic Section Cost". This concludes the calculation of the Basic Section Cost. The user is returned back to the "Main Screen" (Figure A5) as soon as the "Next" command button is pressed. The user then clicks on one of the other three buttons to calculate the other cost components.

If the user clicks on the "Accident Cost" command button, the software asks the question "Does the section require the calculation of Accident Cost". On clicking the "Yes" button the user is taken to the "Accident Cost" screen. If "No" is chosen, the color of the Accident Cost button changes to white and no further action is taken here. The "Accident Cost" screen (Figure A13) has the following inputs, "Fatal Accident Rate", "Injury Accident Rate" and "Property Damage Only." 


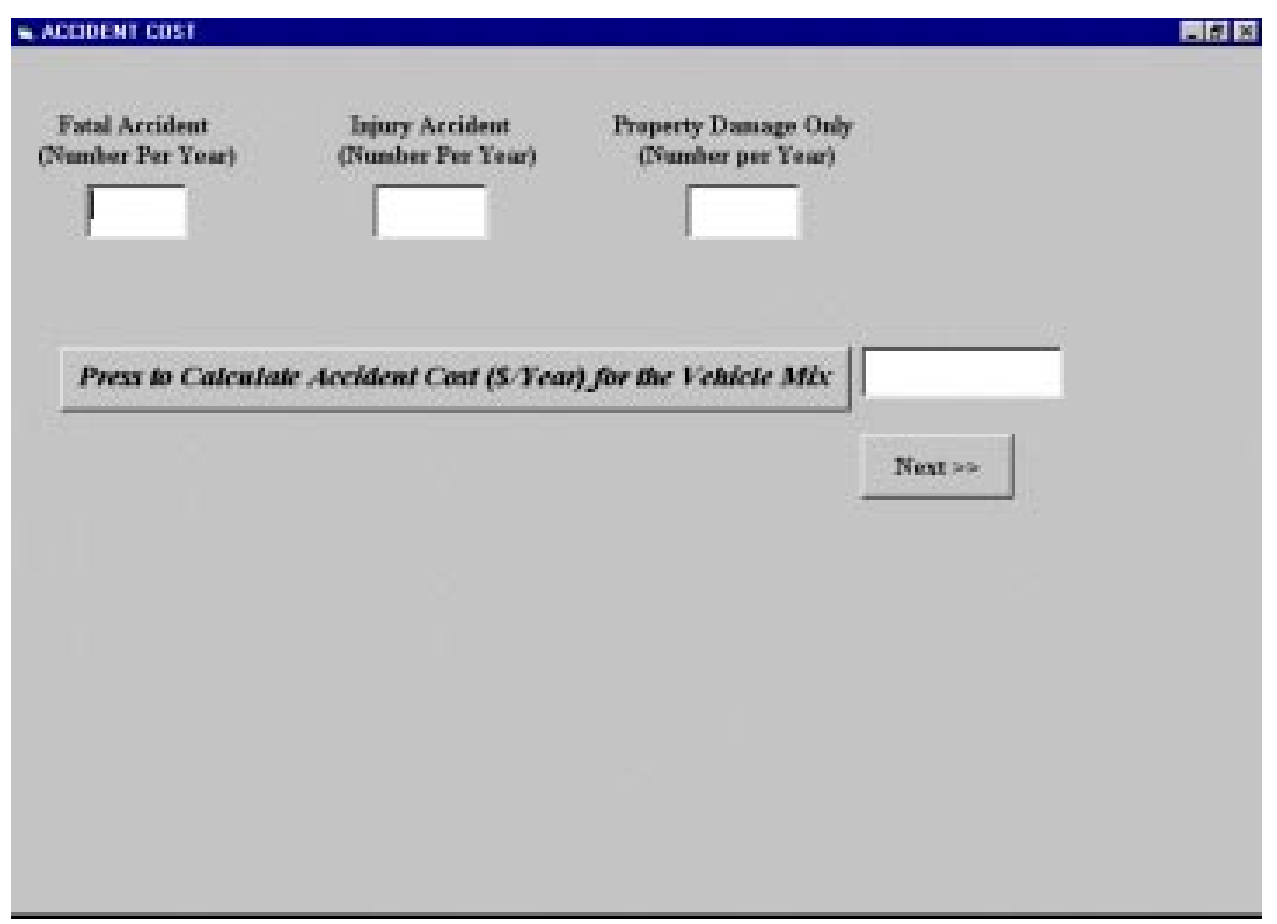

Figure A13: The Accident Cost Screen

If any of these accident results is considered to be negligible, a value of zero must be entered for that component. On the click of the button "Press to Calculate the Accident Cost", the annual accident cost is displayed in the output box.

Next, if the "Transition Cost" button is pressed, the question "Does the section require the calculation of Transition Cost?" will be displayed. If the answer is "Yes", the “Transition Cost" screen will be displayed (Figure A14). 


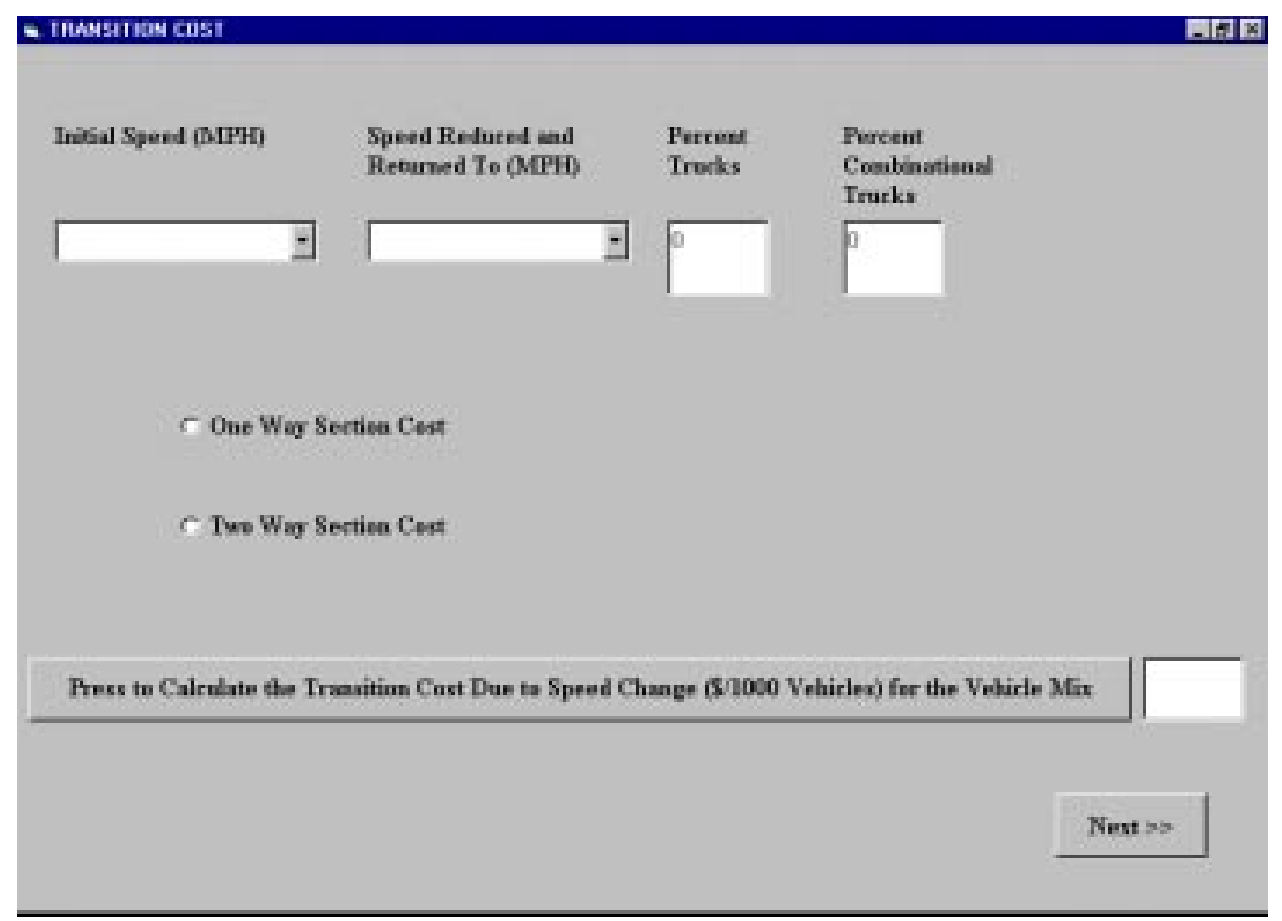

Figure A14: The Transition Cost Screen

The "Transition Cost" screen requires the following inputs: the initial speed of the vehicle, the reduced speed, and whether the calculated cost is for a one-way or two-way section. The speed data are in the form of dropdown menus, in which the user has to select from a list and the number of ways is in the form of an option button. On clicking the button "Press to Calculate the Transition Cost", the transition cost is displayed in the output box. The "Next" button takes the user back to the "Main Screen".

The final cost component to be calculated is the intersection delay cost. If the user chooses to include the delay cost in the calculations, the "Delay Cost" screen (Figure A15) will be displayed. To calculate the Delay Cost, the following inputs are required: "Traffic Volume", "Road Capacity", " Signal Cycle Time (Seconds)", "Effective Green Time (Seconds)", "Intersection Approach Speed" and "Hourly Value of Time for Passenger Cars". The intermediate components like green time to cycle time ratio (Lambda), capacity of 
approach and the volume to capacity ratio of approach are calculated on the click of the button labeled "Press to Calculate the Delay Cost".

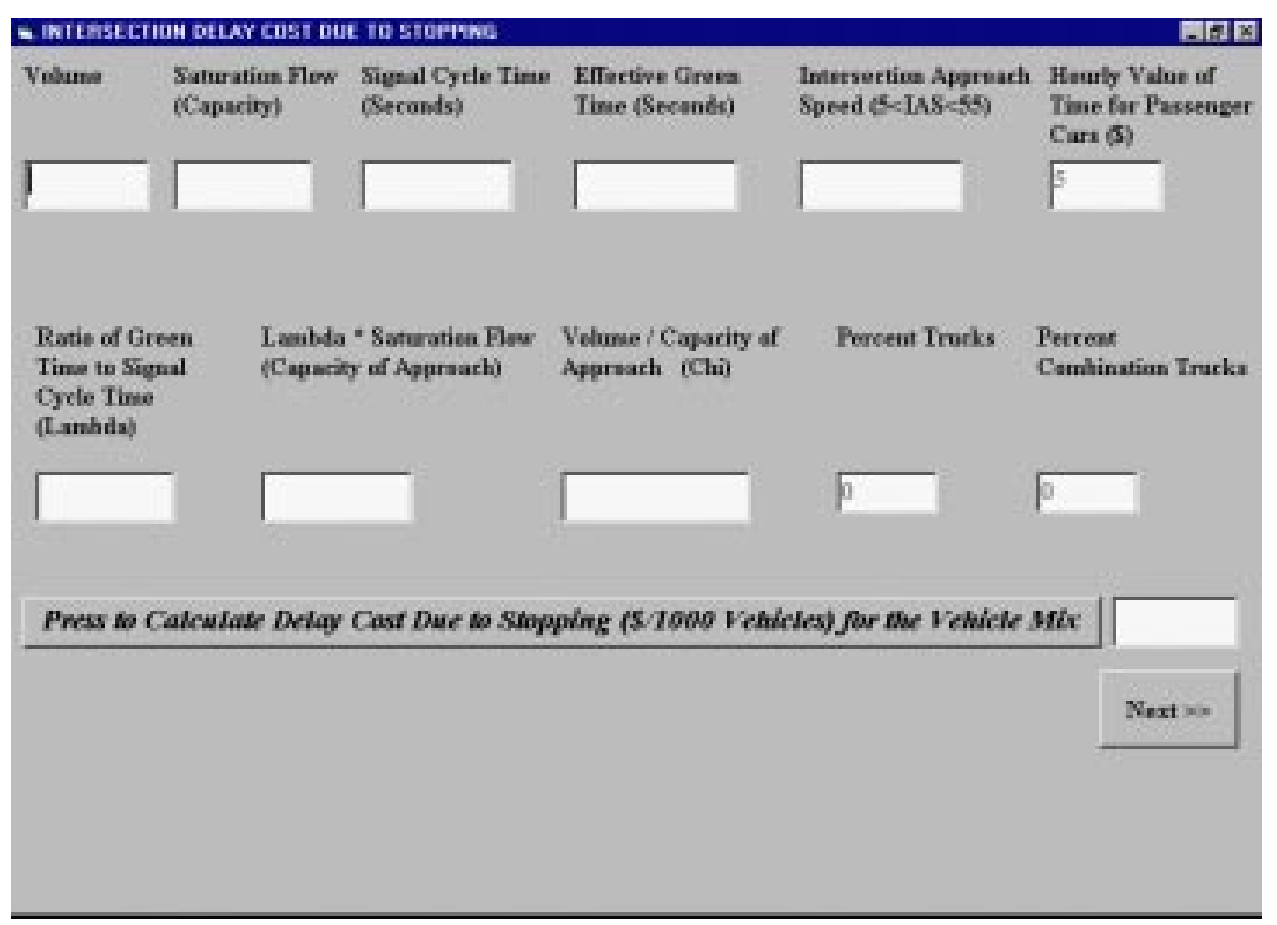

\section{Figure A15: The Intersection Delay Cost Due to Stopping Screen}

The next screen is entitled "Intersection Delay Cost due to Idling" (Figure A16) where the idling cost is computed. The input data are the same as for the Delay Costs and are displayed here for the user's information. The user needs to enter only the "Number of Intersections". The Total Intersection Cost (Delay Cost + Idling Cost) is calculated and displayed in this screen. The user then goes back to the "Main Screen." If at this time the color of all four buttons has changed to white, the "Next" button will appear on the Main Screen. This button leads to the screen labeled "Total Cost" (Figure A17), where all the costs calculated so far is displayed. The user is now required to enter the length of the section (in miles). The total cost is displayed as soon as the button "Press to Calculate the Total Cost" is clicked. 


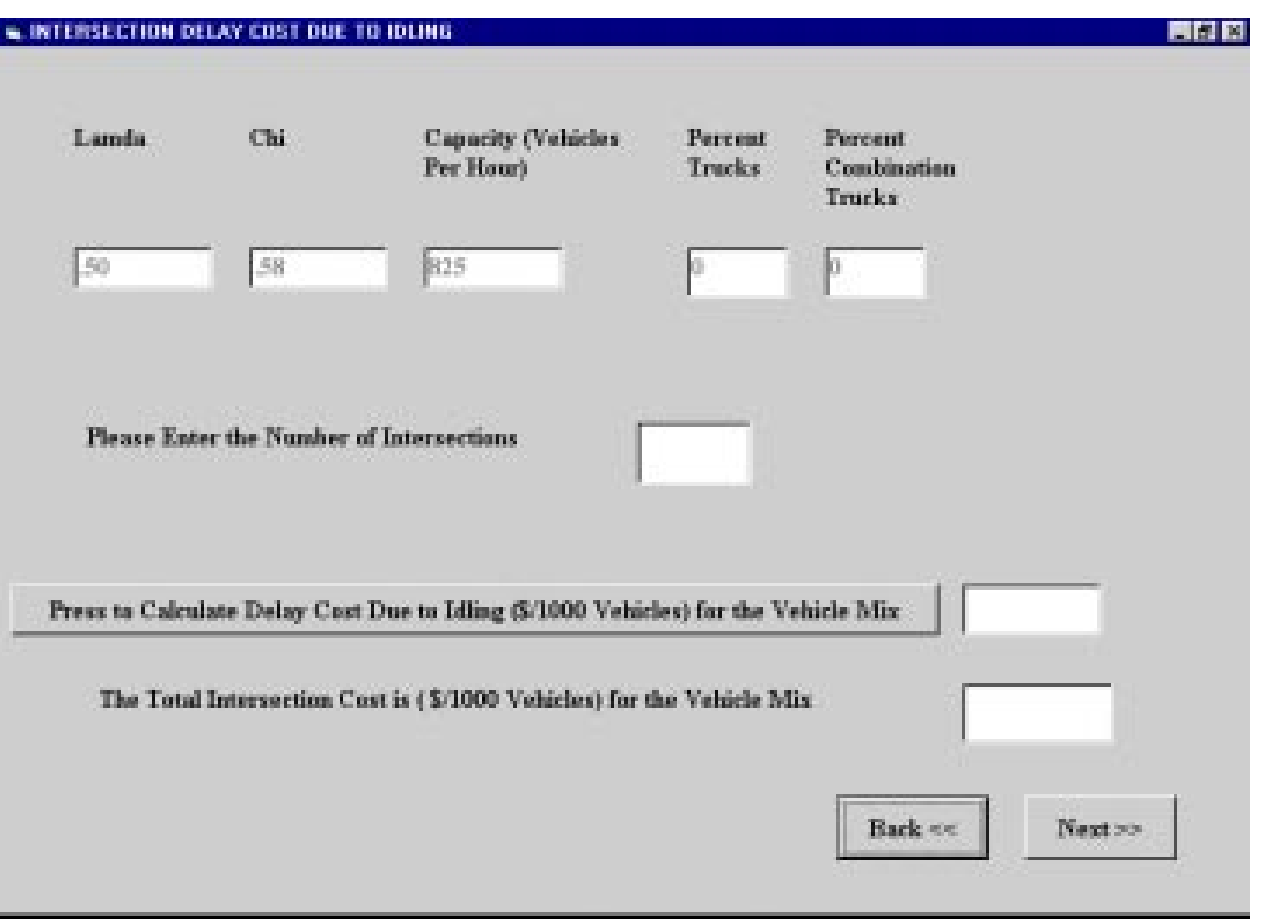

Figure A16: The Intersection Delay Cost Due to Idling Screen

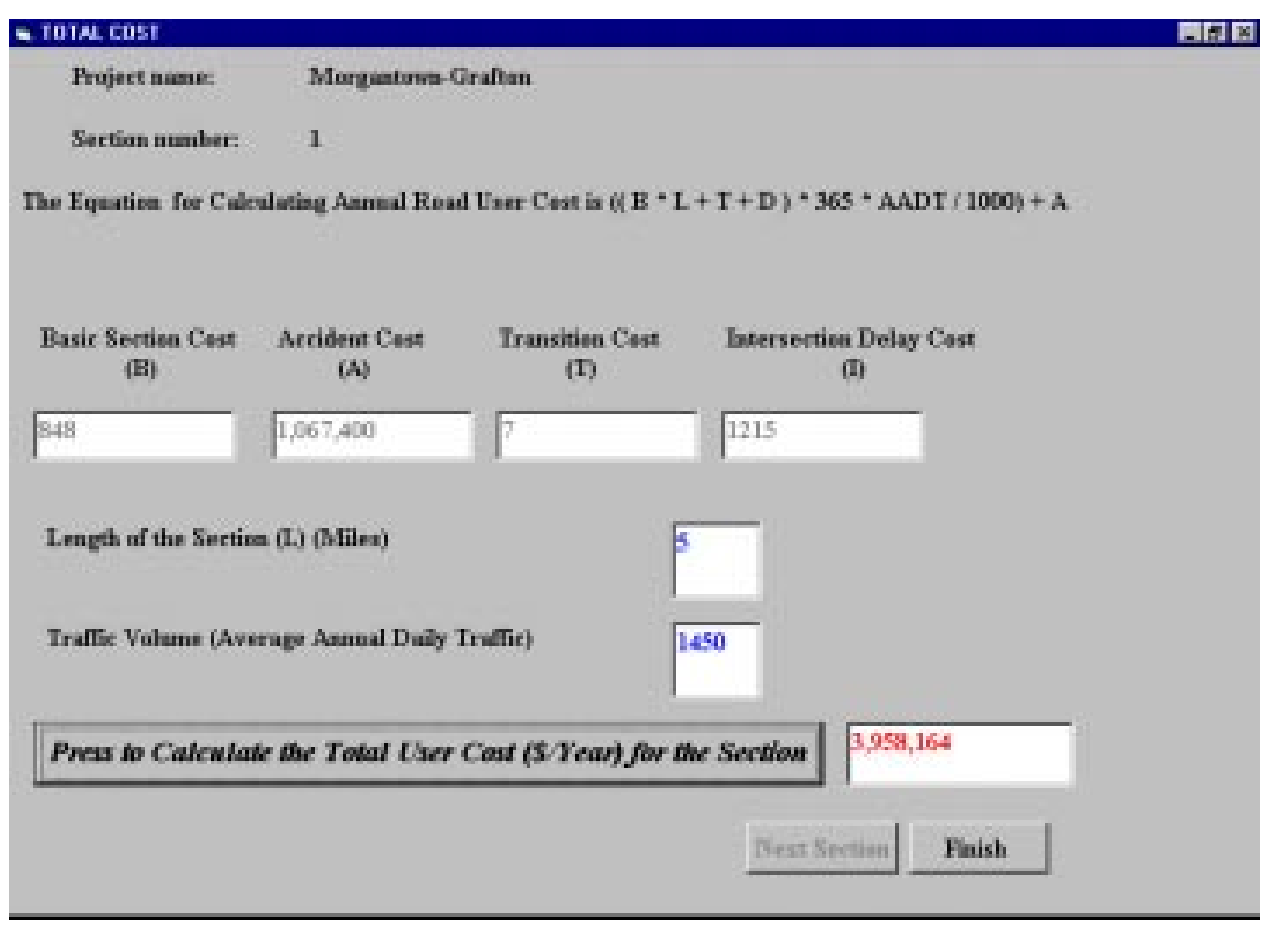

Figure A17: The Total Cost Screen 
If there are more sections left to be included, the user will click on the "Next Section" button which clears all the screens and displays the "Main Screen" (Figure A5) with the following section number. The same procedure is repeated and costs are calculated for the new section. Once all calculations are completed for every section in the project, the "Next Section" button becomes disabled and the "Finish" button is activated. As all the sections are completed at this juncture, the user may wish to view all inputs and outputs on one screen. This can be achieved using the screen titled "View/Edit Results", shown in Figure A18 which is displayed when the "Finish" button (Figure A17) is pressed. The table displayed in this screen is called a "Flexigrid." The user can widen the cells of the grid to view all the costs. The left most column shows the input labels and the top most row shows the section number. The user can perform a variety of operations by clicking on one the four "Section Editing Buttons" displayed. These buttons are "Edit a Section", "Add a Section", "Delete a Section" and "Save the Project". Edit a Section button is used to make modifications in a particular section. If the user clicks on this button, an input box will be displayed prompting the user for the section number to be edited, after which the "Main Screen" will be displayed. All calculations for that section can be repeated with the modified inputs.

If it is desired to add a new section to the project, clicking on the "Add a Section" button will take the user back to the "Main Screen". The number of sections in the project will be increased by one. However, if there are already 50 sections in the project, no more sections can be added. Attempts to increase the number of sections above 50 will result in an error message.

The "Delete a Section" button is useful if the user is not interested in a particular section and wants to remove it from the project. An input box will be displayed asking the 
user to enter the section number to be deleted. Once the section number is entered, it is automatically deleted from the project. Multiple sections can be deleted one by one.

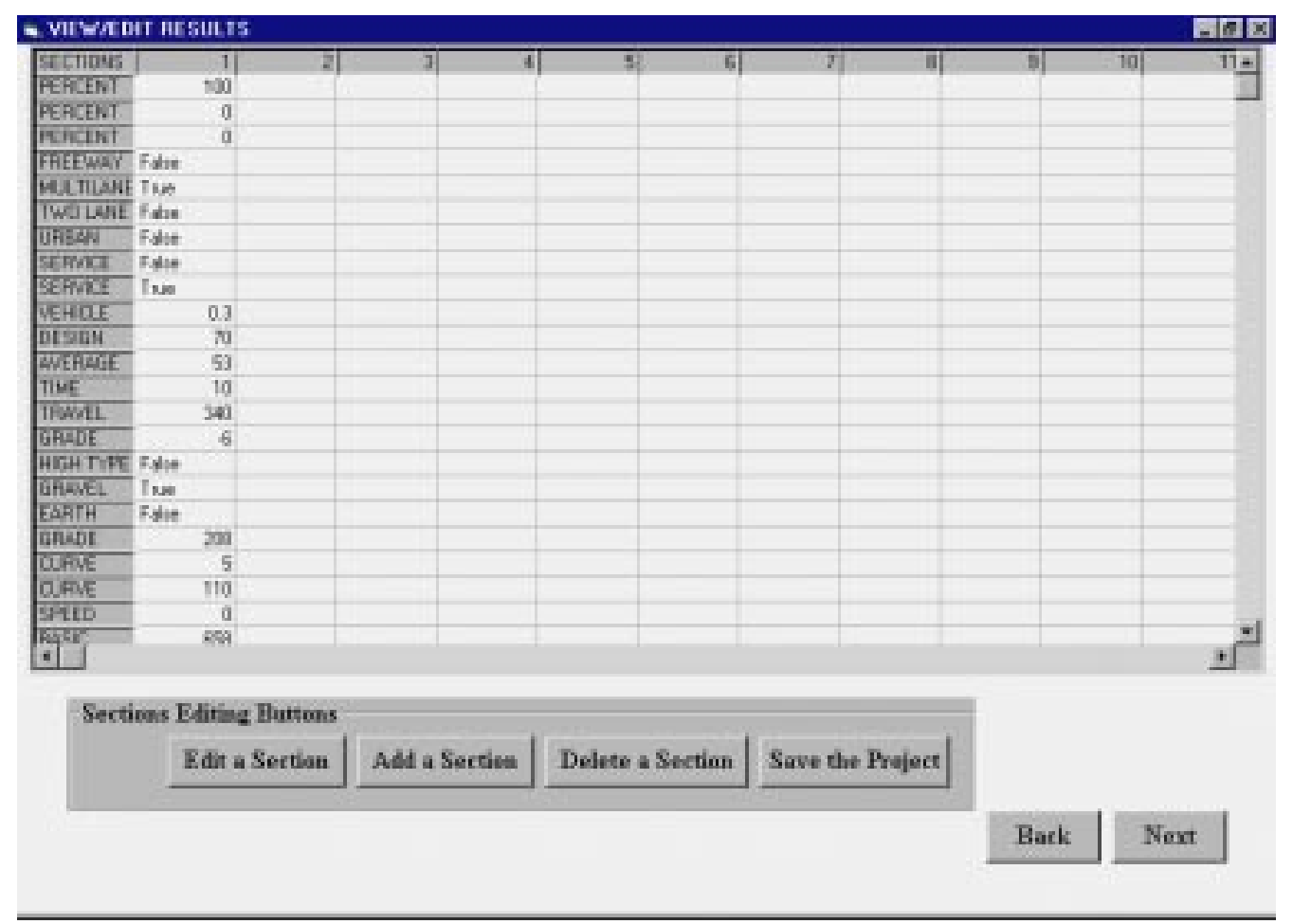

Figure A18: View/Edit Results Screen

Once the user is fully satisfied with the results, "Save the Project" button must be pressed. A window, as shown in Figure A19, will be displayed and the "View/Edit Results" screen will be disabled. The user has to press the "Save" button to save the project in a desired directory. The project is then saved in an ASCII text file in the harddrive (C:I) for future retrieval and the "View/Edit Results" screen is enabled. A message titled "If you have not saved the file, Please do so" is displayed as soon as the "Next" button is pressed. It is the responsibility of the user to save the file in the desired directory. If the project is not saved at this juncture, the user may lose all information. On pressing the "Ok" button of the message box, the next screen titled "Inputs for the Project" screen (Figure A20) is displayed. 


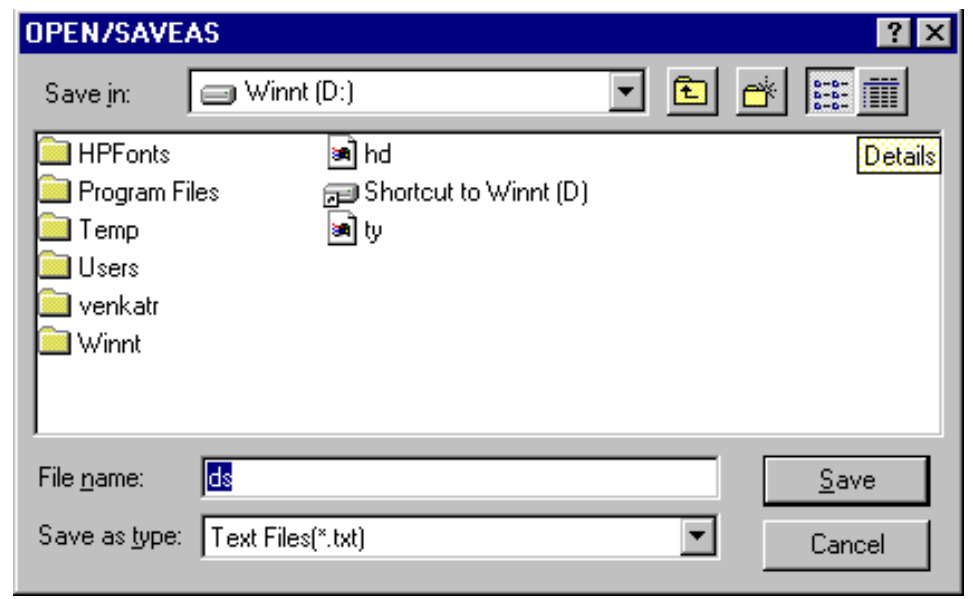

\section{Figure A19: The Open/Saveas Dialog Box}

Once the above steps are completed, the "Inputs for the Project" screen (Figure A20) will be displayed. This screen summarizes the data for a section in a concise format ready to be printed for archival purposes. The user can select any individual section to view. The first section is displayed by default. Subsequent sections can be viewed by selecting the section number from the dropdown menu shown just below the "Section to View" label.

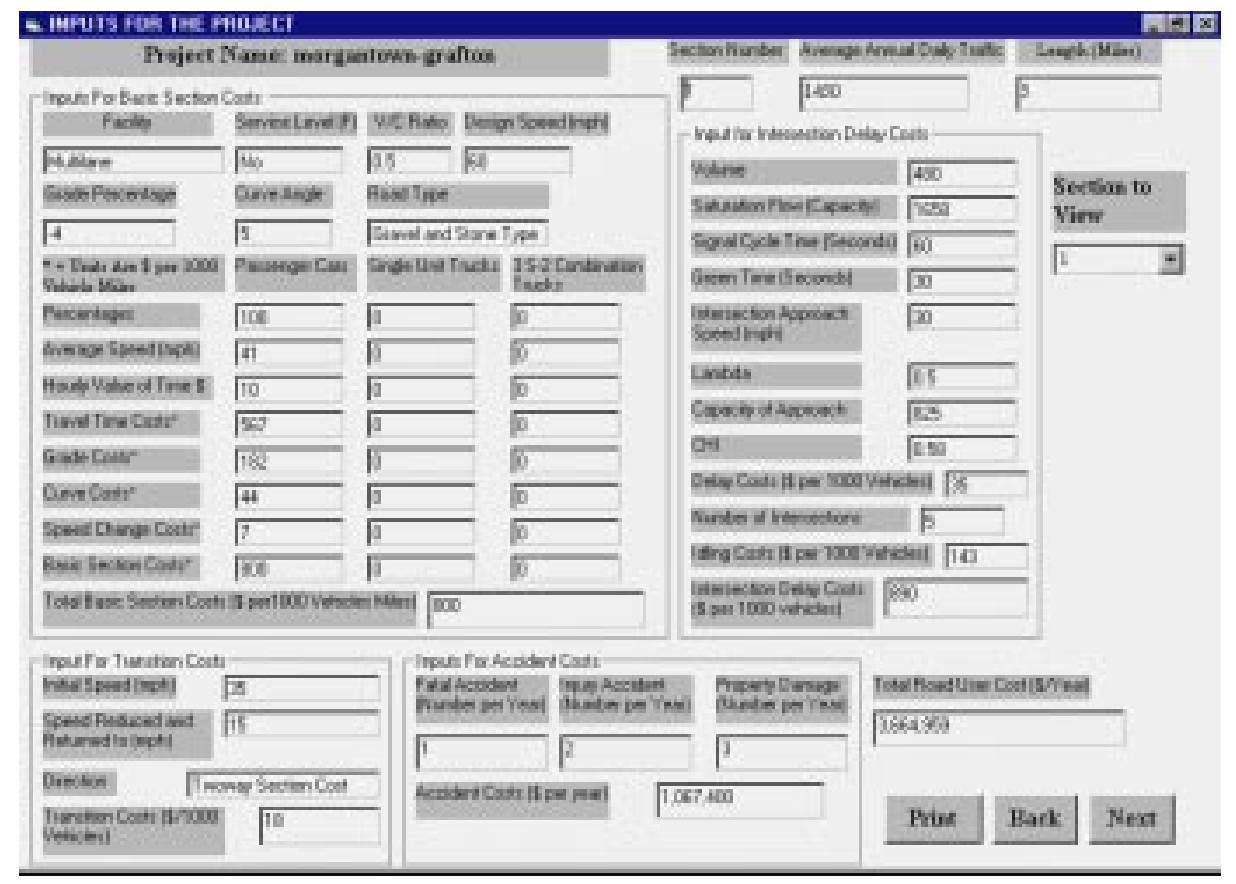

Figure A20: Inputs for the Project Screen 
He can also take printouts of the inputs by simply pressing the "Print" button. On clicking the "Print" button, a window titled "Print Results" is displayed as shown in Figure A21.

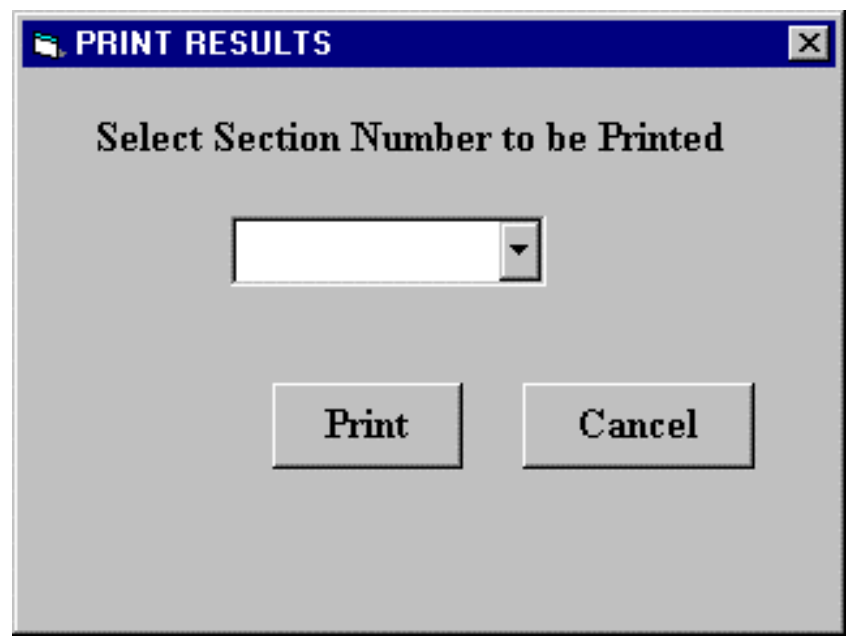

Figure A21: The Print Results Screen

The user has to select a section number to print. He can print individual sections by selecting a particular section number from the dropdown titled "Select Section Number to be Printed" or select "All" from the dropdown to print all sections in succession. Each section will be printed on a separate page.

Clicking on the "Next" button in Figure A20 will take the user to the "View Results" screen (Figure A22). This screen displays all the cost components of each section (ten sections per screen) and the total costs for the whole project. At this point the user can print the results for future reference. 


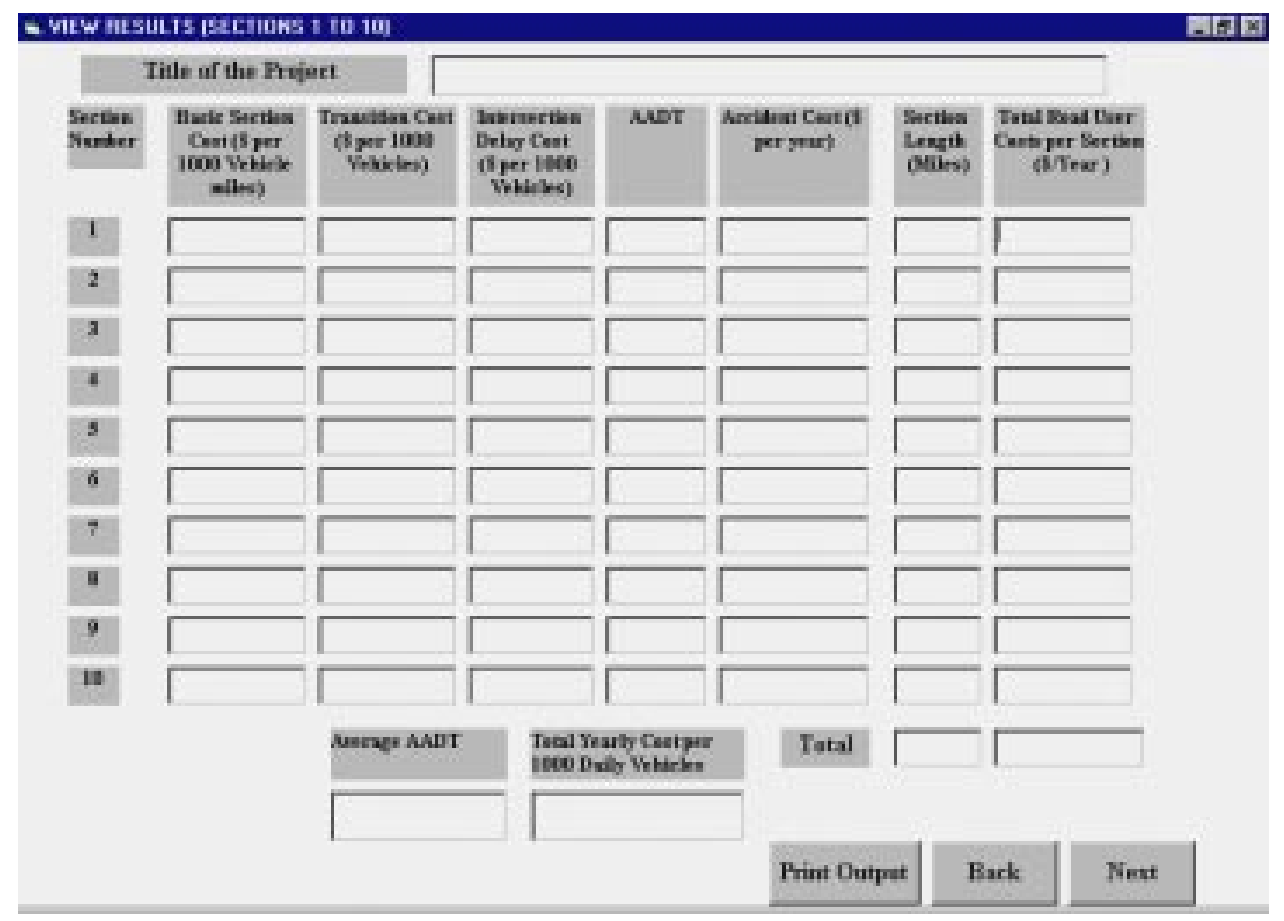

Figure A22: The View Results Screen

The "Back" button helps the user go back to the previous screen. The "Next" button helps the user to move to the next screen in case there are more than ten sections. Otherwise, the "Next" button is replaced by the "End" button, which helps the user to exit the software. On pressing the "End" button, a window appears with a message "Do you want to go to a New Session?". If the user presses the "Yes" button, the screen in Figure A1 appears. The "No" button terminates the software.

\subsection{Opening an Existing File}

To retrieve information saved in an existing file, the user must click on the "Opening an Existing File" button displayed in the "Startup" screen (Figure A3). This would bring up the open/saveas dialog box similar to that shown in Figure A19 from which the user selects the file to open. The user can also browse through all directories to find the desired file. 
Once a file is selected, a new screen entitled "Opening an Existing File" (Figure A23) will be displayed. This screen shows the file name, the title of the project, brief comments on the project and the number of sections. An input box is also shown prompting the user for the section number to be viewed or edited. If the value entered for the section number to be viewed is larger than the number of sections in the project, an error message will be displayed.

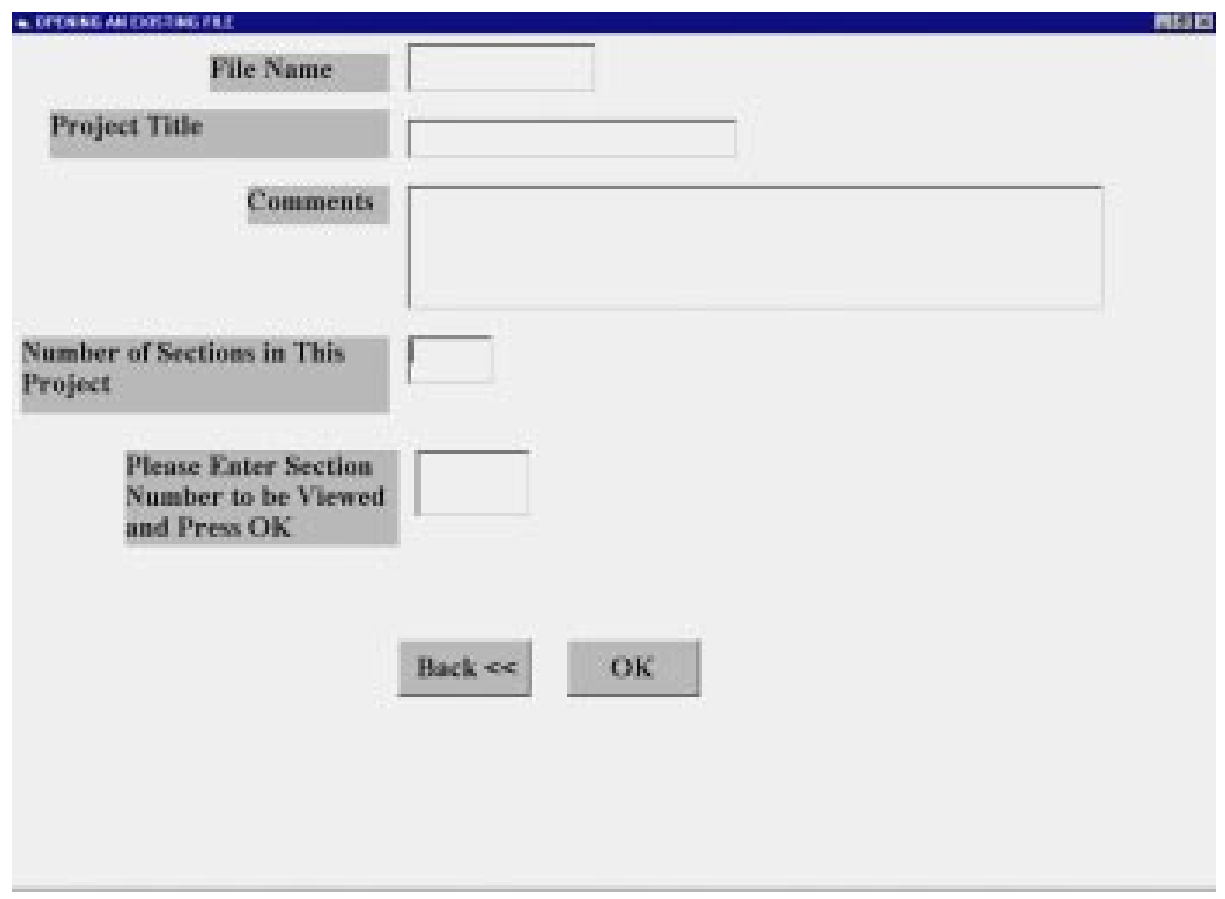

Figure A23: Opening an Existing File Screen

The user must enter a valid section number and press the "Ok" button to proceed to the "Main Screen". A label on top of the screen shows the section number being viewed. The "Basic Section Cost", "Accident Cost", "Intersection Delay Cost" and "Transition Cost" buttons are displayed on the screen. The user may press any one of them to view or make changes to the cost components. 
Due to the fact that change in inputs in one screen may affect other screens, the user has to make sure that changes are reflected in all the required screens. If the user fails to do so, error messages will be displayed. As an example, if the user wants to change the grade percentage for passenger cars, he has to go to the "Grade Cost for Passenger Car" screen, select a new grade percentage from the dropdown menu and click on the button "Press to Calculate Grade Cost" to complete the calculation. The new grade cost also changes the total Basic Section cost, so the user has to proceed to the "Speed Change Cost for Passenger Cars" screen and click on "Press to Calculate the Speed Change Cost" to display the changed cost.

Once all the necessary changes are made, the user clicks the "Next" button on the "Main Screen" to move to the "Total Cost" screen. Here, the new costs are displayed in their respective output boxes. At this point it is also possible to change the length of the section. When the user is satisfied with the changes, the button "Press to Calculate the Total Cost for the Section" must be pressed to display the new total cost.

The user can go to the next screen titled "View/Edit Results" (Figure A18) where it is possible to use the various editing buttons available. The old costs may be revised either by viewing each section as in the screen "Opening an Existing File" (Figure A23) or by using the edit buttons in the screen "View/Edit Results" (Figure A18). After making all the changes needed, the user must save all the work for future retrieval. The user can proceed to obtain printouts of the projects after changes.

\subsection{Updating Cost Tables}

All cost tables are stored in Excel worksheets. These tables must be updated annually so that calculated costs reflect the latest cost figures. The first step is to press the "Update 
Cost Tables and Indices" button on the "Road User Cost Application" screen, shown in Figure A2. Once this button is clicked, screen entitled "View/Update Indices" (Figure A24) is invoked. This screen opens and displays the base year and consumer price indices (CPI) for all price components: CPI (Fuel), CPI (Motor Oil), CPI (Depreciation), CPI (Tires) and CPI Maintenance) and the latest producer price indices (PPI), previously called wholesale price indices like PPI (Fuel, Single Unit Truck), PPI (Fuel, Combination Truck), PPI (Motor Oil), PPI (Depreciation, Single Unit Truck), PPI (Depreciation, Combination Truck), PPI (Tires), CPI (Total) and WPI (Industrial Commodities) The user must enter the current year and the latest CPI's and PPI's in the specified input boxes and click the "Save Changes and Update Cost Tables" button to update all the tables.

The latest available vehicular accident costs, as published by the National Safety Council, must also be entered. Once the updating is finished, the user goes back to the "Road User Cost Application" screen. If the user is not interested in any modifications, he can go back to the "Road User Cost Application" screen by pressing the "Back (No Modifications)" button. 


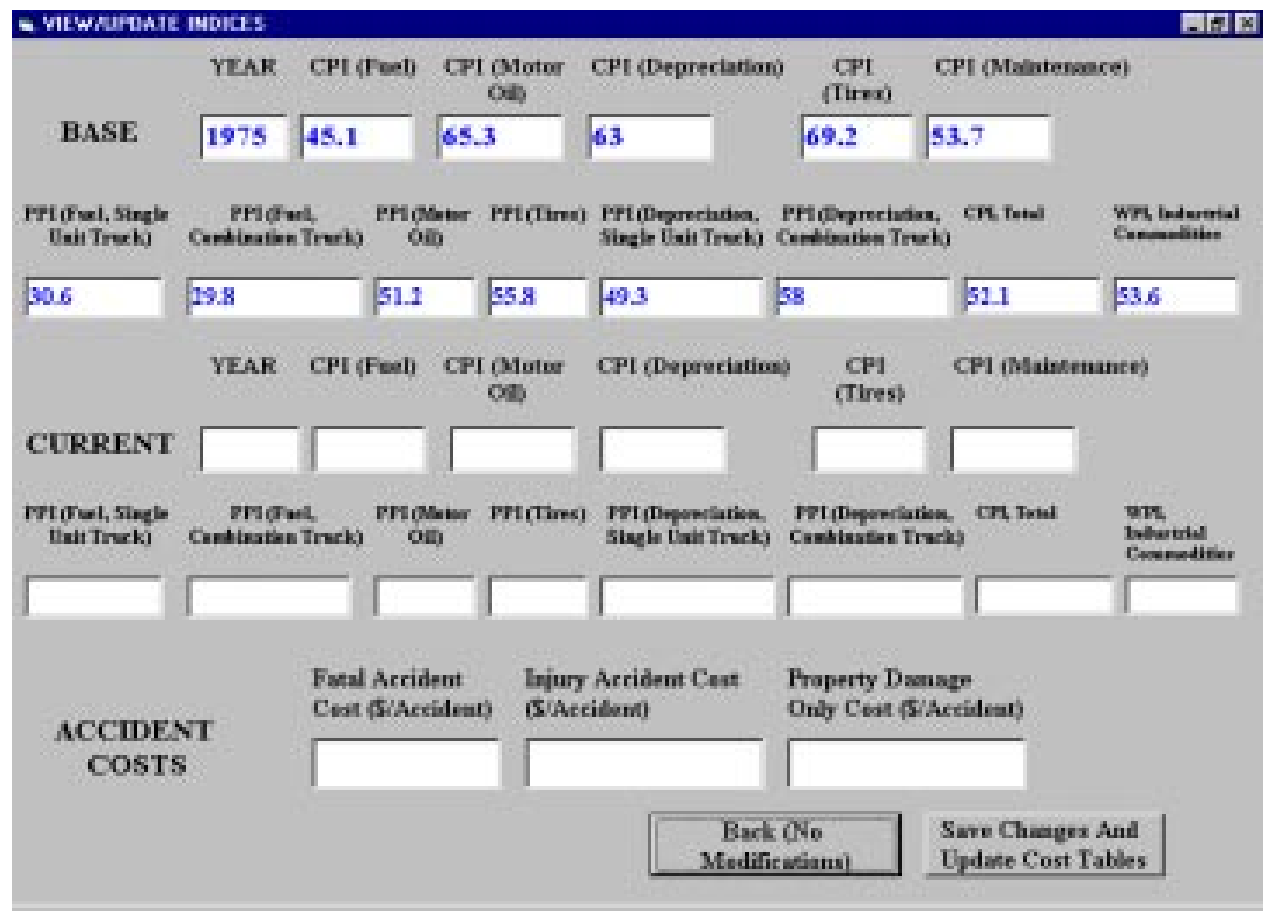

Figure A24: The View/Update Indices Screen

The Consumer Price Indices can be obtained form the Bureau of Labor Statistics (BLS) site on the World Wide Web at www.bls.gov. This is the official site of the BLS and is part of U.S. Department of Labor. The first step here would be to press an icon labeled "Data" which is a hyperlink to the address www.bls.gov/datahome.htm. Next, another icon labeled "Series Report" must be chosen. This page contains an input box for the user to enter the series identity number to extract the latest Consumer Price Indices. The latest identity numbers have to be extracted for 1) CPI - Motor Fuel, 2) CPI - Motor Oil, 3) CPI Depreciation or New Vehicles, 4) CPI - Tires and 5) CPI - Maintenance.

The identity numbers for the CPI's are shown in the Table A1. 


\begin{tabular}{|l|l|}
\hline CONSUMER PRICE INDICES & IDENTITY NUMBER \\
\hline CPI, Total & CUUR0000SA0 \\
\hline CPI, Motor Fuel & CUUR0000SETB \\
\hline CPI, Motor Oil & CUUR0000SS47021 \\
\hline CPI, Depreciation or New Vehicle & CUUR0000SETA01 \\
\hline CPI, Tires & CUUR0000SETC01 \\
\hline CPI, Maintenance & CUUR0000SETD \\
\hline
\end{tabular}

\section{Table A1. Consumer Price Indices and their Identity Numbers}

Once the identity numbers have been entered in the input box, the user must select the choice "All Years" from the dropdown titled "Year(s) to Report for:" and press the button "Retrieve Data" after which the latest Consumer Price Indices will be displayed. The same procedure has to be adopted to extract the producer price index (In 1975, the producer price index was called Whole sale price index) which is used to update the truck cost factors. Table A2 shows the identity numbers for the producer price indices. The latest identity numbers have to be extracted for 1) WPI - Industrial Commodities, 2) PPI - Fuel, Single Unit Truck, 3) PPI - Fuel, Combination Truck, 4) PPI - Motor Oil, 5) PPI - Tires and 6) PPI Depreciation, Single Unit Truck and 7) PPI - Depreciation, Combination Truck. 


\begin{tabular}{|l|l|}
\hline PRODUCER PRICE INDICES & IDENTITY NUMBER \\
\hline WPI, Industrial Commodities & WPU03THRU15 \\
\hline PPI, Motor Fuel (Gasoline), Single Unit Truck & WPU0571 \\
\hline PPI, Motor Fuel (Diesel Fuel), Combination Truck & WPU057303 \\
\hline PPI, Motor Oil & WPU09150751 \\
\hline PPI, Depreciation, <10,000 lbs. (Single Unit Truck) & WPU141105 \\
\hline PPI, Depreciation, >10,000 lbs. (Combination Truck) & WPU141106 \\
\hline PPI, Tires & WPU07120105 \\
\hline
\end{tabular}

Table A2. Producer Price Indices and their Identity Numbers

For any other query or information, the LABSTAT helpdesk can be contacted at LABSTAT@bls.gov.

The national safety council publishes the latest accident costs. The address for the web site for finding the latest accident costs is http://www.nsc.org/lrs/statinfo/estcost7.htm. The 1997 costs are as follows (Table A3).

\begin{tabular}{|l|l|}
\hline Type of Accident & Cost (\$/Accident) \\
\hline Fatal Accidents & $\$ 980,000$ \\
\hline Injury Accidents & $\$ 34,100$ \\
\hline Property Damage Only & $\$ 6,400$ \\
\hline
\end{tabular}

Table A3. Accident Costs for the Year 1997 


\subsection{Economic Analysis}

Another application of the software is to compute the present value of all the annual user benefits due to the improvement over the analysis period, and to compare this present value with the computed present value of the project costs associated with the improvement. A project (or project alternative) can be deemed economically justifiable if the present value of the project-related benefits exceeds the present value of all project-related costs. The user

clicks on the Button "Economic Analysis" displayed in the "Welcome" screen (Figure A1), to invoke the "Economic Analysis" screen, shown in Figure A25, which includes three buttons.

The "Net Present Value for Project with Constant Growth" button is used to calculate the present value for a project that has a constant anticipated annual growth rate for maintenance and user costs during the analysis period. On clicking this button, the screen entitled "Economic analysis for Uniform Increase or Decrease" (Figure A26) will be displayed. 


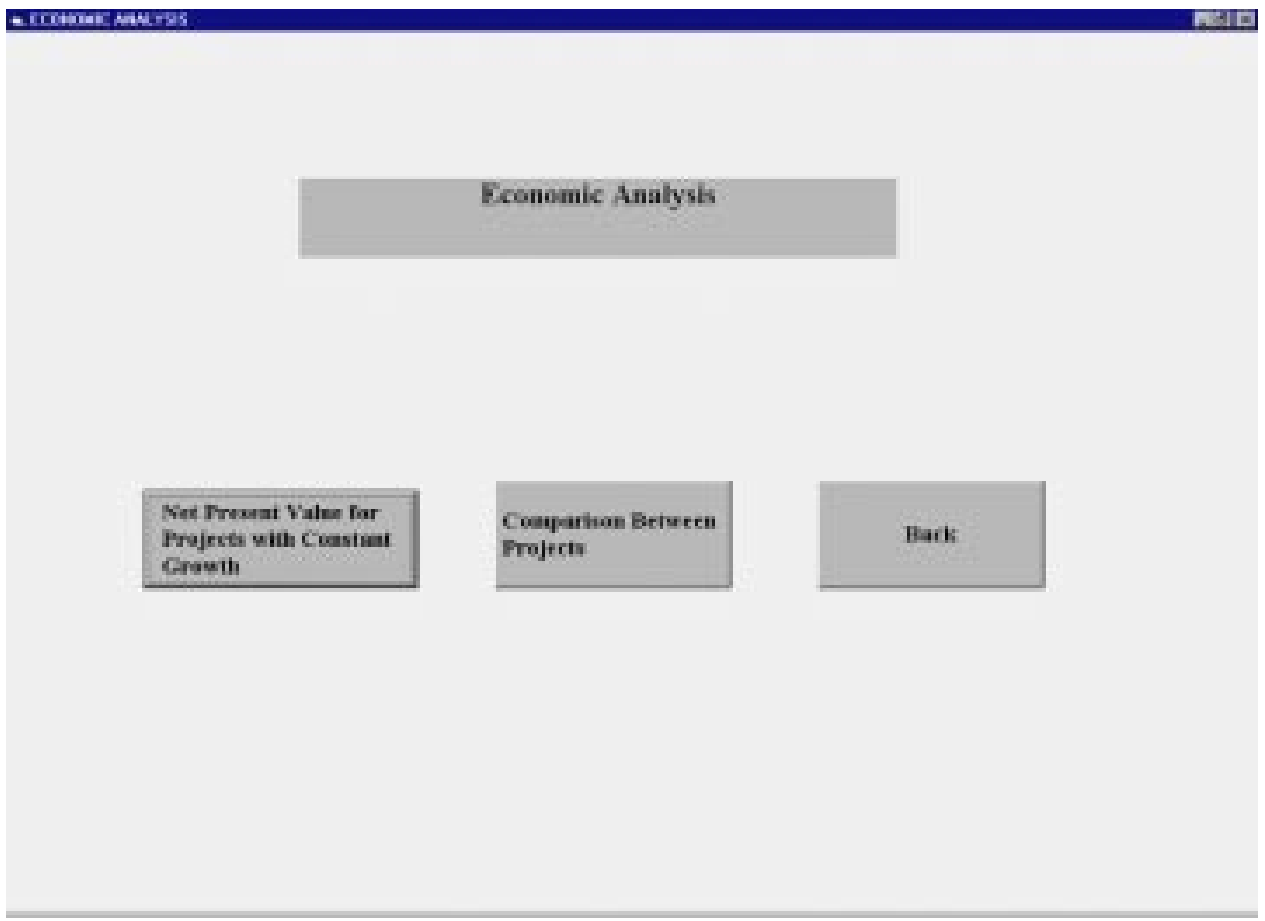

Figure A25: The Economic Analysis Screen

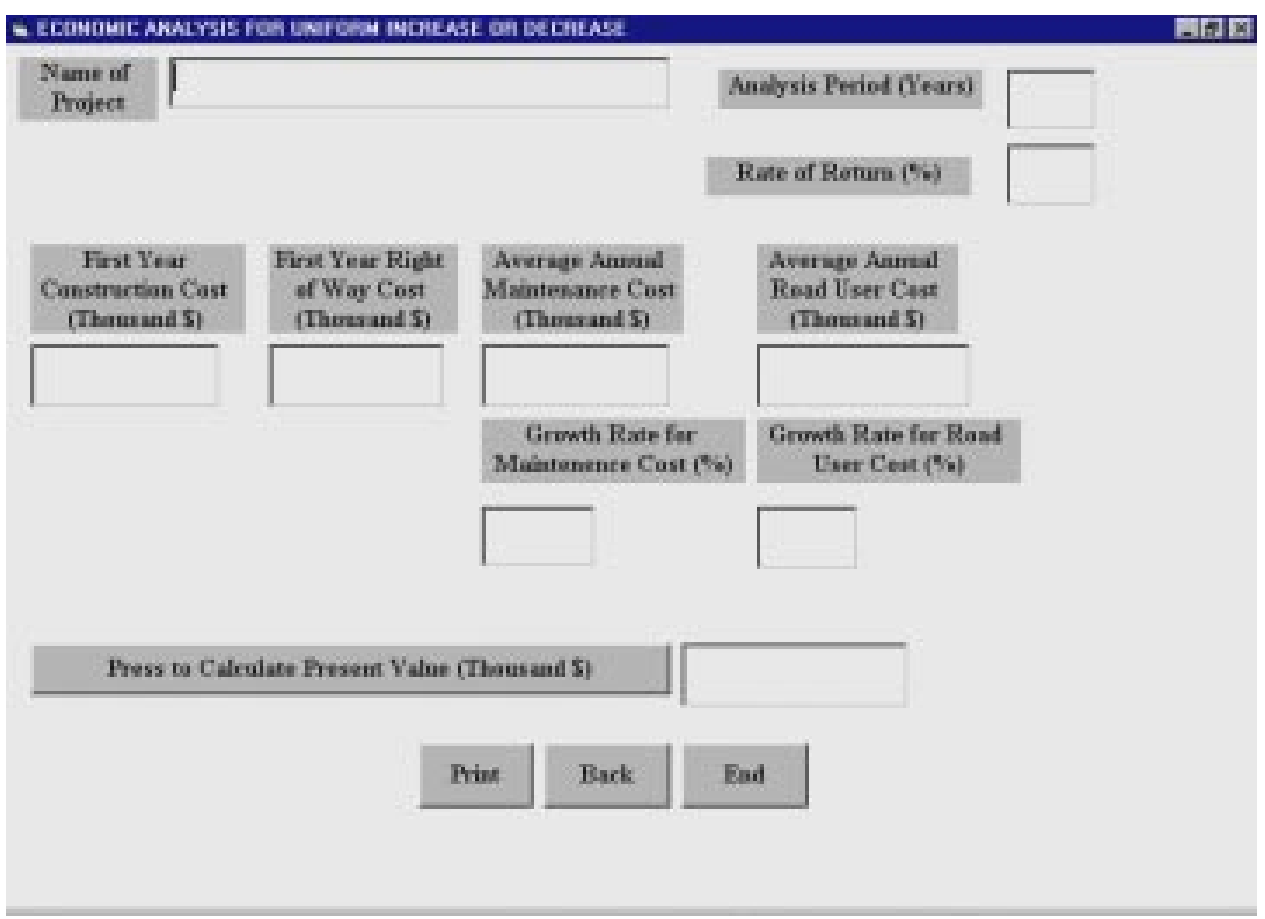

Figure A26: The Economic Analysis for Uniform Increase or Decrease Screen 
The user must input the analysis period (in years), the growth rate for road user cost and maintenance cost, the rate of return, construction costs and right of way costs for first year and average annual maintenance cost and average annual road user cost in the specified input boxes. On clicking the button entitled "Press to Calculate the Present Value", the present value is calculated and displayed on the screen. The user can also print the screen by pressing the button "Print".

To compare between two projects, the user has to click the button "Comparison between Projects" in the "Economic Analysis" screen. A new screen entitled "Input Data for Economic Analysis" (Figure A27) will appear. The user must input the rate of return and analysis period in the input boxes and click on the "Next" button. The analysis period must not exceed forty years.

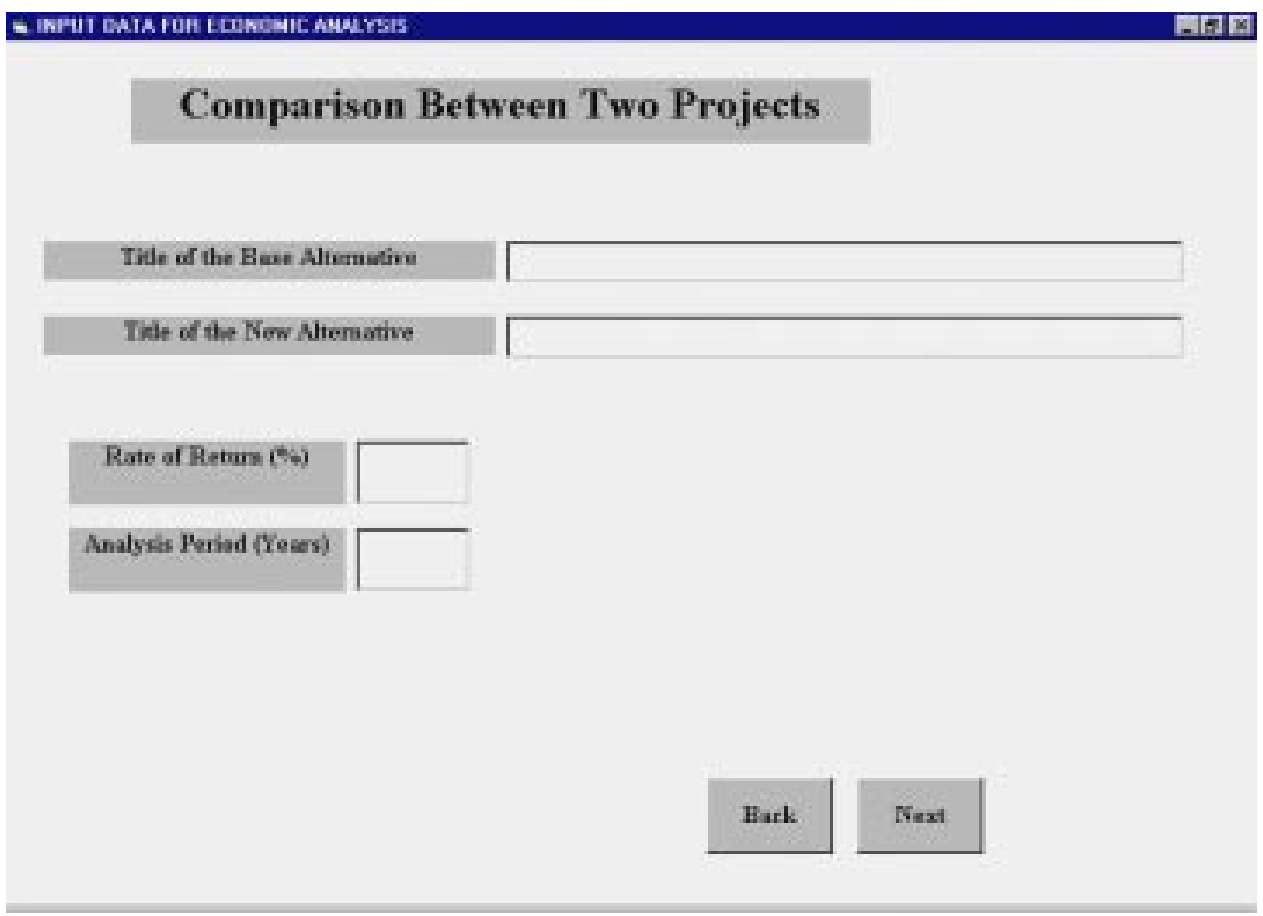

Figure A27: The Input Data for Economic Analysis Screen 
"Base or Alternative 0" screen, Figure A28, displays input boxes for construction cost, right of way cost, maintenance cost, road user cost and volume of traffic (corresponding to the Total Yearly Cost per 1000 Daily Vehicles and The Average AADT respectively, calculated in Figure A22. The input boxes appear dynamically depending on the analysis period, i.e. if the number of years is ten, then ten sets of input boxes appear. After inputting all data for base or alternative, the user clicks on the "Next" button to go to the new screen entitled "The New Alternative", shown in Figure A29, which has the same display format as the previous screen. The data entered here pertains to the new alternative or the costs of making improvements to an existing roadway. After all inputs are complete, the user clicks on the "Next" button to go to the screen where the net present value is calculated. This screen is entitled "Net Present Value Analysis", Figure A30, which displays the net construction costs, net right of way costs, net maintenance costs, and net benefits and the net residual cost.

There are also several boxes displayed in which the present value of the costs (construction cost + right of way cost + maintenance cost) and present value of the benefits are shown. The present value of the benefit for the final year of analysis period also incorporates the residual cost. The user must click on the "Press to Calculate the Net Present Value" button to calculate the present values of annual costs and benefits, the net present value for each year and the overall net present value. 


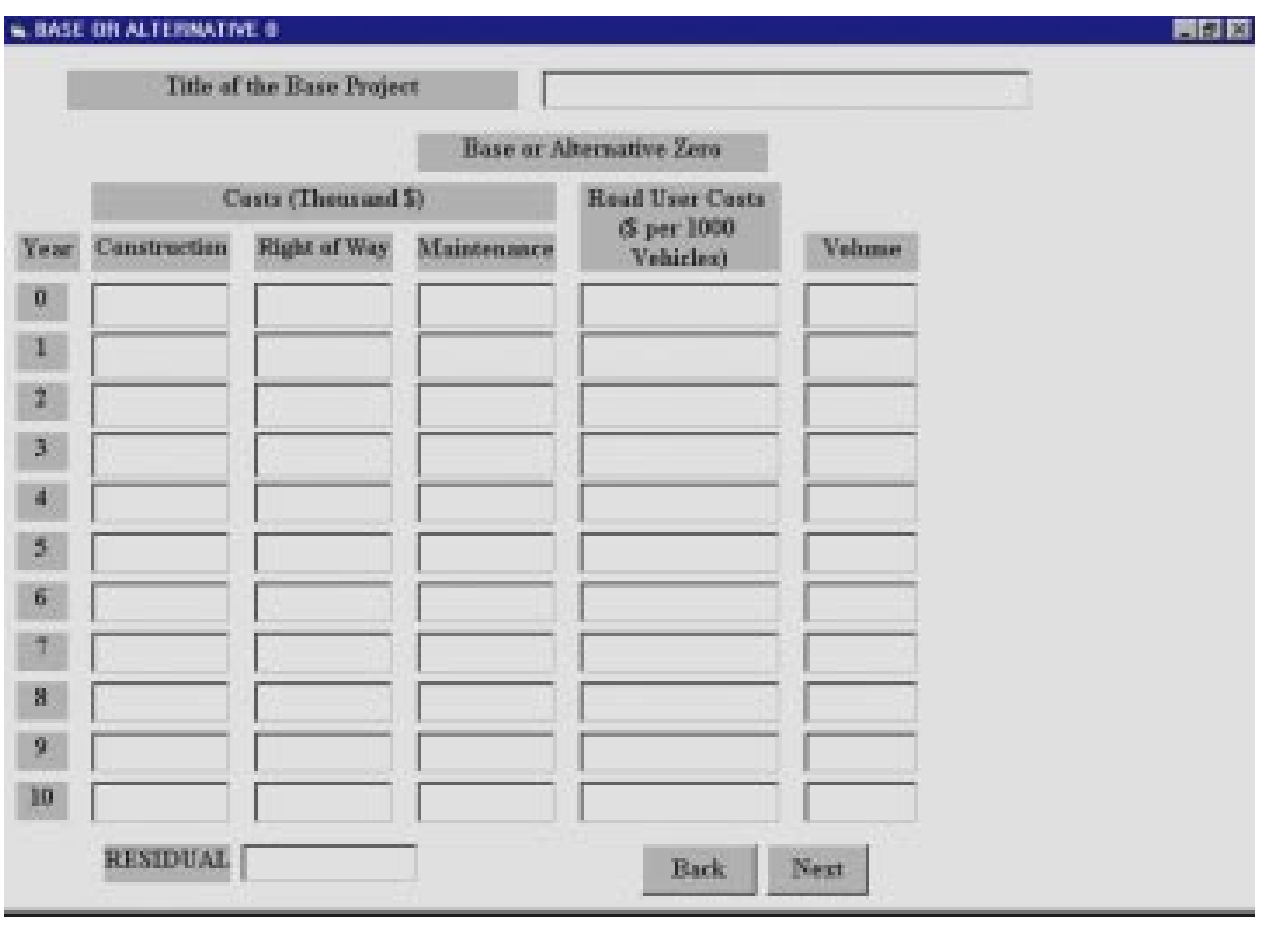

Figure A28: The Base or Alternative 0 Screen

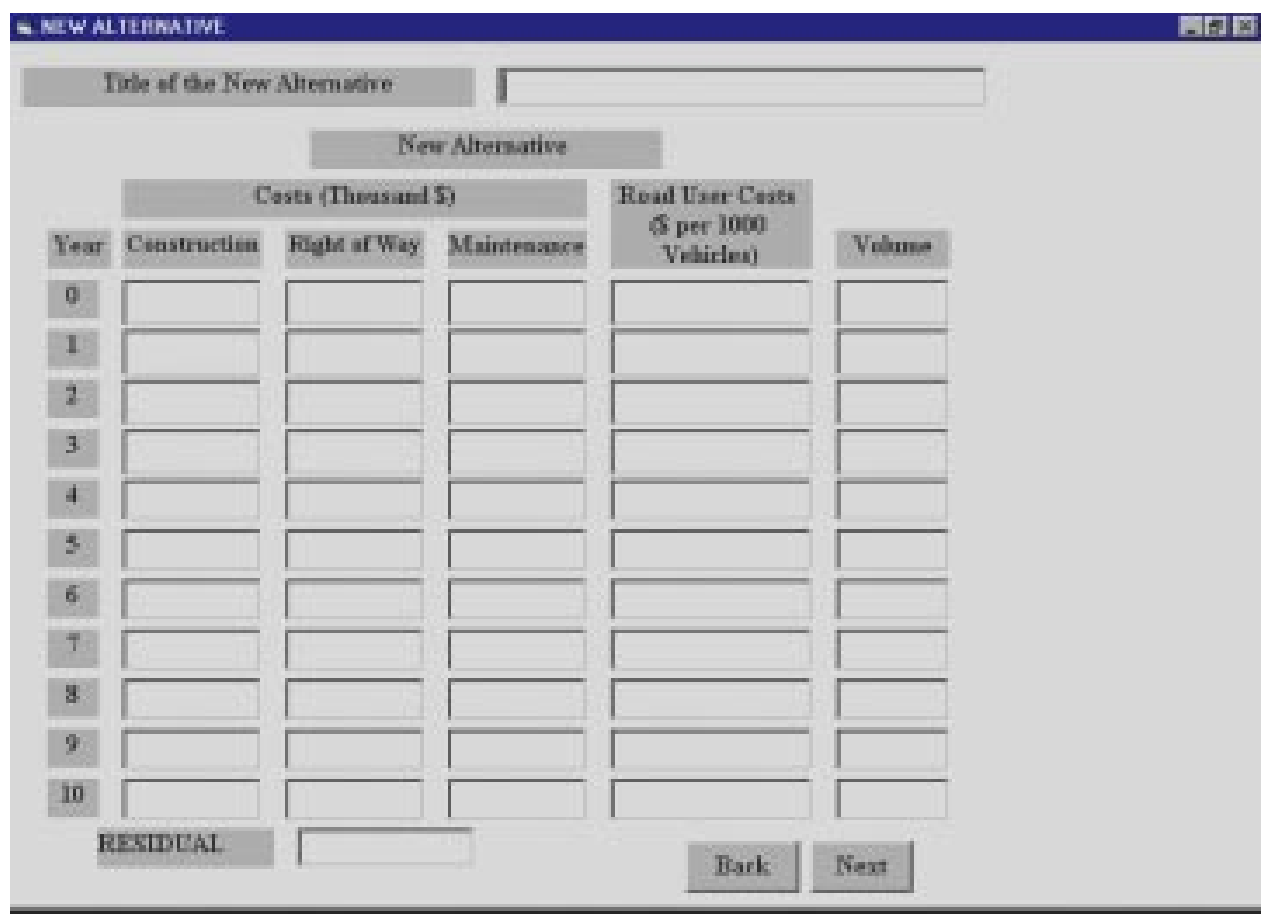

Figure A29: The New Alternative Screen 
The user can terminate this session by pressing the "End" button. This button is replaced by the "Next' button if the analysis period exceeds 10 years. The screen shown in Figure A30 had an analysis period of 10 years. In short, the last screen would have the "End" button required to terminate the session.

As an alternative, the user may compare between two or more projects that have uniform cost increase/decrease by calculating the present value for each project (see Figure A25) and comparing between the projects.

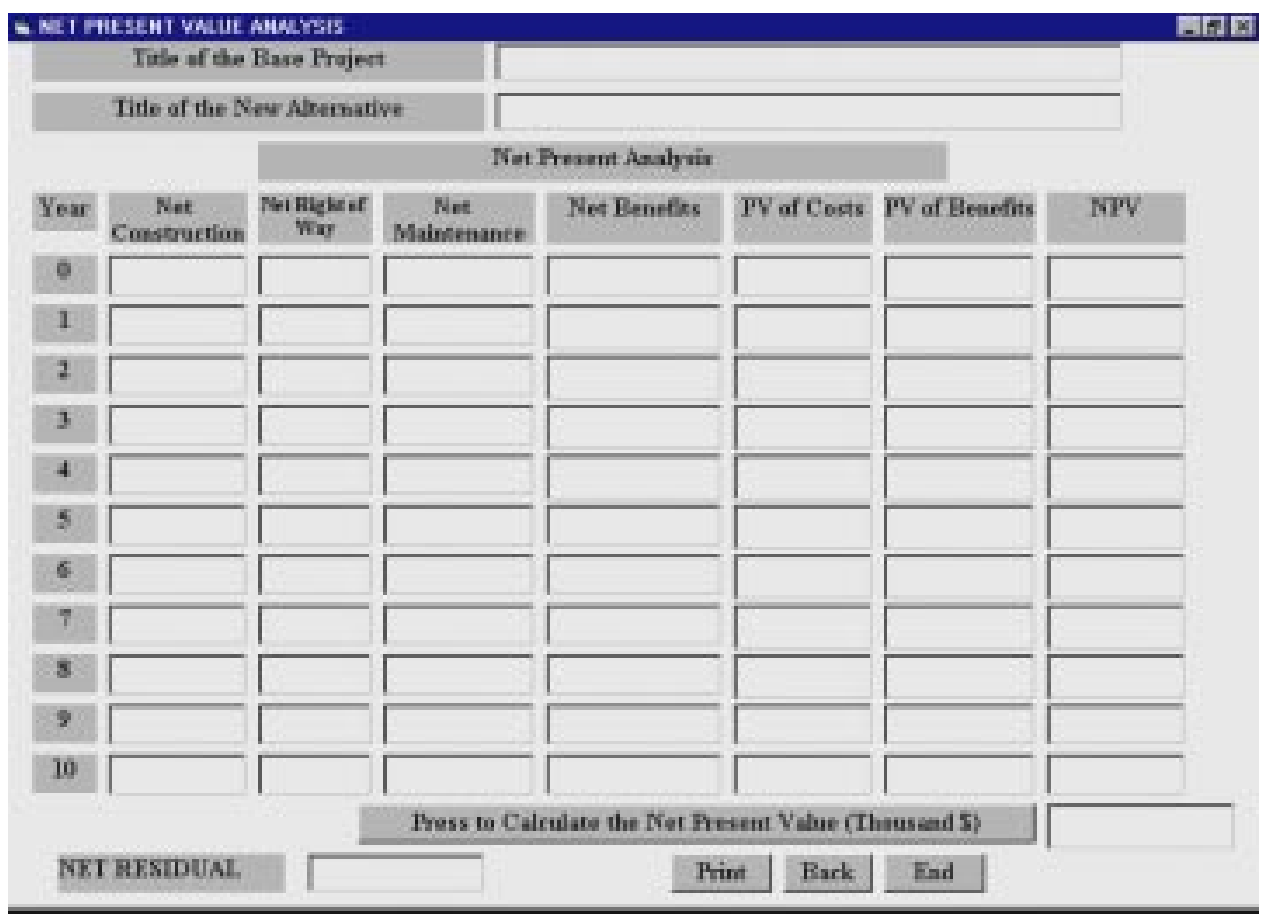

Figure A30: The Net Present Value Analysis Screen 


\section{Valid Ranges for Inputs and Parameters}

User inputs have to be consistent and valid for the proper functioning of the software. Also, calculations can be completed only if all the inputs are entered. Several display and error messages are designed to alert the user in case of missing or inconstitent inputs. In the following, a number of possible inconsistencies are discussed.

In most cases, the user is required to enter a value for a variable or choose from a drop-down menu. If the value entered is not included in the drop-down menu, the software will not respond. For example, valid choices for the design speed for a freeway is 70 miles per hour, 60 miles per hour and 50 miles per hour. A speed other than the above-mentioned values, such as 65 miles per hour, will result in the software not responding to the input. Another example is the user input for vehicle to capacity ratio. It has a range form 0 to 1 in steps of 0.1 increase. An input of 0.25 is considered inconstitent.

A different type of inconsistent input may occur when calculating intersection delay costs. A number of intermediate values are calculated like lambda (Ratio of Green Time to Signal Cycle Time), Capacity of Approach (Lambda * Saturation Flow or Capacity) and chi (Volume / Capacity of Approach). The value of lambda must be between 0.2 and 0.8 . The value of capacity of approach is between 200 and 4,400. The value of chi is between 0.1 and 0.8. Intersection approach speed is between 5 to 55 miles per hour.

The software also assumes that percentage of cars is greater than zero for every section of a project. An input of zero percent for cars will result in an error message to be displayed. 


\section{Example}

The following example illustrates the use of the software. The software essentially does three tasks, namely calculating the user costs for a highway project, update the costs so that the most recent cost tables are used, and perform an economic analysis to determine project feasibility and comparison of alternatives.

The user enters the number of section in the screen shown in Figure 4.4. In this example, the title of the project is Morgantown-Grafton and the number of section is 1 . We can have as many as 50 sections. Inputs for Basic Section cost shown in Table A4 are common for all type of vehicles irrespective of the vehicle mix. The inputs for a particular vehicle type belonging to the vehicle mix are shown in the Table A5.

\begin{tabular}{|l|l|}
\hline \multicolumn{1}{|c|}{ Inputs } & \multicolumn{1}{c|}{ Section 1 } \\
\hline Facility & Freeway \\
\hline Service Level & No \\
\hline V/C Ratio & 0.6 \\
\hline Design Speed (mph) & 70.0 \\
\hline Grade (\%) & -3.0 \\
\hline Curve Angle & 4.0 \\
\hline Road Type & High Type Surface \\
\hline
\end{tabular}

Table A4: Inputs for Basic Section Cost. 


\begin{tabular}{|l|l|l|l|}
\hline Inputs for Section 1 & $\begin{array}{l}\text { Passenger } \\
\text { Cars }\end{array}$ & $\begin{array}{l}\text { Single Unit } \\
\text { Trucks }\end{array}$ & $\begin{array}{l}\text { 3 S-2 Combination } \\
\text { Trucks }\end{array}$ \\
\hline Percentages & 100 & 0 & 0 \\
\hline Average Speed (mph) & 50 & 0 & 0 \\
\hline Hourly value of Time (\$) & 10 & 0 & 0 \\
\hline Travel Time Cost & 616 & 0 & 0 \\
\hline Grade Cost & 174 & 0 & 0 \\
\hline Curve Cost & 37 & 0 & 0 \\
\hline Speed Change Cost & 5 & 0 & 0 \\
\hline Basic Section Cost & 832 & 0 & 0 \\
\hline $\begin{array}{l}\text { Total Basic Section Cost (\$ per 1000 } \\
\text { Vehicle Miles) }\end{array}$ & \multicolumn{2}{|l|}{} \\
\hline
\end{tabular}

Table A5: Inputs for Basic Section Cost for the Vehicle Mix.

Table A6 shows the input for the accident cost. The three inputs for the accident costs are the number of fatal accidents, the number of Injury Accidents and number of Property Damage Accidents per year.

\begin{tabular}{|l|l|}
\hline FATAL ACCIDENT & 1 \\
\hline INJURY ACCIDENT & 2 \\
\hline PROPERTY DAMAGE & 3 \\
\hline ACCIDENT COST (\$ PER YEAR) & $1,067,400$ \\
\hline
\end{tabular}

Table A6: The Accident Cost Table

Table A7 and Table A8 show the input for the Transition Costs and Intersection Delay Costs respectively. 


\begin{tabular}{|l|l|}
\hline \multicolumn{1}{|c|}{ Inputs for Transition Cost } & \\
\hline Initial Speed (mph) & 40 \\
\hline Final Speed (mph) & 30 \\
\hline Direction & Two-Way Section Cost \\
\hline Transition Cost (\$/ 1000 Vehicles) & 8 \\
\hline
\end{tabular}

Table A7: Inputs for Transition Cost

\begin{tabular}{|l|l|}
\hline \multicolumn{1}{|c|}{ Inputs for Intersection Delay Cost } & \\
\hline Volume & 480 \\
\hline Saturation Flow & 1650 \\
\hline Signal Cycle Time & 60 \\
\hline Green Time & 30 \\
\hline Intersection Approach Speed & 30 \\
\hline Lambda & 0.5 \\
\hline Capacity of Approach & 825 \\
\hline Chi & 0.58 \\
\hline Delay Cost (\$ per 1000 Vehicles) & 49 \\
\hline Number of Intersections & 5 \\
\hline Idling Cost (\$ per 1000 Vehicles) & 198 \\
\hline Intersection Delay Cost (\$ per 1000 Vehicles) & 1,235 \\
\hline
\end{tabular}

Table A8: Inputs for the Intersection Delay Cost

The length of the section is 5 miles and the annual daily traffic is 1,450 . The formula for the Total Road User Cost is executed and the calculated value is $\$ 3,926,938$ per year. The average AADT is also 1,450 and the Total yearly cost per 1000 daily vehicles $\$ 2,708$. 